\title{
Megarons and Minoan Hall Systems A Comparison of the large hall systems in Minoan and Mycenaean Architecture
}

By Melanie Teahan

A thesis submitted to the Victoria University of Wellington in fulfilment

of the requirements for the degree of Master of Arts in Classics

Victoria University of Wellington

2017 


\section{Contents}

Abstract

Acknowledgements 6

$\begin{array}{lr}\text { Table List } & 8\end{array}$

$\begin{array}{lr}\text { Figure List } & 8\end{array}$

Plan List $\quad 9$

Chapter 1: Introduction $\quad 12$

1.2 Introduction to Minoan Hall Systems

1.3 Introduction to Mycenaean Megaron-Units 17

$\begin{array}{ll}1.4 & \text { Limitations } \\ \end{array}$

Chapter 2: Spatial Structure $\quad 22$

2.1 Introduction $\quad 22$

2.2 Space Syntax Analysis $\quad 22$

2.3 Clinton's Typology of Access and Circulation Patterns $\quad 25$

Spatial Structure of Minoan Hall Systems 28

2.4 Space Syntax Analysis $\quad 28$

2.5 Approach $\quad 30$

2.6 Connections $\quad 32$

2.7 Conclusions 34

Spatial Structure of Mycenaean Megaron-Units 36

2.8 Space Syntax Analysis 36

2.9 Approach $\quad 39$

2.10 Connections $\quad 42$

2.11 Conclusions $\quad 43$

2.12 Comparison and Conclusions $\quad 45$

Chapter 3: Climate and Climate Manipulation in Hall Systems 50

3.1 Introduction: Climate in the Bronze Age Aegean $\quad 50$

3.2 Open-Air Spaces $\quad 52$

3.3 Pier and Door Partitions $\quad 59$

3.4 Hearths $\quad 63$

$\begin{array}{ll}3.5 \text { Conclusions } & 72\end{array}$

$\begin{array}{ll}\text { Chapter 4: Conclusions } & 76\end{array}$

Works Cited $\quad 84$

Appendix 1: Space Syntax Analysis of Mycenaean Megaron-Units 90

Tables $\quad 99$

$\begin{array}{ll}\text { Figures } & 106\end{array}$

$\begin{array}{ll}\text { Plans } & 118\end{array}$ 


\section{Abstract}

Scholarship comparing the Minoan Hall System with the Mycenaean 'megaron' has in general emphasized either the similarities or differences between the two types of suite. Early archaeological literature tends to equate the two suites, with scholars such as Joseph Hazzidakis (Hazzidakis 1934:16-17) suggesting that the differences between the two can be explained by differences in climate between Crete and mainland Greece. On the other hand, in more recent scholarship, the two forms are distanced from one another, in effect polarizing the two architectural forms. Comparisons such as these tend to imply that the form of both types of hall system is very regular, with each suite likely hosting the same function as the next.

In order to study the similarities and differences between the Minoan Hall System and Mycenaean 'megaron', 27 Minoan hall systems and 15 megaron-units have been analysed and compared. These hall systems will be compared in their form, in the way they were incorporated into the surrounding building, and in the features they incorporate. To discuss how the hall systems were incorporated into buildings, Space Syntax Analysis will be used alongside a typology of access and circulation developed by Miriam Clinton (2013) for Minoan architecture. The climate-controlling features of open-air spaces, pier and door partitions and hearths will also be discussed.

A close examination of a wide variety of Minoan Hall Systems and Mycenaean 'megarons' shows that both forms differed considerably from site to site. Within each architectural form are examples of vastly different sizes, which are incorporated into buildings in very different ways. It is likely, therefore, that these buildings would have functioned in different ways. With this wide variation, it is unsurprising, therefore, that in comparison while some Minoan Hall Systems and Mycenaean 'megarons' are very different, others are very similar. It is likely that the functions of some of these more standard hall systems may have overlapped. An examination of the climate-controlling features of open-air spaces, pier and door partitions and hearths reveals that Minoan Hall Systems and Mycenaean 'megarons' likely did not differ primarily based on differences in climate. Though these features would have certainly been used for climate control, it will be shown that they likely had some other significance. Finally, from this comparison some tentative and broad conclusions about the possible functions of the two types of hall system have been drawn. 


\section{Acknowledgements}

I would like to thank my supervisor, Judy Deuling, for her constant support and guidance throughout my studies, both in the writing of this thesis and earlier, and for passing on her enthusiasm for Bronze Age Archaeology. This thesis would not have been possible without her support. I would also like to thank the staff and postgraduate students of the Classics Department at Victoria University of Wellington, for their academic and moral support, their feedback and ideas and for the fantastic community I have been privileged to be part of for the last six years. Finally, I would like to thank my friends and family, for their incredible support and encouragement. 


\section{List of Tables}

Table 1: Minoan Hall Systems (studied by Letesson). 99

Table 2: Other Certain Minoan Hall Systems. 100

Table 3: Other Hypothetical Minoan Hall Systems. 100

Table 4: Mycenaean Megaron-Units. 101

Table 5: Space Syntax Analysis of Minoan Hall Systems. 102

Table 6: Minoan Hall System Connections. 103

Table 7: Space Syntax Analysis of Mycenaean Megaron-Units. 104

Table 8: Light Wells in Minoan Hall Systems. 105

\section{List of Figures}

Figure 1: Plan of Phylakopi showing the walls of the LCIII 'Megaron' and LCI 'Mansion' $\begin{array}{ll}\text { which it was built on top of. } & 106\end{array}$

Figure 2: Middle Cycladic Building at Phylakopi with megaron-unit and flanking corridor. 106

Figure 3: a) Plan and b) reconstruction of a typical Minoan hall system. 107

$\begin{array}{ll}\text { Figure 4: Pier and Door Partitions, reconstruction and plan. } & 107\end{array}$

Figure 5: Pier and door partitions, showing the three ways they can be used - as a wall, $\begin{array}{ll}\text { door or void. } & 108\end{array}$

Figure 6: Comparison of the three palatial megaron-units from Mycenae, Tiryns and Pylos.

108

Figure 7: Rectangular buildings with central hearths. a) Reconstructed EB I-II settlement at Demircihüyük, Turkey, b) Plan of a typical Chinook plank house with several central hearths based on remains from $14^{\text {th }}-15^{\text {th }}$ Century AD Oregon c) Modern Central-hearth house from Dalecarlia, Sweden, d) Reconstruction of a traditional Tlingit house from the North-West coast of North America.

Figure 8: Space Syntax Analysis of House He at Gournia. a) Connections between the various spaces as seen on the plan. b) The standard Justified Graph, with the exterior as carrier. c) Justified Graph with Space 31 as carrier. d) Depth and Integration figures for the exterior and space 31 of Gournia House He.

Figure 9: Ringy system in the House of the Frescoes at Knossos, represented on a) a plan and justified graph (b).

Figure 10: Ringy systems in Akhladia, with type $d$ spaces shaded in green, represented on (a) a plan and justified graph (b).

Figure 11: Plan of Tiryns showing bent axis approach to the two Megaron-units.

Figure 12: Tylissos House $C$ showing circulation patterns into the Minoan Hall System and surrounding matrix.

Figure 13: Comparison of the Minoan Hall System at a) Nirou Hani with b) the monumental entrance to the Palace at Phaistos and c) the megaron-unit at Tiryns. Plans not to scale.

Figure 14: a) Archanes House Model, showing half wall of the Minoan Hall System, b) Reconstruction of the South House at Knossos with a half wall at the Minoan Hall System. 
Figure 15: Double doors opening onto the Storage Magazines at Phaistos. 114

Figure 16: Circular hearth from Tell Judeideh, Syria. $\quad 115$

Figure 17: Rim of the Hearth at Pylos showing painted decoration. 115

Figure 18: The hearth at Mycenae: a) Remains, b) illustration of construction, c) decoration. 116

Figure 19: Sherd-based hearth from House M, Tiryns. 117

\section{List of Plans}

Plan 1: Akhladia, Building A. $\quad 118$

Plan 2: Chania, House $1 . \quad 118$

Plan 3: Gournia, Building G/Palace. 119

Plan 4: Knossos, House of the Frescoes. 120

Plan 5: Knossos, Little Palace. 121

Plan 6: Knossos, Royal Villa. $\quad 122$

Plan 7: Knossos, South House. 122

Plan 8: Malia, Palace Ilôts III and IV. 123

Plan 9: Malia, Maison $\Delta \alpha . \quad 123$

Plan 10: Malia, Maison Za. $\quad 124$

Plan 11: Malia, Maison Z $\beta$. 125

Plan 12: Mochlos, Building B.2, restored plan of second floor, east wing. 125

Plan 13: Nirou Hani. 126

Plan 14: Palaikastro, Building X1-17. 127

Plan 15: Phaistos, Palace, Secondary Minoan Hall System 63-64. 128

Plan 16: Phaistos, Palace, Residential Quarters. 128

Plan 17: Pseira, Building BC. $\quad 129$

Plan 18: Tylissos, Building A. $\quad 130$

Plan 19: Tylissos, Building C. 131

Plan 20: Vathypetro, West Building. 131

Plan 21: Zakros, Palace, Minoan Hall Systems. 132

Plan 22: Archanes, Villa. 132

Plan 23: Galatas, Palace. 133

Plan 24: Hagia Triada, Villa Reale. 134

Plan 25: Knossos, Southeast House. 135

Plan 26: Knossos, Residential Quarter. 136

Plan 27: Mycenae, Megaron-unit. 137

Plan 28: Tiryns, Upper Citadel. 138

Plan 29: Pylos, Main Building and South-Western Building. 139

Plan 30: Gla, Residence. 140

Plan 31: Dimini, Megaron A. $\quad 141$

Plan 32: Dimini, Megaron B. $\quad 141$

Plan 33: Menelaion, Mansion $1 . \quad 142$

Plan 34: Mycenae, West House. $\quad 142$

Plan 35: Phylakopi, Megaron. 143 
Plan 36: Gournia, House He.

Plan 37: Mycenae, House of the Sphinxes. 144

Plan 38: Korakou, House L. $\quad 144$

Plan 39: Thermos, Megaron A. $\quad 145$

Plan 40: Tiryns, Building 110a. $\quad 145$

Plan 41: Pyrgos Myrtos. 146 


\section{Chapter 1: Introduction}

In early archaeological literature, the main suites in the newly discovered palaces at Mycenae and Tiryns were given the name 'megaron'. ${ }^{1}$ The term was taken from the ancient Greek word $\mu \varepsilon \dot{\gamma} \alpha \rho \circ$, which was used by Homer to describe the main halls of the Mycenaean palaces as well as the women's quarters, and occasionally the entire building. ${ }^{2}$ At Tiryns, as in Homer's palaces, a second, smaller 'megaron' was discovered adjacent to the main suite, and after Homer this was labelled the women's hall. ${ }^{3}$ When Arthur Evans excavated a similar double hall at Knossos, with a larger suite adjoined by a more isolated, smaller suite, he also called the area a 'megaron'. ${ }^{4}$ Early scholars continued to use the name 'megaron' to describe buildings similar to those found at Knossos. In his 1934 report of the excavation of Tylissos, Joseph Hazzidakis insisted that the Minoan suite of rooms should be seen as the Minoan equivalent to the Mycenaean 'megaron', and should thus be given the same name:

Nous avons donné à la salle le nom de mégaron, terme qu'on a coutume d'appliquer, avec plus ou moins de justesse, aux salles du même type dans les palais minoens. Nous sommes convaincus, pour notre part, que ce type de salle qui se retrouve si régulièrement dans toutes les constructions minoennes correspond bien au mégaron des palais de la Grèce continentale. Ce sont les salles les plus vastes; elles renferment ordinairement très peu de vases de grande taille, au contraire des autres salles remplies de jarres; elles sont entourées de salles plus petites, comme les mégara du Péloponnèse, avec cette seule différence qu'en Crète la communication est directe, tandis qu'en Argolide elle a lieu indirectement par l'intermédiaire d'étroits couloirs. L'absence, en Crète de foyer central s'explique aisément par la douceur du climat. Aussi, jusqu'à preuve du contraire, maintenons-nous l'appellation de mégaron.

We have given the room the name megaron, a term which is customarily applied, more or less accurately, to rooms of the same type in the Minoan palaces. We are convinced, for our part, that this type of room which is found so regularly in Minoan buildings corresponds well to the megaron of the palaces of mainland Greece. These are the largest rooms, they ordinarily have very few large vases in contrast to other rooms full of jars, they are surrounded by smaller rooms, like the megara of the Peloponnese, with the only difference that in Crete the communication is direct, while in the Argolid it is indirect through narrow corridors. The

\footnotetext{
${ }^{1}$ Schliemann 1885; Tsountas 1886.

${ }^{2}$ Knox 1973:2, 7.

${ }^{3}$ Schliemann 1885:239.

${ }^{4}$ Evans 1900-1901:21.
} 
absence in Crete of a central hearth is explained by the mild climate. So, until proven to the contrary, we maintain the name megaron. ${ }^{5}$

Despite this early enthusiasm for the term, in later years the use of the term 'megaron' in Minoan contexts was more reserved. In 1959, Graham donned the name 'Queen's Hall' for the smaller suite at Knossos "to avoid the term 'megaron' in a Cretan context". ${ }^{6}$ The unique Minoan suite of rooms was instead given the name 'Minoan Hall System'. The two suites are in fact quite different in many ways. While the Minoan Hall System contains an interior unroofed space, generally called a light well, and is divided by pier and door partitions, the Mycenaean 'megaron' generally has only one door leading between the three spaces which make up the suite. Instead of incorporating an interior unroofed space, it contained a large central hearth.

However, as Hazzidakis insisted, the two do still have similarities. Both sets of rooms are generally among the largest in the house or palace, and the most impressively built and decorated. They are generally surrounded by smaller suites of rooms. They generally yield very few finds, and they are both made up of three different spaces, two smaller, with the third generally the largest. At first glance, it is their climate-controlling features that contrast the most, namely the 'light well', pier and door partitions, and the hearth. As the climate on Crete would have been warmer than that on the mainland, particularly over winter, it is possible that these differences could be explained at least in part by a difference in climate, as suggested by Hazzidakis.

Much of this early scholarship tends to over-emphasize either the similarities or differences between Minoan and Mycenaean architecture in comparison, and in doing so seems to imply that both the Mycenaean 'megaron' and Minoan Hall System were uniform entities, with each example structurally and functionally very similar to the previous. However, both the Minoan Hall System and the Mycenaean 'megaron' had a high degree of variability, making it entirely possible and even likely that different structures given each label may have functioned differently. In emphasizing the uniting features of each type, a strong continuity of architectural tradition is implied where one may not have existed.

Furthermore, in polarizing the differences between these two architectural traditions, similarities of form or function that may have been shared by the two suites or the two cultures are ignored. While the fixed hearth is far more common in Mycenaean contexts than Minoan, it is also found in Minoan contexts and should not be considered a uniquely Mycenaean feature. ${ }^{7}$ Likewise, though

\footnotetext{
${ }^{5}$ Hazzidakis 1934:16-17. English translation by author.

${ }^{6}$ Graham 1959:47.

${ }^{7}$ Maeir and Hitchcock 2011:53.
} 
the pier and door partition is found far more commonly in Minoan contexts it has also been found in Mycenaean buildings on the mainland. In over-emphasizing the two different forms, there is a danger that Minoan or Mycenaean influence can be recognized where it does not exist. For example, the form of the so-called 'megaron' at Phylakopi led the excavators and other scholars to conclude that this was the centre for Mycenaean elite on the island. ${ }^{8}$ However, the LCIII 'megaron' replicates very closely the plan of the destroyed $\mathrm{LCl}$ building it replaced, which predates any possible Mycenaean influence on the island (Fig. 1). ${ }^{9}$ Furthermore, earlier buildings throughout the town, though significantly smaller, are also very similar to the plan of the 'megaron' (Fig. 2). ${ }^{10}$ The presence of a similar architectural form alone is not enough to prove a cultural connection, and though the Minoan Hall System and Mycenaean 'megaron' often differ in form, outliers and aspects of each appear extremely similar. Cultural differences should be ascertained through a survey of all material culture, rather than architectural form alone.

There are therefore three research objectives that will be discussed in this study. Firstly, the Minoan Hall System and Mycenaean 'megaron' will be examined separately, to determine how uniform each type of suite actually was. The presence of both the Minoan Hall System and the Mycenaean 'megaron' in a building or settlement immediately draws conclusions about the function and prestige of the area in question, but as stated both forms appear to vary considerably from site to site. This variation in form seems to suggest that some Minoan Hall Systems and Mycenaean 'megarons' may have functioned very differently from each other, making assumptions of function based on architectural form unhelpful. A study of how similar these forms were between various sites may therefore help to draw conclusions about the two types of suite.

Secondly, the Minoan Hall System and Mycenaean 'megaron' will be compared in order to determine how and in what ways the two suites were similar or different. As already stated, both the Minoan Hall System and Mycenaean 'megaron' varied considerably from building to building, and while in some instances the two architectural forms were vastly different, in other cases the Minoan and Mycenaean suites appear almost identical. Therefore, it is the main purpose of this study to consider whether some or all of the suites may have been incorporated into buildings or incorporated features in similar ways.

\footnotetext{
${ }^{8}$ Mackenzie 1898/1899:6; Barber 1987:224 “Even the most superficial comparison between the plan of the Phylakopi complex and the main units of the Mycenaean palaces at, for example, Pylos, Mycenae or Tiryns, can hardly fail to demonstrate the essential fact that there was now a Mycenaean palace on Melos."

${ }^{9}$ Pantou 2010:82.

${ }^{10}$ E.g. J2: 21, 22; J3:2, 3, 7, which contains a megaron-unit and a flanking corridor. Atkinson (1904:44) states: "The plan has some resemblance to that of the palace of the succeeding period."
} 
Finally, the ways in which the climate is controlled in each suite will be examined in order to determine if Hazzidakis' theory that the suites differed based on climate is likely. Though open-air space, pier and door partitions and hearths can be used to control the climate, other less elaborate and more flexible climate control methods could have been utilised, and were used in other Minoan and Mycenaean contexts. All three features were far more elaborate than necessary for simple climate control, so though it is possible their main purpose was simply to control the climate, each likely had other functions.

In order to discuss these three factors, the Minoan Hall System and Mycenaean 'megaron' will be examined from three different perspectives. Firstly, in the following introductory remarks, the form of the two hall systems will be briefly discussed. Secondly, in Chapter 2, the relationship between the hall systems and the buildings they appear in will be discussed. Space Syntax Analysis will be used to discuss the way the hall systems have been integrated into the surrounding buildings, and Miriam Clinton's (2013) typology of access and circulation will be used to analyse firstly the way in which each hall system was approached from the exterior and secondly how they were connected to the spaces that surrounded them. Finally, in Chapter 3, the climate controlling features of the Minoan Hall System and Mycenaean 'megaron' will be compared. As the climate may have differed between the Bronze Age and the present day, the ancient climate will be briefly discussed. The open-air spaces incorporated into each different hall system will then be compared, and finally the Minoan pier and door partition and Mycenaean monumental hearth will be discussed, with comparisons from the other culture drawn where appropriate.

The Minoan Hall System and Mycenaean 'megaron' are emblematic architectural forms of their respective cultures. They are generally among the largest, most elaborate and lavishly decorated parts of the buildings they are found in. However, their precise functions remain elusive. While this study does not attempt to definitively answer the question of their functions, a comparison of each hall system's relationships with the surrounding building and the use of features such as open-air space, pier and door partitions and hearths may allow for a better understanding of the ways in which each type of hall system may and may not have functioned.

\subsection{The Minoan Hall System}

The Minoan Hall System (hereafter MHS) is a set of three spaces, axially aligned, which is found both in the Minoan palaces and in smaller elite buildings throughout Crete. All were built in the Neopalatial Period, between MMIII and LMIB. ${ }^{11}$ The system consists of a main hall, a light well and a

\footnotetext{
${ }^{11}$ Letesson 2009:303; 336-337.
} 
vestibule separating the two (Fig. 3). The light well is separated from the vestibule by columns and the vestibule from the main hall by pier and door partitions. Pier and door partitions, also known as polythyra, are a series of double doorways separated by small pier walls (Fig. 4). ${ }^{12}$ Each pier had a small niche where the door could be folded away when not in use.

The MHS is designed to be a very flexible space in its every day function. Users of the room would be able to control the amount of light and air in the main hall, the degree of access and privacy, and would also be able to alter the size of the space by opening or closing the pier and door partitions (Fig. 5). Opening all the pier and door partitions would allow in the maximum amount of light and air from the light well, as well as allowing easy access to any visitors to the main hall and creating one large space in the place of two smaller spaces. Closing all the pier and door partitions, on the other hand, would create a smaller, private space, where only the invited could enter, sheltered from the elements.

In her 1998 study, Jane Lloyd divided MHS into three different types based on their form. The Canonical MHS included the three spaces of main hall, vestibule and light well aligned axially, with each space at the same width as the next. Most MHS fit this type, such as the Hall of the Double Axes and Queen's Megaron at Knossos, for example. ${ }^{13}$ In Broken-Axis halls, the light well, instead of retaining the full width of the MHS as in the Canonical type, was included in a corner of the vestibule, as in Tylissos House A. The light well was still partitioned off with columns, but it was surrounded by walls on only two sides, rather than three as in the Canonical MHS. ${ }^{14}$ Finally, the Truncated MHS was missing either the vestibule (such as at Malia Z $\beta$ ) or the light well. ${ }^{15}$ Where the canonical light well is missing, this is sometimes replaced by another exterior space which the MHS opens on to, such as at Nirou Hani.

As should be apparent, one of the key features of the MHS is its flexibility. While it would have been flexible in its use, the MHS is also very flexible in form, with very different MHS co-existing at the same sites and at times in the same buildings. This flexibility of form often makes it difficult to compare different MHS and pin down their function. ${ }^{16}$ The MHS is incorporated into different buildings in very different ways, with some very isolated from the rest of the building and others highly integrated into the surrounding spaces, providing critical access to various spaces. To some extent these different halls would have necessarily functioned differently, and it is indeed possible

\footnotetext{
12 This is based on the reconstruction by most scholars (eg. Palyvou 1997; Marinatos and Hägg 1986) that there were doors between the pier walls, however in many cases this is not certain.

13 Lloyd 1998:123.

14 Lloyd 1998:130.

15 Lloyd 1998:130.

${ }^{16}$ Letesson 2013:304.
} 
that MHS were incorporated into various buildings for different reasons. This unfortunately makes it difficult to compare the different spaces firstly with each other and secondly with Mycenaean hall systems.

The various halls were vastly different in their sizes. While the average MHS is around $49 \mathrm{~m}^{2}$, the smallest hall at Pseira takes up only $14.5 \mathrm{~m}^{2}$, and the largest hall at the Little Palace at Knossos measures $159 \mathrm{~m}^{2}$, over ten times the size (see Tables 1-3). Based on their size alone, these MHS must have functioned rather differently. While the large halls such as at the Little Palace and Hall of the Double Axes at Knossos could have hosted large gatherings, any equivalent gathering in the MHS at Pseira would have necessarily been much smaller.

The fragmentary nature of many Minoan buildings also complicates the study of MHS. While in many buildings MHS can be reconstructed with certainty, there are also many MHS that due to their fragmentary nature remain only hypothetical. Scholars frequently disagree as to which spaces should be considered MHS and which should not because it is often difficult to know with any certainty whether spaces were uncovered light wells, for example. For convenience, in this study the spaces considered MHS by two scholars, Lloyd (1998) and Quentin Letesson (2013) will be considered, as these two lists cover the majority of buildings complete enough to be reconstructed as containing MHS with any certainty. In his 2013 study, Letesson selected 23 MHS whose plans were complete and understandable enough to be analysed with Space Syntax Analysis (Table 1). Of these, 11 were certain MHS and 12 were more hypothetical. He supplemented his study by studying the changes made to four of these MHS (at Mochlos B.2 and the palaces of Malia and Zakros) over subsequent periods, totalling 27 different MHS. As these MHS come from the most complete buildings, these $27 \mathrm{MHS}$ will be the primary systems considered in terms of their spatial structure in the surrounding building in Chapter 2. A further 9 certain (Table 2) and 12 hypothetical (Table 3) MHS were recognized between Letesson and Lloyd. Where appropriate, these will be included also for comparison. A final MHS proposed by Hitchcock (1994:33) at Hagia Triada has also been included. In total, this gives 49 possible MHS for consideration.

\subsection{The Mycenaean Megaron-Unit}

The term 'megaron' in Mycenaean architecture is a controversial one. The term has been applied by various scholars to almost every rectangular building found on mainland Greece from the Neolithic period onwards. It is most often used to describe the main suites of the palaces at Mycenae, Tiryns and Pylos, which closely resemble one another (Fig. 6). These suites are made up of 
three spaces, a porch, a vestibule and a main hall, arranged on axis. The porch is the first space accessible from the exterior; it opens from a courtyard and has two columns in antis. The porch leads on to the vestibule, which generally has a doorway on at least one side that leads through to smaller adjacent rooms, and a main door leading directly into the main hall. The main hall is dominated by a large central hearth surrounded by four columns. The hearth is monumental, 3.5$4 \mathrm{~m}$ in diameter and lavishly decorated. To the right of the room, a throne has been reconstructed. All three suites are enormous, at over $200 \mathrm{~m}^{2}$ (see Table 4).

In all three cases, the area around the 'megaron' is also very similar. All three are accessed from an open-air courtyard. Although the area at Mycenae is fairly fragmentary, these courtyards are all accessed from the opposite side to the 'megaron', off axis. At Pylos and Tiryns this is through a roofed gateway with columns, to the left of the courtyard. The 'megaron' is also surrounded by smaller rooms at Pylos and Tiryns, including another smaller room containing a large, decorated hearth. These rooms are accessible from the courtyard and through the side doorways in the vestibule.

While the term 'megaron' has been used widely and many sites have been claimed to be similar to those at the palaces, none of these so-called 'megarons' retain all the features of the 'megarons' at Tiryns, Pylos and Mycenae. Because of this, these non-palatial suites should only be cautiously linked with the three palatial examples. Likewise, to avoid confusion, for the purpose of this thesis the term 'megaron-unit' will be used to describe these central units often called 'megarons'. However, it is unlikely that these palatial suites occur without parallel outside the palaces, or that there were no other spaces with similar features, layouts and use. In considering the meaning behind these aspects of the palatial megaron-units, then, it would be helpful to consider similar buildings and suites elsewhere.

E. Baldwin Smith defines a 'megaron' as:

An isolated, rectangular or apsidal structure used as a dwelling... which consisted of a main hall, entered usually, but perhaps not necessarily, at one end, and commonly, in its developed stage, through an open porch with antae; it may or may not have been large enough to require interior supports, which, when present, were set in several different ways, in order to carry the roof; it originally had an interior hearth, frequently circular, associated with it. ${ }^{17}$

In this definition, the only requirements for a building to be defined as a 'megaron' are that the building be isolated, rectangular or apsidal, with a main hall. The type of dwelling typically

\footnotetext{
${ }^{17}$ Baldwin Smith 1942:101.
} 
understood to be a 'megaron' based on this description are buildings such as House $L$ at Korakou. It consists of three rooms, axially aligned, with the entrances found on the shorter ends, and it contains a central hearth. On the other hand are apsidal structures such as Megaron A at Thermos, which has a similar structure but an apsidal back room. There are many Mycenaean buildings that fit this description, but this isolated rectangular or apsidal structure is not unique to Mycenaean Greece. Isolated, rectangular buildings with central hearths can be found in the Early Bronze Age in Turkey, in traditional houses still built today elsewhere in Europe, as well as traditional houses of many different cultures in North America (Fig. 7), for example.

Furthermore, this definition includes buildings of vastly different sizes. While the three palatial megaron-units all measure over $200 \mathrm{~m}^{2}$, this definition of 'megaron' includes buildings as small as the tiny building 110a (Plan 40) in the lower citadel at Tiryns, with an internal area of only $4.9 \mathrm{~m}^{2} .{ }^{18}$ Though these buildings may be similar structurally, the vast differences in size necessitates that the day-to-day use of these two buildings would have differed greatly. Any gathering or activity in Building 110 a would have by necessity been of a much smaller scale to those at the palatial megaron-units. In using the same terminology to describe both, there is an implication of a continuity of design and of function that does not exist. If there is a uniform tradition of 'megarons' in Mycenaean Greece, then these buildings must have more in common than simply their general shape.

In terms of features, the palatial megaron-units have most in common with rooms with central hearths. In Mycenaean architecture hearths are common, with many (but by no means all) located in the centre of the room. ${ }^{19}$ However, these hearth rooms and the hearths they contain are significantly smaller and much less elaborate than the palatial megaron-units. The average nonpalatial hearth room is $23.83 \mathrm{~m}^{2}$, with the average hearth measuring $1 \mathrm{~m}^{2}$, while the main halls of the three palatial megaron-units measure $115.6-148.9 \mathrm{~m}^{2}$ and include hearths measuring $8.5-12.7 \mathrm{~m}^{2} .^{20}$ Again, from these sizes alone it is likely that these rooms functioned rather differently and hosted activity of a very different scales. While the palatial megarons included four columns placed around the hearths, only two Mycenaean buildings outside of the palaces contain a central hearth flanked by four columns. ${ }^{21} \mathrm{~A}$ few more are flanked by two columns, although this is still fairly rare. ${ }^{22}$ These

\footnotetext{
18 Darcque 2005:151.

${ }^{19}$ Darcque 2005:171-175.

${ }^{20}$ Calculated from Darcque 2005:171-173.

${ }^{21}$ Malthi B85 (Valmin 1938:174) and Iklaina Г1 (Cosmopoulos 2009:103-105). Four columns have been reconstructed at Midea but are not certain (see note 129).

${ }^{22}$ Such as Nichoria Unit IV-A, Tiryns Megaron W, Mycenae Panagia House II, Korakou House M \& L. See Darcque 2005 for plans.
} 
discrepancies may be explained in part by the prestige gap between the three palatial sites and the more common dwellings. The smaller hearth rooms would generally not have needed columns for roof support, and large buildings would not be necessary in smaller settlements. However, while it is possible that these buildings had functions and aspects in common, it is also entirely possible that they were used for vastly different purposes.

It should also be noted that as well as being easily applied to many vastly different buildings over a long time period, this traditional definition of 'megaron' also does not fit with the three palatial megaron-units. One of Baldwin Smith's requirements were that the 'megaron' be isolated, and the three palatial megaron-units were a central part of a larger building, surrounded on all sides by other rooms and connected through doors on either side of the vestibule. As such, they have little in common spatially with the isolated rectangular buildings usually labelled 'megaron'. Far more similar are the buildings Panagiota Pantou (2010) calls 'Corridor Buildings'. ${ }^{23}$ These are contemporary LH buildings that consist of a central megaron-unit with two or three rooms arranged on antis, flanked by a corridor which provides access to a series of smaller rooms. ${ }^{24}$ While the palace at Tiryns lacked the flanking corridor, the structures are very similar to the palatial megaron-units, and include many of the buildings purported to be regional palatial centres. Though these buildings are similar in plan to the palaces, there are some clear differences. Firstly, the megaron-units of the Corridor Buildings are considerably smaller than the halls of the three palatial megaron-units, ranging from $46 \mathrm{~m}^{2}$ to $83 \mathrm{~m}^{2}$ (see Table 4). Likewise, though there are some exceptions most do not contain a hearth.

Furthermore, while these buildings are similar spatially, the form varies considerably in each case. Mansion 1 at Menelaion includes a second megaron-unit and has a vestibule as well as a porch. The West House at Mycenae incorporates a courtyard in front of the megaron-unit. The megaron-unit of the House of the Sphinxes at Mycenae consists only of a single large room without porch or vestibule. The access to the main hall of Megaron B at Dimini is through a side door in the vestibule rather than a door on the shorter side. It should not be a surprise then that in analysing them functionally, contextually and architecturally, Pantou concluded that Corridor Buildings likely had a range of uses. While some, such as the House of the Oil Merchant and West House at Mycenae, should be interpreted as private houses, others such as Megarons A and B at Dimini and Mansion 1 at Menelaion should be interpreted as having a public function, potentially controlled by local elites. ${ }^{25}$ While these buildings may have aspects in common with the three palatial megaron-

\footnotetext{
${ }^{23}$ Pantou's 'Corridor Buildings' should not be confused with spatially different EH 'Corridor Houses'.

24 Pantou 2010:1.

${ }^{25}$ Pantou 2010:255.
} 
units, it is important to consider each case individually. A similar structure does not guarantee a common function; these buildings should not be grouped with either the palaces or the isolated non-palatial megaron-units of Baldwin Smith's definition but instead be considered separately.

In light of this, the megaron-units of the palaces at Tiryns, Pylos and Mycenae should be considered a separate architectural type, related, but not equivalent to contemporary Corridor Buildings and rectangular hearth rooms. The focus of this thesis will therefore be the three palatial megaron-units at Tiryns, Pylos and Mycenae. Seven Corridor Buildings and two isolated megaronunits will be used for comparison where appropriate. Additionally, the secondary megaron-unit suite at Tiryns and two megaron-units at the non-palatial site Gla will also be used comparatively (Table 4).

\subsection{Limitations}

While every attempt has been made to include as much material as possible, it should be noted that in comparing large numbers of buildings it has not been possible to consider all aspects of the megaron-unit and MHS. In this study only the most prominent features of the two hall systems have been analysed, setting aside features such as the throne in the palatial megaron-units, and any other finds in the halls. In order to fully understand and interpret each hall it would be necessary to consider each individually in the context of the building and settlement it was found in. ${ }^{26}$ Instead, the purpose of this thesis is to consider broader themes and patterns in an attempt to better understand the similarities and differences between the two types of hall.

\footnotetext{
${ }^{26}$ Letesson 2013:335.
} 


\section{Chapter 2: Spatial Structure}

\subsection{Introduction}

As both MHS and Mycenaean megaron-units rarely yield many finds to shed light on their use, in comparing the two and their function it is necessary to investigate the relationship that these suites may have had with the spaces that surround them. There are currently a large number of analysis techniques and typologies used by scholars to do this, but for the purposes of this study I have selected two. ${ }^{27}$ Space Syntax Analysis is a system used by archaeologists and architects alike to compare buildings or areas in terms of their connections. On the other hand is a typology of circulation patterns developed by Miriam Clinton (2013) specifically for Minoan architecture. While space syntax focuses on the connections between spaces, Clinton's typology focuses on the morphological properties which are largely ignored by space syntax. It is my hope therefore that these two techniques of analysis will complement one another.

Although as stated 49 certain or hypothetical MHS have been identified, for the purposes of this section only 27 will be considered, including the changes made to four MHS (Mochlos B.2, the palace at Malia and the two systems at Zakros) in subsequent phases. These MHS are in general among the most certain and complete hall systems, and those for which the surrounding area is most understandable. These are therefore the halls which are most suited to Space Syntax Analysis. As Letesson (2013) has already studied these MHS closely, a summary of his findings will be presented here. For the Mycenaean comparison, 12 different buildings with a total of 14 different hall systems and one hearth room will be compared. Unfortunately, the area around the megaron-unit at Mycenae is too fragmentary to prove useful for analysis, so the two megaron-units at Tiryns and the main suite at Pylos will be compared, along with the secondary hearth room (46) at Pylos. For comparison, seven of Pantou's Corridor Buildings, two of the isolated megaron-units, (Korakou House L and Thermos Megaron A) and two similar megaron-units at Gla will also be analysed.

\subsection{Space Syntax Analysis}

Space Syntax Analysis (SSA) or Gamma Analysis was developed by Hillier and Hanson as a system of architectural analysis that studies buildings in relation to the connections between spaces. ${ }^{28}$ In examining the ways in which spaces are and are not connected, it is possible to study the ways in which people may have moved through the building. For this study, using Space Syntax Analysis allows us to study and compare the ways individuals may have accessed and moved through MHS

\footnotetext{
${ }^{27}$ For a list and explanation of some of these techniques see Clinton 2013:30-39.

${ }^{28}$ Hillier and Hanson 1984.
} 
and megaron-units both from the exterior and from other parts of the building. SSA has been used extensively to study Minoan architecture. ${ }^{29}$ It has been used less in Mycenaean architecture, but has been applied in a small number of studies of Pylos and Tiryns. ${ }^{30}$ The system is used by reducing the plan of the building or site to a justified graph, showing only its connections to other spaces. ${ }^{31}$ Each space is represented by a circle, and are organised onto a graph based on the shortest distance between the space and the exterior (see Fig. 8). From this justified graph, numerous different figures and properties can be gleaned about the building.

As an example, Gournia House He has been analysed in Figure 8. The exterior is represented by a circle with a cross through it. From the exterior, only the porch (31) is accessible. From 31, the main hall (32) and the corridor (33) can be accessed. While the main hall is a dead-end space, from the corridor 33 rooms 35,37 and 38 can be entered, and finally, rooms 35 and 37 provide access to rooms 34 and 36 respectively. To represent this on a justified graph (Fig. 1b), the exterior is placed at the bottom, representing a depth of zero. Space 31, as the first space accessible from the exterior, has a depth value of one and is therefore placed one level above the exterior, while spaces 32 and 33, accessible from 31 and with a depth value of two are placed above this, and so on.

From this justified graph, a number of different calculations can be made in order to compare buildings with each other. The main calculations used will be the total and mean depth values and integration values. The total depth of any given space is the total distance or number of connections required to reach each different space in the building. It is calculated by adding up depth of each space relative to the carrier space. This is easily illustrated by the construction of a Justified Graph. The justified graph generally represents the depth of each space relative to the exterior. Thus, at Gournia He (Fig. 8b), space 31 is at a depth of 1 from the exterior, while spaces 32 and 33 are at a depth of 2, spaces 38,37 and 35 at a depth of 3 and finally spaces 36 and 34 are at a depth of 4 (Fig. $8 d)$. By multiplying the number of spaces at each depth level for the exterior $(1 \times 1,2 \times 2,3 \times 3$ and $2 \times 4$ ), we reach the total depth value for the exterior (22). Using the same process, total depth values can be calculated for each space in the building. As an example, the depth values for space 31 have been represented on a justified graph (Fig. 8c). Unlike the exterior, three spaces are immediately accessible from space 31 (Space 32, 33 and the exterior), giving it three spaces at depth 1. Spaces 38,37 and 35 are at depth 2 and spaces 36 and 34 are at depth 3 (Fig. $8 d$ ). Space 31 thus has a lower total depth value of 15 .

\footnotetext{
29 Letesson 2009, Letesson 2013, Hacigüzeller and Thaler 2014, Romanou 2007 etc.

30 Thaler 2005, Duinker 2014, Hacigüzeller and Thaler 2014.

${ }^{31}$ For a detailed explanation of how to apply Space Syntax Analysis, see Otswald 2011.
} 
The mean depth is simply the total depth for a given space divided by the total number of spaces in the building, allowing for comparisons to be drawn between buildings. To compare buildings with vastly different numbers of spaces it is better to use relativized figures such as Relative Asymmetry (RA) or Real Relative Asymmetry (RRA). For this study, the RRA value has been used as the integration value. This is simply the mean depth value relativized for comparison between buildings of very different sizes. Therefore, a space with a high RRA or integration value is distant or segregated from the rest of the building, requiring a longer path to reach other spaces within the building, whereas a space with a low RRA value is highly integrated into the surrounding building, taking only a short path to reach most other spaces. In the example of Gournia House He, the exterior has a higher RRA value than space 31 (Fig. 8d).

The individual spaces can also be divided into four different types based on their connections. Type ' $a$ ' spaces have only one connection to the rest of the building, and have only one entrance or exit. It is necessary to pass back through the door that was entered to visit any other space in the house. See for example Gournia He space 32 (Fig. 8a-b). To enter or exit the room, it is necessary to pass through the door from space 31. Type ' $b$ ' spaces have more than one door, and may connect to a large number of spaces, but these spaces also only have one way in and one way out. To leave the building, it is necessary to pass back through this space again. In Gournia House He, spaces 31, 33, 35 and 37 are all type b spaces. Space 33 for example provides access to multiple different rooms, but in each case it would be necessary to pass back into room 33 in order to leave this area of the building.

Type ' $c$ ' and ' $d$ ' spaces are characterised by their place on one or more ring or ringy system. Ringy systems are easily recognised in the justified graph, as they are found where the connections formed by a series of spaces form a closed shape (Fig. 9b and 10b). As such, it is possible for a visitor to leave the area via two different routes instead of being required to backtrack their steps as in types $a$ and b. This is easily seen in the House of the Frescoes at Knossos (Fig. 9), where most of the rooms are located on a single ring. From space $\mathrm{H}-3$, for example, it would be possible to exit the building by passing through either rooms $\mathrm{J}-5, \mathrm{~K}-7$ and $\mathrm{A}-8$, or F-2, D-4, C-6 and finally A-8 (Fig. 2a). Type $\mathrm{c}$ spaces are located on a single ring, making rooms A-8, K-7, J-5, H-3, F-2, D-4 and C-6 at the House of the Frescoes all type c spaces. Type d spaces, on the other hand, are located on two or more of these systems, giving them the potential to be hubs of circulation and movement within the building. This is easily seen at Akhladia, where almost every room is located on one or more ring. In Figure 10, four of these ringy systems are highlighted in different colours. Spaces 1, 2b, 3 and 6 are all type ' $d$ ' spaces, located on two or more of these systems. 
Space Syntax Analysis is a useful tool in comparing the spatial structure of a large number of different buildings, but there are a few difficulties in its application. Firstly, in order for space syntax to be accurate or useful, the floor plan must be complete or very nearly so. ${ }^{32}$ Unfortunately in archaeology this is rarely the case. Where floor plans are incomplete or the location of doorways is not known, space syntax can only be tentatively applied. The analysis presented here is therefore based only on one interpretation of the archaeological remains and in many cases could be debated. In several instances it has also not been possible to include some buildings in the survey due to their incomplete nature.

Secondly, space syntax is limited in its response to features such as columns and pier and door partitions, and it does not take into account features such as long or bent corridors that could be used to visually or physically distance spaces from one another. ${ }^{33}$ For example, though in the space syntax analysis the two megaron-units at Tiryns appear at the same depth from the exterior, this is due to the very long corridor 36 , which takes the place of several different spaces in the route to the main megaron-unit. Many of the small rings observable around MHS are due to the nature of their columns and pier and door partitions. At Malia $\Delta \alpha$ for example, while the main hall of the MHS is accessible from three spaces $-2,5 \& 11$, these three spaces are not separated by any doorway. Though it would be possible to move between them by passing through the MHS, this would certainly not be a shorter route.

Finally, as mentioned, space syntax analysis is most effective when used to compare large numbers of buildings. ${ }^{34}$ While this is not a problem in the case of MHS, only two true palatial megaron-units are well enough preserved to make space syntax effective, giving only a very small body of evidence. However, for a broader comparison, some structures featuring similar suites have also been analysed and their results compared.

Regardless of these difficulties, Space Syntax Analysis remains a useful and interesting tool to use in the comparison of buildings, particularly in comparing large numbers of buildings with a large range of sizes.

\subsection{Clinton's Typology of Access and Circulation Patterns}

Miriam Clinton's typology of access and circulation in Minoan Architecture (2013) was developed in order to facilitate a way for archaeologists to interpret archaeological remains as they were

\footnotetext{
${ }^{32}$ Clinton 2013:34-35.

${ }^{33}$ Clinton 2013:34.

${ }^{34}$ Letesson 2013:315.
} 
excavated, in incomplete form, and to help to identify spaces as private or public spaces. ${ }^{35}$ The typology focuses on circulation patterns and takes into account aspects such as the direction of approach (bent axis) and type of space which is not taken into account in SSA. In order to do this, Clinton identified six different types of circulation that can be applied to most spaces in buildings in the Minoan world. The first two - the circulatory nexus and room to room circulation form the basis of most different circulation patterns in both Minoan and Mycenaean architecture. The remaining four build on the above two to create a more specific picture of the circulation in any given building. As Clinton states, this typology only takes into account the most common types of circulation patterns, rather than all possibilities. ${ }^{36}$ In order to better take into account the different possible movements for comparison over many different buildings, I have altered the use of some of these terms slightly.

Firstly, the circulatory nexus is a space similar to a type ' $d$ ' space in space syntax, where two or more circulation patterns in the building meet. ${ }^{37}$ Clinton gives the example of the MHS as a common type of circulatory nexus, but as will be seen the MHS should not always be seen as such. ${ }^{38}$ For the purposes of this study, the term 'circulatory nexus' will be used to describe any space which provides access to three or more spaces, in an attempt to more fully cover the possible types of circulation in any given building. In the example of Gournia He, space 31 is a circulatory nexus.

Room to room circulation, on the other hand, should be seen as the opposite of the circulatory nexus. Instead of being characterised by multiple access routes, room to room circulation occurs when there is only one way forward. ${ }^{39}$ This is most often seen in space syntax types $a$ and $b$, although type ' $c$ ' spaces also sometimes display this type of circulation. It is characterised by a lack of transitional spaces; to reach any space in the building it would be necessary to pass from one room or activity space directly into the next. ${ }^{40}$ For the purposes of this study, this term will be used specifically to denote rooms with only one or two doorways, particularly those that were also large enough to host some kind of activity. In Gournia House He, room to room circulation is used between room 35 and 34, and between room 37 and 36 .

Corridor spaces are transitional spaces, which are generally too small or narrow to be likely to host activity as well as movement. ${ }^{41}$ While some corridors host a variant of room to room

\footnotetext{
${ }^{35}$ Clinton 2013:2-3.

${ }^{36}$ Clinton 2013:50.

${ }^{37}$ Clinton 2013:50-51.

${ }^{38}$ Clinton 2013:50-51.

${ }^{39}$ Clinton 2013:53.

${ }^{40}$ Clinton 2013:53.

${ }^{41}$ Clinton 2013:54.
} 
circulation, offering only one entrance and exit, others act as circulatory nexuses, with multiple rooms opening off them. In order to distance this form of circulation from the common usage of the word, I have elected to use the term 'passageway' for the purposes of this study. The corridor 33 in Gournia House He is a good example of a passageway acting as a circulatory nexus, and due to their small sizes, spaces 35 and 37 may have acted as passageways with room to room circulation to the larger spaces 34 and 36 which they open onto.

Clinton's matrix is an isolated group of rooms with few connections to the rest of the building. ${ }^{42}$ One example she illustrates is rooms 5-9 at Nirou Hani, which form a separate section of the building accessible only through one door from the passageway $4 .{ }^{43}$ This term is particularly useful in terms of the Minoan palaces, where the MHS often control a small matrix isolated from the rest of the building, for example at Phaistos in the case of both suite 63-64 and 77-79.

Exterior circulation is a form of circulation which is fairly rare in Minoan architecture, but reasonably common in Mycenaean architecture. This is a type of room to room circulation, where a space is accessible only through one door from the exterior, with no internal communication with the rest of the building. ${ }^{44}$ This type of circulation can be seen at Pylos in room 57, or at Pseira in room 8, for example.

Finally, bent axis is a term which can be used to modify most of the above types. ${ }^{45}$ Circulation is bent axis simply when it requires the individual to turn a corner rather than moving straight forward. This increases privacy simply because it distances the individual from their destination, both physically and visually, ensuring that the visitor cannot view their destination from the entrance. ${ }^{46}$ Examples of bent axis approaches can be seen in the approach to the MHS from the entrance foyer (1) at Akhladia, in bent passageways such as corridor 36 at Tiryns and in the off-axis approach to the megaron-units at Tiryns (Fig. 11) and Pylos from the main gateway.

While this typology was developed to look at individual buildings in terms of their circulation patterns and public/private nature, I have attempted to use it to compare large amounts of buildings with one another. In order to do so, I have used the typology to compare the nature of the hall systems in the buildings in terms firstly of how they were approached from the exterior, and

\footnotetext{
42 Clinton 2013:51-53.

${ }^{43}$ Clinton 2013:Fig. 4.2.

${ }^{44}$ Clinton 2013:54-55.

${ }^{45}$ Clinton 2013:55.

${ }^{46}$ Clinton 2013:55-56.
} 
secondly in the ways they were connected to the rest of the building, and specifically the spaces surrounding them.

\section{Spatial Structure of Minoan Hall Systems}

\subsection{Space Syntax Analysis}

In his space syntax analysis of 27 different buildings with MHS, Letesson discovered that spatially MHS vary a large amount. ${ }^{47}$ A summary of these findings can be found in Table 5. In terms of cell type, while $57 \%$ of light well spaces are type 'a' spaces, both the vestibule and main hall of the MHS are far less consistent. No main hall is a type ' $a$ ' space, but the results are fairly evenly spread over the remaining three types (Type b: 30\%, Type c: 37\%, Type d: 33\%), and similar results are found with the vestibule (Type a: $8 \%$, Type b:27\%, Type c: 35\%, Type d: 31\%). This inconsistency led Letesson to divide the MHS into two different broad groups - linear or ringy - based on their spatial function, and from there into a further five types characterized by cells of similar types and a similar function within the overall structure.

In the first two types of MHS, strictly linear systems and linear systems, each space of the MHS is at a higher depth level to the previous, giving them a linear arrangement. ${ }^{48}$ They are entered through the main hall first, and in halls where a light well is included, this is the most secluded space. In this category, the light well is always a type 'a' space, meaning that theoretically, access can be easily cut off. ${ }^{49}$ In the strictly linear systems, the main hall is a type ' $b$ ' space, with only one connection to the rest of the graph (see Table 5). To exit the building, a visitor would need to retrace their steps through the MHS. However, these systems are by no means dead-ends. Of the 7 halls in the category, only two can be seen as such, with all others providing access to at least one other space outside of the MHS (Table 6). At Mochlos the system is located near the entrance to the house, making it necessary to pass through the system to access most spaces in the house. This is the exception, rather than the rule, as most of the spaces provide access only to a few rooms of type $a$ and $b$. The two linear MHS differ from the strictly linear spaces in that their main halls are type $c$ or $d$ spaces, rather than type b, meaning they have are located on a ring, and therefore have more than one connection to the rest of the building. ${ }^{50}$ Generally, the main hall of the two categories has a below average integration value, making it an integrated space, while the vestibule and light wells

\footnotetext{
47 Letesson 2013.

48 Letesson 2013:320.

${ }^{49}$ Letesson 2013:320.

${ }^{50}$ Letesson 2013:319-20.
} 
have above average values, making them more segregated spaces. ${ }^{51}$ The light wells of the two linear systems are the most segregated spaces in the building. ${ }^{52}$ The mean depth of the MHS is also generally higher than the mean depth of the building.

In the remaining three types of MHS a least two spaces of the MHS lie on a ring, and can be divided into three categories based on the nature of this ring. Ten systems are located on ringy systems of local range, connecting only a small number of spaces. Six systems are located on ringy systems of global range, which connect a large proportion of spaces within the building. Finally, two systems are accessed from the exterior as part of external ringy systems. As part of ringy systems, these MHS have the potential to host far more elaborate and complicated circulation patterns than those without. ${ }^{53}$ These systems present integration and depth values that are much more varied than the linear systems and are as such difficult to compare.

Firstly, the MHS located on ringy systems of local range connect only a small amount of spaces, creating very little impact on the circulation patterns of the building. ${ }^{54}$ In general, it is the vestibule and main hall that host these ringy patterns, leaving the light well as a type a or b space. ${ }^{55}$ The main hall or the vestibule are generally the first spaces accessible from the exterior. However, it is important to note that many of these local rings are created simply as a side effect of the pier and door partitions or columns inherent in the MHS. While as stated it would be possible at Malia $\Delta \alpha$ to access the corridor 5 from corridor 11 by passing in and out of the MHS, practically this would be inefficient and the route would not be used as such.

The six MHS that are part of ringy systems of global range connect proportionally more spaces than those of local range, giving them the potential to have a much larger influence on the overall circulation of the building. ${ }^{56}$ In three of the four systems that include light wells this space is a type c or $\mathrm{d}$ space like the hall and vestibule, but in most other respects these halls are topologically similar to the systems on ringy systems of local range. In both types of MHS the space first accessible from the exterior generally displays a lower than average integration value, with the vestibule almost always displaying a low value. In 12 out of the $16 \mathrm{MHS}$ at least two spaces display below average integration values, but only 6 display below average integration for every space of the MHS.

\footnotetext{
${ }^{51}$ See Table 5. Mochlos is the exception, as the spaces of Mochlos' MHS are the highest integrated spaces in the building.

52 Letesson 2013:319.

53 Letesson 2013:320-22.

54 Letesson 2013:320.

55 Table 5. The exception is Tylissos House A, whose light well is located on a ring involving the vestibule (A) and the adjoining space $d$, also part of the hall system.

56 Letesson 2013:321-22.
} 
Finally, the villas at Vathypetro and Nirou Hani incorporate a MHS which is accessible from the exterior and located on a large, exterior ringy system. Instead of including a light well, the vestibule is directly adjacent to the exterior. All the spaces of both systems display below average integration values, with the main hall at Nirou Hani the most integrated space of the building.

It seems likely from this comparison that MHS in various buildings may have functioned very differently. The various suites were included and connected to the surrounding building in a wide range of different ways. While some were isolated from the rest of the building, with very little interaction with other spaces, other systems were integral to the building's circulation. It is very unlikely, for example, that the MHS at Nirou Hani, which was located on an exterior ringy system and formed one of the main entrances to the building, could have functioned in a similar way to Malia $\mathrm{Z} \alpha$ 12 , a strictly linear system with only one door connecting it to the rest of the building. ${ }^{57}$

\subsection{Approach}

The way in which each MHS was approached or accessed from the exterior varies considerably. In smaller buildings, while some MHS were located close to the entrance, others were distant from the entrance or accessed through bent axis approaches, making the route to the MHS much less obvious. In the palaces, some halls were located near the Central Court, while others required a long and often obscure route from either the Central Court or the main entrance. This again suggests that in different buildings the MHS may have been incorporated for different uses; while MHS near the entrances to buildings or matrices may have been used to welcome guests, for example, MHS that were more secluded may have had more private or restricted access.

Firstly, many MHS were accessible in a direct, obvious line from either the main entrance or the Central Court in the palaces. The MHS at Tylissos House A, Malia $\Delta \alpha$, Chania House 1, Malia Z $\beta$, Nirou Hani, both halls at Zakros, the secondary MHS at Phaistos (63-64) and both periods of Building B.2 at Mochlos were all easily accessible from an entrance. At Nirou Hani, the MHS is the entrance, while at Zakros, the two halls are directly accessible from the central court. At Chania, Mochlos, Phaistos 63-64 and Malia Z $\beta$, the MHS are accessible through one or two small foyers at the main entrance to the building (or the central court). At Chania and Malia $Z \beta$, this foyer serves as a circulatory nexus, but the other spaces which the foyer opens onto all have a bent axis approach. The MHS is therefore the space the visitor is directed towards. The foyers leading to the systems at Mochlos and Phaistos 63-64 have a room to room access pattern, making the MHS the only

\footnotetext{
${ }^{57}$ The interpretation of Malia Z $\alpha$ follows that of Letesson (2009:132) who suggested that due to the presence of the foundations for a wall at the back of this system, it would likely be open to the air by a window, rather than being an entirely open space.
} 
destination possible. Each have a bent axis approach, giving the MHS some privacy. The systems at Tylissos House $A$ and Malia $\Delta \alpha$ are both slightly further away from the entrance. At Tylissos House $A$, the system has a bent axis approach from the main entrance, but from this doorway the MHS is the obvious and logical destination. At Malia $\Delta \alpha$, the MHS is directly ahead from the entrance, but one must pass through an intermediary passageway to reach it.

In contrast, the MHS at Tylissos House C, Malia Z $\alpha$, the Little Palace at Knossos, Pseira, Palaikastro, Gournia, Akhladia, the Royal Villa and South House at Knossos, both periods at the Palace of Malia and Phaistos 77-79 all have more obscure routes. In the case of both Palaikastro and Akhladia, the MHS is located like at Chania and Malia Z $\beta$ off a small foyer near the main entrance to the building, but unlike at Chania and Malia, these two systems are located through small side doors, rather than the largest and most obvious route directly ahead, giving them a more private bent axis approach.

The route to the MHS at Tylissos House C, Malia Z $\alpha$, and the South House and Little Palace at Knossos are even more obscure. In all of these buildings, visitors are not directed towards the MHS by the architecture. At Tylissos House $\mathrm{C}$ and Malia Z $\alpha$, the MHS are located off passageways, and in both cases the door is not the last or largest door, making it less obvious that the door in question leads to the MHS. ${ }^{58}$ Both also incorporate a bent axis approach. The hall at the South House is also located off a narrow corridor, but it is then accessible through a pier and door partition wall, on a bent axis to the entrance. ${ }^{59}$ The Little Palace is characterized by a high amount of room to room circulation, making most routes to the MHS obscure and unobvious.

The remaining palatial MHS all form a part of a secluded matrix, isolated from the rest of the palace. At Gournia and similarly at the Royal Villa at Knossos, a visitor hoping to access the MHS would have to make their way through several spaces, mostly circulatory nexuses. At Phaistos (7779), while the MHS is fairly close to both the main entrance and the central court, the approach in both cases is bent axis. Though the system is accessed from a stairway that acts as a circulatory nexus and a passageway in terms of circulation (76), the stairway only gives access to one other space (50), also a MHS. This stairway could easily be blocked off for privacy, providing no access to this secluded matrix. At the palace at Malia, in both periods the access to the MHS is through several small corridors or intermediary spaces, off the smaller North or West Courts. Both require the visitor to pass through several spaces in room to room circulation with many on a bent axis.

\footnotetext{
${ }^{58}$ See Hitchcock 2000:158-159 on Tylissos House C.

${ }^{59}$ Based on the reconstruction proposed by Lloyd 2011.
} 
The MHS at Pseira and the House of the Frescoes at Knossos are interesting in their approach. Both have two circulation routes through the house, both room to room, which culminate in the MHS. At Pseira, this consists only of a small amount of spaces, but at the House of the Frescoes both routes pass through two intervening rooms from the small foyer at the entrance. While it is possible that the smaller two rooms (K-7 \& J-5), were simply transitional passageway spaces, the larger C-6 and D-4 were certainly living or activity spaces.

Finally, the approach to the MHS at Vathypetro is also interesting in that while it is accessible from the exterior it is still relatively isolated. The MHS along with the tripartite shrine it opens onto forms its own separate matrix in the building, and while it may have been intended to be approached from the exterior, it is also possible that visitors to the shrine and the MHS were required to pass through the house in a series of corridors and circulatory nexuses to gain access.

This large variation in approach to the different MHS means that many must have functioned in different ways. While those located at or near the entrances to buildings may have been used in welcoming visitors to the building, whether informally or in a formal ceremony, and would have had some measure of control over access to the rest of the building, those that were more distant, particularly those such as at Tylissos House $\mathrm{C}$ which were very distant from the entrance would not have been used in the same way. To reach these more distant halls, a guest would have already gained access to much of the building, giving the MHS less control and more privacy than those at entrances.

\subsection{Connections}

Just as the MHS differ vastly in their access, they also differ in the way they connect to other spaces in the building. Only three MHS connect to the rest of the building through one single door (South House at Knossos, Malia Z $\alpha 12$ and Vathypetro). The remaining systems vary, connecting directly with between 2 and 7 different spaces (Table 6). Interestingly, 17 of the 27 MHS studied provide the only access to one or more spaces on the floor which they are found. In the building containing the most integral MHS (Mochlos II), it is necessary to pass through the MHS to access a total of 14 spaces, although the average is lower at 3.3 spaces. However, when stairs and the other levels of the buildings are taken into account, the numbers drop. A total of $13 \mathrm{MHS}$ provide the sole access to at least one space, while the average is lower again at 2.45 spaces. It is only at Mochlos and Tylissos House A that the MHS has the most connections in the building. Most spaces of the MHS have less than 4 connections, with only a handful exceeding this. 
At Malia $\Delta \alpha$, Malia Z $\alpha$ (12), Vathypetro, Phaistos 63-64 and the South House at Knossos, the MHS is a separate matrix, entered generally through room to room circulation and is essentially a deadend. It is cut off from the rest of the building, providing no essential access to other spaces. Each is entered through room to room circulation. Interestingly, few of these spaces are Letesson's Strictly Linear halls. Malia $\Delta \alpha$ is one of Letesson's Linear spaces, as it has multiple access routes. However, as already stated, these doors are along the same wall of the MHS's main hall, through a pier and door partition wall. While technically the space is on a ring, practically it would never be used as such; the MHS would only be entered for the purpose of using the space, rather than as a passage to any other space. Vathypetro, on the other hand, is located on an external ringy system. It is therefore accessible both from the exterior and internally from the corridor space 23 . However, due to the presence of the tripartite shrine it is unlikely that the MHS was used as a thoroughfare to access the house. It is more likely that the system was used as an isolated unit, and the entrance through the passageway 23 would have only been used in conjunction with any ritual or ceremonial activity taking place in the MHS and tripartite shrine.

On the other hand, at least one space in the rest of the MHS was a circulatory nexus. Many of these were far more integral to the overall plan of the building. The systems at Tylissos House A, Akhladia, Nirou Hani, Malia Z $\beta$, Phaistos 77-79, the Royal Villa and Little Palace at Knossos and both periods at Mochlos and the Palace at Malia all provided easy access to multiple spaces and the only access to a few of these spaces. The systems at Mochlos and Phaistos 77-79 are adjacent to the entrance to the house or to the matrix, and provide the only access to the majority of spaces in the house or matrix (at Phaistos). At the Palace of Malia, the MHS can be bypassed more easily, but it also provides the sole access to a few spaces in the second period. The MHS at Malia Z $\beta$ provides the only access to just a few small spaces, but it is connected to the central room by an open wall at one end, creating one large open living area and circulatory nexus, possibly acting as an entrance hall close to the building's main entrance. The hall at Nirou Hani also acts as an entrance, and while it does not provide the sole access to any spaces, it gives access to multiple different matrices in the house, and provides the only ground floor access to one matrix of nine spaces. The MHS at the Little Palace at Knossos serves as its own matrix, like the isolated halls above, but it is a circulatory nexus as it does have several access points to the rest of the building.

The halls at Malia Z $\alpha$ (5-8), Chania, Gournia and Palaikastro were more isolated. Though all technically circulatory nexuses, they were essentially type b spaces in terms of space syntax, with 
only one connection to the rest of the building. ${ }^{60}$ Each provides the only access to one or more small spaces, through room to room circulation. The two halls at Malia Z $\alpha$ and the hall at Gournia form their own isolated matrices, both with a lustral basin included. On the other hand, while the MHS at Pseira and the House of the Frescoes at Knossos are technically circulatory nexuses, this is only because two room to room circulation patterns which connect the remainder of the spaces in the building meet in the MHS.

Although the MHS at Zakros are also technically circulatory nexuses, they are very disconnected from the rest of the palace. One system (37) provides the only access to three spaces $(63,67$ and an unnumbered intermediary space) through room to room circulation, but aside from these spaces the two MHS are fairly isolated. Both have multiple doors opening onto the central court and are separated from each other by a series of pier and door partitions. They are therefore circulatory nexuses, although they cannot host circulation to the remainder of the palace.

Finally, the hall at Tylissos House C, like those at Chania, Palaikastro and Malia Z $\alpha$, is also very isolated, but it does still incorporate the meeting of two separate circulation patterns, making it a circulatory nexus. Unlike many of the MHS, it is doubtful that this space would have been used as a passage between these two circulation patterns. The main hall is entered from the corridor $\mathrm{B}^{\prime}$ and room 12, both part of the same large matrix as the MHS itself. Both corridor B' and room 12 were accessed from corridor $B$, though corridor B' accessed this space directly, while room 12 accessed the corridor through the passageway $C$. Only a short distance separates these two routes, and to exit the building, individuals coming from both directions would need to make their way back through corridor B. Functionally, this suggests that the two access points met in the MHS for activities taking place in the hall, rather than as a short cut to the other direction (Fig. 12).

It seems that as in the approach to the various MHS, the way in which different MHS were connected to the building they were located in also differed vastly. This would similarly have affected the way these halls were used. Those such as at Mochlos and Tylissos House A which provided essential access to much of the remainder of the building would necessarily have acted as hubs of circulation and movement, whereas isolated halls such as at Malia Z $\alpha$ and $\Delta \alpha$ would have only hosted movement to and from the MHS itself. Though some aspects of their use may have been similar, because of the way they were connected to the rest of the building the environment would have been very different in the various halls.

\footnotetext{
${ }^{60}$ At Palaikastro, this is based on the interpretation (After Preziosi 1983:66) that space 6 was a light well entered through the MHS.
} 


\subsection{Conclusions}

It is evident from this analysis that though MHS may be very consistent in form, in terms of their spatial structure in relation to the rest of the building, MHS are very diverse. Their location within the building, access routes from the exterior and their connections to other spaces vary considerably from building to building. While some are close to or at the entrance of the building or matrix within the building, others are distant from the entrance. Some are integral to the use of the surrounding building, providing the only access to many spaces, while others are isolated, dead-end spaces, and still others, while highly integrated into the building, provide no essential access and can be bypassed. This diversity suggests that the different systems may have functioned very differently, with some being used as hubs of circulation and others as secluded spaces with more restricted access.

Many scholars have suggested that the MHS was ideally situated as an intermediary meeting place between visitors and residents, as it often was accessible directly from the entrance and included a secondary, private entrance giving direct access to more private rooms. ${ }^{61}$ This is certainly possible at many of the palatial sites. All of the palatial MHS are located in their own isolated matrices, separate from much of the building, and each of the MHS are located at or very near the entrance to these matrices. The visitor would be required to pass through the MHS before gaining access to the remainder of the matrix. This is also true of the matrix surrounding the Hall of the Double Axes at Knossos.

Outside the palaces, while this would be possible at some MHS, it is not always the case. As we have already seen, a number of MHS are entirely isolated from the rest of the building, only accessible through one door and leading to no other spaces, giving residents no private spaces to retreat to. Even among the halls which did serve as circulatory nexuses, many do not fit these requirements. Some, such as the MHS at Palaikastro and in the palaces, those at Gournia and Zakros, give access to too few spaces to allow for private quarters. Others are simply too open to allow for this interpretation, including the halls at Zakros and many outside the palaces. At Malia Z $\beta$, for example, while two access routes are present, there is no wall or doorway surviving that would separate visitors from the open central space adjacent to the MHS which would give them access to the rest of the building. Finally, it should be noted that in many cases while two circulation patterns may meet in the MHS, many of the MHS are only accessible through a single door, including most of the matrices surrounding the MHS at the palaces. Though there may be enough room for residents

\footnotetext{
${ }^{61}$ E.g. Palyvou 1997.
} 
to retire in privacy, to exit the area they would be forced to leave through the same door as the guests. Any such activity in the MHS must therefore have varied from site to site.

Evidently, MHS were included in buildings in a wide variety of different ways, making them spatially very diverse. These different MHS would have necessarily functioned in different ways, as movement into and out of these MHS varied between the sites. Though some aspects of their use may have been similar, MHS are not a uniform system, and could be used in very different ways.

\section{Spatial Structure of Megaron-Units}

\subsection{Space Syntax Analysis}

Though the Mycenaean megaron-unit differs in form more than the MHS, in spatial structure the buildings it is found in are in general far more uniform. In part, this is because the buildings studied were selected on their structural similarity. However, the various types of Mycenaean buildings differ, and will therefore be analysed separately. Justified Graphs and details of total depth, mean depth and RRA values for each space in the 12 buildings studied can be found in Appendix 1, and a summary of the findings can be found in Table 7.

Firstly, the simplest isolated megaron-units prove challenging to analyse through Space Syntax Analysis both because they are often not well preserved enough, and secondly because they are too simple. As already stated, space syntax relies on a complete or almost complete floor plan to be effective, and even when these isolated megaron-units are fully excavated, the locations of their doorways are often uncertain. Without certain locations for these doorways, space syntax is not possible. It is also far more effective and useful with more complex buildings than the simple, small and linear isolated megaron-units. As an example, I have analysed House $L$ at Korakou and Megaron A from Thermos, whose doorways and floor plans are relatively certain. These isolated megaronunits in general display a simple circulation pattern with no ringy systems. Both House $L$ and Megaron A contain back rooms, meaning that the porch, vestibule (where applicable) and main hall of the megaron-unit are all type $b$ spaces.

In this linear arrangement, it is unsurprisingly the central rooms that display the greatest integration and the smallest total depth values. ${ }^{62}$ At Korakou the central room is the vestibule, while at Thermos the building consists of fewer spaces, so the smallest values are shared by the porch and

\footnotetext{
62 For these two buildings, Relative Asymmetry (RA) figures have been used instead of Real Relative Asymmetry (RRA) figures, as these buildings are too small to apply the adjustment needed to calculate RRA values (see Hillier \& Hanson 1984:109-113).
} 
main hall. Likewise, the exterior and the back rooms of each share the largest total depth and integration values.

Secondly, of the proposed 12 'Corridor Buildings' identified by Pantou (2010), only seven have plans complete enough for space syntax analysis. Unfortunately, the analysis of some of these seven is based on reconstructed plans and therefore should not be considered definitive. In general, these Corridor buildings are fairly simple buildings, the spatial structure of which is characterized by a large amount of type $a$ and $b$ spaces. Only three of the buildings (Megaron A at Dimini, Mansion 1 at Menelaion and the Megaron at Phylakopi) contain ringy systems; in all other structures all spaces are therefore exclusively type a or b. The main hall of all the Corridor Buildings is a dead-end space of type a. The Corridor Buildings can be divided into three groups by the role of the megaron-unit.

The first group consists of buildings in which the megaron-unit is isolated from the rest of the building. At Phylakopi and the House of the Sphinxes at Mycenae, the megaron-unit is accessed externally, with no direct communication with the rest of the building. At the West House at Mycenae, similarly, the building is accessed through a courtyard, and the megaron-unit is accessed from this courtyard with no other point of contact with the rest of the building. In terms of integration values, the megaron-units of these buildings have little consistency. While the megaronunits of Phylakopi and House of the Sphinxes at Mycenae have higher than average integration values, making them secluded spaces, the porch and vestibule of the West House at Mycenae are two of the most integrated spaces of the building, with very low integration values.

The second group consists of two of the buildings containing ringy systems, Megaron A at Dimini and Menelaion Mansion 1. In both cases the vestibule of the megaron-unit lies on a ringy system, making it a type $c$ space, not type $b$ as in all other examples. Both vestibules open both onto an exterior space (the courtyard (7) at Megaron A at Dimini, at Mansion 1 the porch (9) of the megaronunit) and through a side door, onto the flanking corridor. While the vestibule of these buildings features a below average integration value, they are by no means the most integrated spaces in the building and remain reasonably isolated.

In the final group, consisting of Megaron B at Dimini and House He at Gournia, the vestibule or porch of the megaron-unit is the first space accessible from the exterior, and it is through this space that the rest of the building is accessed. The vestibule features doors into the main hall and in the side onto the flanking corridor. As the only access to the corridor and therefore the rest of the building, the vestibule is an integral part of the building's circulation system, which is unusual. In all other corridor buildings, and at both Tiryns and Pylos, the megaron-unit is unimportant to the circulation of the building as a whole. Unless the megaron-unit itself is the destination, the suite can 
be avoided entirely, albeit through a longer and more circuitous route. This is clearly not the case in these two buildings. The vestibule in these buildings is the second most integrated space in the building, coming second only to the adjacent corridor.

Integration values for the units vary considerably. In general, the vestibule or porch of the unit has a below average integration value, while all the main halls have above average integration values. In almost every case, the main hall of the megaron-unit is one of the least integrated spaces in the building. In three buildings, it is the least integrated space, while in most of the others it has a higher integration value than around $85 \%$ of other spaces. The exception to this rule is House He at Gournia, which while it has a higher integration value than average is only higher than $62.5 \%$ of other spaces. The most integrated space in each building is unsurprisingly the flanking corridor that gives access to the majority of rooms. ${ }^{63}$ In most cases it is also this corridor that has the highest number of connections to the rest of the graph. ${ }^{64}$ The vestibules range in integration from around 0.607-1.281, with an average of 0.872 . The integration values of the main halls vary a lot more, ranging from 1.138 to 2.141 with an average of 1.653 . The average integration values for each building also vary considerably, ranging from 0.811 to 1.352 .

The Residence at Gla is a large, unusual building consisting of two long wings. At the end of each wing are large megaron-units. Although neither contained hearths or columns, their similar spatial arrangement make the Residence at Gla an interesting comparison. The building contains a large external ringy system, with $43.5 \%$ of spaces on a ringy system. The building's spaces are fairly evenly distributed between the four room types, with $28 \%$ each of type a and b, $26 \%$ of type c and only $18 \%$ at type $d$. Both the megaron-units are located on smaller, local rings, adjacent to the larger ringy system.

Like the other megaron-units studied, both the main halls at Gla have above average integration values, with the vestibule spaces slightly below average. The average integration of the building at 1.521 is higher than all other Mycenaean buildings studied. Unusually, the space that could be considered the 'porch' of the larger megaron-unit, room 1, is the most integrated space of the unit, instead of the vestibule. In the secondary suite, there is no porch, and the main hall (23) is not a type a space, with an entrance leading in through the vestibule (24) and another in the back wall to a small corridor $(T)$. The main entrance to the vestibule is also through the side door, rather than directly opposite the entrance to the main hall.

\footnotetext{
63 In the West House at Mycenae this space is a courtyard rather than a corridor.

${ }^{64}$ Excepting the West House (see above), Megaron B, Dimini (where the vestibule has an equal number of connections), and Phylakopi (where the exterior and room 12 have an equal number of connections).
} 
Finally, both Tiryns and Pylos, like Gla, are characterized by large, global ringy systems, connecting a large proportion of the building ( $47 \%$ of spaces at Pylos, $39 \%$ at Tiryns). In both cases, the megaron-unit is adjacent to this global system, but not part of it. At both sites, the megaronunit's porch is type $\mathrm{c}$, and like in the Corridor Buildings, the main halls are type a. Both vestibules are on ringy systems, making them type $\mathrm{c}$ or $\mathrm{d}$ spaces ( $\mathrm{c}$ at Tiryns, $\mathrm{d}$ at Pylos). While the most common type of space at Tiryns (36\%) is type a, the most common type at Pylos is type c (35\%). At Tiryns, the spaces with the most connections are the corridors flanking the main megaron-unit and the smaller 'Queen's' megaron-unit $(12,19,28)$, but at Pylos as this corridor is separated at regular intervals no space has more than four connections.

In terms of integration, while the two buildings display average integration values that are remarkably similar (1.42 for Tiryns and 1.414 for Pylos), the values of the hall systems vary considerably. At Pylos, the vestibule of the megaron-unit is the second most integrated space in the building, second only to the adjacent corridor (35). The porch (4) has only a slightly higher value. Even the megaron-unit and the secondary hearth room (46) have below average integration values, making them integrated spaces. At Tiryns, on the other hand, the vestibule has an integration only just below average, higher than the integration value of the main hall at Pylos. Only the vestibule of the Queen's megaron-unit (17) has a low value; all the other megaron spaces display integration values well above average. Of the megaron-unit in both, it is the vestibule that displays the highest integration, followed by the porch and finally the main hall is the most segregated space.

Though the different types of building vary considerably in their size and complexity, some patterns in their spatial structure are apparent from the Space Syntax Analysis. With the exception of the isolated megaron-units, the main hall is generally a type 'a' dead-end space, making it a destination or activity space rather than a transitory space. It is also generally the vestibule (where one is included) which is the most integrated space of the megaron-unit, and the main hall the least integrated. As has been seen, the ways in which the megaron-unit is connected to the surrounding spaces differs. While many suites such as those at Pylos and Tiryns, the Menelaion and Megaron A at Dimini contain a ringy system which connects the surrounding rooms with the vestibule of the megaron-unit, for several Corridor Buildings, no such connection exists. On the other hand, the isolated megaron-units Megaron A at Thermos and House L at Korakou are connected to the back rooms of the megaron-unit through the main hall itself, and the porch or vestibule of the Corridor Buildings Gournia House He and Megaron B at Dimini provide the only access to the other rooms found at these two sites. Though these buildings may have many similarities, there is also a large amount of variation. 


\subsection{Approach}

The ways in which each type of megaron-unit is accessed from the exterior are again remarkably similar. Almost every hall system is accessed directly from some kind of exterior space, excepting the two suites at Gla which are accessed through passageways at the building's two entrances. However, though the megaron-units are more uniform in their access from the exterior than the MHS, there is still a large amount of variation between different buildings.

The isolated megaron-units provide unsurprisingly the simplest approach. These are accessed on axis entirely through room to room circulation with no transitional spaces. The Corridor Buildings, while simpler than the palaces, are more varied. House He at Gournia and Mansion 1 at Menelaion are most similar to the isolated megaron-units, accessible directly from the exterior. At Gournia, the circulation from the exterior into the porch or vestibule of the megaron-unit is room to room, whereas at Menelaion, the exterior provides access to three spaces, making the exterior itself a circulatory nexus. Megaron B at Dimini is also accessible from the exterior through the vestibule, but unusually this entrance gives the megaron-unit a bent axis approach. The megaron-units at Phylakopi and at the House of the Sphinxes at Mycenae have exterior circulation, with no communication with other spaces in the building except through the exterior. The megaron-unit at the West House at Mycenae is accessible from the courtyard that serves as a circulatory nexus for the majority of the building. Finally, Megaron A at Dimini is slightly more distant from the exterior. To reach the megaron-unit it is necessary to pass through a space 2 , a passageway space with circulatory nexus circulation, and a courtyard also serving as a circulatory nexus (7). From the courtyard, the entrance to the vestibule is also on a bent axis. Although these differ in their precise form, each is accessible from an unroofed space, some from internal courtyards and some from spaces outside the building.

At the palaces, the approach to the megaron-unit is more complicated. At Tiryns, where the entire citadel is well preserved, the upper citadel and palace is entered through a series of roofed gateways, each at a bent axis to the previous. Although at first glance, the circulation through these gates appears room to room, through the first gate (1a-b) a second door opens leading into the palace and towards the smaller, secondary megaron-unit (17-18). This is on a bent axis and the visitor is directed through the gates and towards the main megaron-unit. After passing through each of these the two gates, the visitor accesses a large courtyard, each serving as a circulatory nexus, with multiple routes possible, but the largest and most monumental doorway in both cases is towards the megaron-unit. It is interesting to note that while from the second gate $(3 a-b)$ the megaron-unit lies ahead across the courtyard; this again is a bent axis approach (Fig. 11). While the 
gateway lies on the south-west side of the courtyard, the porch of the megaron-unit lies in the centre of the north side of the courtyard. A visitor would have to cross the courtyard diagonally to reach the megaron-unit, preventing them from seeing inside until they approached the steps. At Pylos, there is only one gate to the main palace building, but this is remarkably similar to the arrangement at Tiryns. The approach to the building and towards the megaron-unit features less of a bent axis approach, but just as at Tiryns the megaron-unit lies slightly off axis to the gateway, and the courtyard (3) also serves as a circulatory nexus.

The secondary megaron-units or hearth rooms at Pylos and Tiryns are more isolated from the entrance to the palaces, and in both cases the approach much more obscure. At Tiryns, while the visitor is directed towards the main megaron-unit through the monumental gateways, a small side corridor (36) leads towards the secondary megaron-unit. This forms its own, isolated matrix in the building, which could be divided into a series of smaller sub-matrices. Unlike the approach to the main megaron-unit, which is straightforward and guided through the gateways, the path towards this secondary megaron-unit is not obvious in the plan. From the corridor (36), a visitor would then have to pass through two areas serving as circulatory nexuses ( $30 \& 16)$ to reach the megaron-unit (Fig. 11). Alternatively, to reach this secondary megaron-unit from the main megaron-unit or central courtyard (4), a visitor would need to pass through a series of small, winding corridors around the back of the megaron-unit. At Pylos, the access to the secondary hearth room (46) is less complicated, but still unobvious. The hearth room is located as at Pylos in its own isolated matrix along with several surrounding rooms. From the main courtyard (3), a visitor would need to pass through the corridor 45 to access the hearth room. The door into this corridor is located in the far eastern corner of the courtyard and would be entirely hidden from view on entry to the courtyard through the gateway (1-2). The doorway is likewise no larger than any of the other doorways leading on from the courtyard (barring the doorway into the main megaron-unit), giving no indication that anything of any significance lies behind it. ${ }^{65}$ The door to the hearth room is located once more on a bent axis, lending even more privacy to the space.

Finally, the approach to both megaron-units at Gla is remarkably simple. The two suites are accessible through passageway circulatory nexus spaces at either end of the residence building, which in turn were accessible from the two entrances to the building. In both cases, from the passageway, the entrance to the megaron-unit itself was bent axis. Both of these aspects are

\footnotetext{
${ }^{65}$ The doorways to 54 and 45 were roughly even in size at 1.05m (Blegen \& Rawson 1966:195), while the doorway to 11 was slightly smaller at approximately $0.90 \mathrm{~m}$ (Blegen \& Rawson 1966:106). Blegen and Rawson gave no width for the doorway to $35 / 37$, but the central threshold block was a similar size at $0.96 \mathrm{~m}$ (Blegen \& Rawson 1966:190).
} 
remarkable in that they are different from most other megaron-units. The vast majority of other suites do not feature a bent axis approach to the same extent as at Gla, and all others have access to the porch or vestibule directly from the exterior, rather than through passageway spaces.

Unlike the MHS, the Mycenaean megaron-units seem to be fairly similar in their approach from the exterior. In general, these suites were one of the most dominant features of the buildings they were found in, and were easily accessible from the exterior. These are the part of the building that the visitor was directed towards, often due to their imposing and impressive entrances. It is therefore notable that the secondary megaron-unit at Tiryns and the hearth room at Pylos should be concealed down such obscure routes. Unlike other suites, to reach these suites it would be necessary for a visitor to know the route to find the way. Some degree of privacy is given by the impressive gates at the palaces and the use of interior courtyards and bent axis approach at some Corridor Buildings, but in general the approach to megaron-units seems to be more public and obvious.

\subsection{Connections}

As the Space Syntax Analysis of the selected Mycenaean buildings was not as affected by pier and door partitions or columns as in the Minoan examples, observations of the connections between the Mycenaean megaron-units and the surrounding buildings are very similar to those already discussed in Space Syntax Analysis. In general, as has already been noted, while megaron-units seem to be well integrated into the surrounding spaces, they are not integral to the building. Unlike many MHS, most do not provide access to other parts of the building aside from the megaron-unit and therefore can be bypassed. However, there are a few notable exceptions to this rule.

The first exception is the isolated megaron-unit. Unlike most of the other Mycenaean buildings studied, it does provide the only, essential access to the back room, which is not included in most megaron-units. This is the only connection that the suite has to any other space outside of the megaron-unit, and the circulation within the building is direct room to room circulation.

Observations of the Corridor Buildings based on their connections in Clinton's typology are very similar to those made based on space syntax analysis. The buildings can be divided into the same three groups. At Phylakopi and at the West House and House of the Sphinxes at Mycenae, the megaron-unit forms its own matrix, with only a room to room communication. In the other four buildings, the vestibule of the megaron-unit forms a circulatory nexus, with doorways leading onwards into the megaron-unit and into the flanking corridor, and back towards the exterior. As has already been seen, the main feature dividing this group of buildings is the presence or lack of a 
second door into the corridor from the exterior. In the case of House He at Gournia and Megaron B at Dimini, the remainder of the building is only accessible through the vestibule, requiring visitors to instead pass through two sets of doorways, into and out of the vestibule, to reach the corridor. Unlike the other Corridor Buildings, therefore, these two buildings provide essential access to the entire building.

In the palaces, the connections the megaron-unit has to other spaces is very similar. At both Tiryns and Pylos, the vestibule serves at a circulatory nexus, at Pylos with two access routes to other parts of the building, at Tiryns with only one. In both cases, as already observed, the main hall is a dead-end space. The megaron-unit itself could be seen as a separate matrix, with only a few doors to connect it to the rest of the building. The secondary megaron-unit at Tiryns is similar, with the porch/vestibule 17 acting as a circulatory nexus and the main hall/hearth room 18 as a dead-end, but at Pylos room 46 serves as a circulatory nexus with entrances to corridors 45 and 48 as well as an exit to courtyard 47. Interestingly, this courtyard space which was walled in the later period of the palace is the only space in the two palaces which could only be entered through the megaron-unit or hearth room. The other three spaces provide no essential access to any spaces and could easily by bypassed.

At Gla, while the smaller suite $23-24$ is connected to the passageway spaces 01 and T through room to room circulation, both space 1 and 2 of the larger suite are circulatory nexuses. Like at the palaces, neither space provides the only access route to any spaces outside of the main hall system. However, space 1, which could be seen as the equivalent to the 'porch' of the larger suite serves as one of the two entrances to the building. On entering space 1, visitors wishing to enter the hall system could move straight ahead from the entrance to make their way into space 2 when invited, while visitors with other business would need to move to the left into another passageway space to access the rest of the building.

Though some hall systems do contribute to the circulation of the surrounding building, in general it is clear that the megaron-unit is far more separate from the building than many MHS. Though the surrounding rooms are often accessible through a side door in the vestibule, it is in general not necessary to pass through the megaron-unit to access many spaces, if any at all. The megaron-unit is therefore more likely a destination or activity area, rather than an area that would be used as a transitory space. Though it would be possible in halls such as at Pylos to pass through the vestibule as a short cut between other spaces, it is likely that these doors were used to make the megaronunit quickly accessible to as much of the building as possible, rather than to join the smaller rooms on either side of the suite. 


\subsection{Conclusions}

Although the megaron-unit's form itself is less consistent than that of the MHS, in its connections to the building it is found in, the megaron-unit is far more consistent. Though all have exceptions, a number of common features may be observed in the Mycenaean buildings studied. Firstly, almost all the megaron-units were accessible from an unroofed, external space. For some this was the exterior of the building, whether a built courtyard or not, but for others this was a courtyard inside the building. The only exception to this rule is the two suites at Gla, which while not open to the air were located next to the two entrances to the building. It should not be surprising that these suites were also generally easily accessible from the exterior of the building. For the most part, it is towards the megaron-unit that visitors are directed through the use of larger doors and monumental gateways. However, this is not the case with the secondary suites at Pylos and Tiryns. Both of these suites are much more isolated from the public and are concealed down several corridors, with no signs obvious in the spatial structure that an important space was located there.

Secondly, the main hall of the megaron-unit is almost always a type ' $a$ ', dead-end space, making it a destination space, not a transitory space. It could only host circulation to and from itself, meaning it was far more likely to host activities than the other spaces of the suite. Although this is the case for the two palatial megaron-units, the secondary suite at Tiryns and all the Corridor Buildings, it is not the case for the isolated megaron-units. The two isolated megaron-units studied both feature back rooms, which can only be reached through the main hall of the megaron-unit. It should be noted that not all isolated megaron-units feature back rooms, but many did, making them different in form to the megaron-units of the palaces and Corridor Buildings ${ }^{66}$ Furthermore, it should be noted that the secondary megaron-unit at Gla (22-24) and the secondary hearth room at Pylos were type $\mathrm{c}$ spaces, rather than dead-end type a spaces as in the other examples. The hearth room at Pylos also served as a circulatory nexus.

Finally, it is interesting to note that for the most part, the megaron-unit was not essential to circulation in the remainder of the building. As one of the most integrated spaces in the building, the vestibule at Pylos, for example, had the potential to be a hub of movement, but if it was cut off entirely, only the megaron-unit would become inaccessible. It is entirely possible, therefore, that the vestibule was intended not as a hub of movement or a short cut to many spaces, but was instead intended to be easily accessible from as much of the palace as possible. As has already been noted, for the majority of buildings studied, the megaron-unit could be entirely avoided if necessary. While

\footnotetext{
${ }^{66}$ Note that the walls of the back room of House $L$ at Korakou are in fact not well enough preserved to be certain there was no other entrance, so this analysis is based on a tentative reconstruction of the building.
} 
it may have been well integrated into the building and easily accessible from many spaces, it was not integral to the circulation of the overall building. Should the megaron-unit be closed off (for an official ceremony, for example), activity in the rest of the building would be able to continue as usual, albeit with a slightly longer commute around the megaron-unit. As such, the megaron-unit and the vestibule in particular may not have served as a circulatory nexus in practise. It may have instead have been used by servants or officials to bring goods or equipment from different parts of the building into the megaron-unit without needing to go out into the courtyard. As already noted, the exceptions to this are Megaron B at Dimini and House He at Gournia. The vestibule of the megaron-unit at each of these two sites provides the only access to the flanking corridor and the rooms lead off it, making it an integral part of the circulation of the overall building, in contrast to the isolation of many other megaron-units.

Though the Mycenaean buildings featuring megaron-units are less variable than MHS, there is still a degree of variability. Because of their distance from the entrances, the secondary hall at Tiryns and hearth room at Pylos would have been used in different ways to the main megaron-units at each site. As they provide the only access to the flanking corridor and secondary spaces, the porch at Gournia He and the vestibule of Megaron B at Dimini would have functioned to some extent as a passageway. Similarly, the main hall of the two isolated megaron-units would have been used to access the back rooms of each building. Though these buildings may have all functioned in similar ways, it is also likely there was some variation in their functions.

\subsection{Comparison and Conclusions}

Though the MHS and Mycenaean megaron-unit both comprise three spaces including a vestibule and main hall, aligned axially, the role of each of these spaces in the surrounding buildings differs. In the Mycenaean megaron-unit, the porch is the first cell of the system reachable from the exterior, and the porch has just one door leading in towards the main hall. The vestibule, by contrast, often has more than one door, leading on to the main hall as well as one or more side doors leading to the rooms flanking the megaron-unit. Finally, the main hall is almost always a dead-end or type ' $a$ ' space, with only one doorway leading in from the vestibule. In contrast, the main hall of the MHS is never a type 'a' space, and instead of being reachable only from within the MHS, as in the megaronunit, it is often the first space reachable from the exterior. ${ }^{67}$ Instead, it is the light well that is

\footnotetext{
${ }^{67}$ The Main hall was the first cell reachable from the exterior in 13 of the 27 MHS studied by Letesson, and was tied with the vestibule as the first cell reachable in a further 3.
} 
generally the dead-end or type ' $a$ ' space. ${ }^{68}$ Furthermore, unlike the generally highly integrated vestibules found in megaron-units, around a third of the Minoan vestibules do not have any connections outside of the MHS (Table 6). ${ }^{69}$ Finally, while in general the megaron-unit is entered through a main entrance located on its shorter side, on axis with the suite, the MHS was more often entered from the longer side, off axis. ${ }^{70}$

In terms of their approach, the megaron-unit is located very close to the exterior or to an exterior space, and is easily located through a monumental porch. In this they are most similar to MHS such as those at Nirou Hani or Chania, and at the palaces to the MHS at Zakros and Phaistos 63-64, all of which are located very close to the main entrance to the building or to the central court. In contrast, the isolated suites such as Tylissos House C, Malia Z $\alpha$ and at the palaces those at Malia and Phaistos 77-79 are hidden far from the main entrance to the building along obscured routes. These more isolated MHS bear more of a resemblance to the secondary megaron-unit at Tiryns and the secondary hearth room at Pylos. Both are located much further from the main entrance to the building, and visitors are not directed there through the architecture. Outside the palaces this does not appear to be the norm in Mycenaean buildings, as most megaron-units are accessible externally.

In their connections and internal circulation, the megaron-unit is, as noted, not at all integral to the circulation of the surrounding building. While it is integrated into the building and it is relatively simple to access most of the building from the megaron-unit, it is rare that the megaron-unit is used to provide essential access to any spaces. It can instead be avoided entirely, cut off from the surrounding building where necessary. However, there are very few MHS that are similar. As already stated, around half the MHS provide the only access to one or more space outside of the suite. The megaron-unit is therefore closer in its connections to more isolated MHS such as those at Malia $\Delta \alpha$ and the South House at Knossos, which are not important to the circulation in the building. Suites such as those at Tylissos House A and Mochlos B.2, and those at the palaces of Phaistos and Malia are in stark contrast to this, as they are an integral part of the surrounding building and provide the only access route to many different spaces. If the suite was cut off, circulation through the majority of the building (or the matrix in the case of the palatial suites) would no longer be possible.

\footnotetext{
6812 of 21 light wells were type 'a' spaces in space syntax. It should be noted also that the light well of Tylissos House $A$ is also essentially a dead-end, though appearing as a type ' $c$ ' space in space syntax, as it is open on two sides to the MHS but does not provide access to any spaces outside of the system.

698 of the 26 vestibules have no connections to spaces outside of the MHS.

${ }^{70} 20$ out of 27 MHS were accessed through their longer side, while 12 of the 14 Mycenaean suites studied were entered through their shorter side.
} 
In their spatial structure, therefore, it seems that while megaron-units are similar to some MHS in different aspects, the two different kinds of suite relate to the surrounding building in different ways, making it likely that many of these halls may have also functioned differently. Furthermore, the differences in spatial structure between different MHS and to a lesser extent between the different megaron-units suggests that these also may have had different purposes at different sites.

As already stated, the ability to completely cut off the palatial megaron-units from the rest of the building makes it possible to conduct official ceremonies or rituals in the suite undisturbed. When official business was underway, individuals working in the rest of the building could continue their business uninterrupted, and when necessary, servants or officials could easily bring items from any part of the building into the megaron-unit unobtrusively through the side doors of the megaron-unit in the vestibule. This is also true, though to a lesser extent, of many of the megaron-units found in the Corridor Buildings.

There are no MHS that offer quite this much flexibility. Though they are also unimportant to the circulation of the overall building, isolated suites such as those at Malia $\Delta \alpha$ and the South House at Knossos provide essentially only one entrance. Guests, residents and servants would be required to enter and exit the suite side by side. On the other hand, more integral MHS such as at Mochlos or Tylissos House A provide access the only access to many different spaces that would be isolated if the MHS was inaccessible. Should the MHS at Mochlos be shut off for a special event, for example, there would be no way for individuals in other parts of the house to exit. Even at slightly more isolated halls such as those at Chania or Malia Za 5-7, isolating the MHS would cut off access to several small spaces, requiring that they were not in use during any such events. These spaces could remain operational as storage spaces or as spaces related to the ceremony or event. Should the MHS be intended for the same purpose as the Mycenaean megaron-unit, it seems that it was the megaron-unit that may have been more suited to the occasion.

As has already been briefly discussed, many scholars have argued in the past that the MHS is an ideal system for the meeting of residents and guests, with one entrance directly from the main entrance of the building and another leading towards more private rooms. ${ }^{71}$ Setting aside for a moment the possible issues with this theory, in those instances that the MHS was located near the entrance of the building, it is entirely possible that these suites were used as an area for the welcoming or reception of guests. In buildings such as Mochlos, which have only one entrance, this would mean that while these events were taking place it would not be possible to exit the building, and when not in use for this purpose, such a hall would likely become a hub of circulation and

\footnotetext{
${ }^{71}$ E.g. Palyvou 1997. See Section 2.7.
} 
movement, but these halls would still be ideally located to welcome guests before they were permitted further into the building. A ceremony such as this could have taken place at halls such as Mochlos, Chania, Malia Z $\beta$ and Akhladia with their small foyers, but also at the MHS at Nirou Hani, forming a grand entrance to the building, and in the MHS at Vathypetro, before access to the tripartite shrine was permitted. Furthermore, with their monumental entrances and the way visitors are guided towards them, a similar ceremony may have taken place in the Mycenaean megaron-unit also. Though the suites are structurally very different, it is therefore possible that some were used in similar ways. 


\section{Chapter 3: Climate and Climate Manipulation in Hall Systems}

\subsection{Introduction: Climate in the Bronze Age Aegean}

In his report of the excavations at Tylissos in 1934, Josef Hazzidakis proposed that the fact that a hearth was found in the megaron-units of mainland Greece but excluded from the MHS "s'explique aisément par la douceur du climat". ${ }^{72}$ The two types of hall system are found geographically quite close to one another, in areas with a reasonably similar climate. If they did differ based on climate, this would be in the ways in which each culture chose to deal with the most extreme weather they experienced: the summer heat in Crete, and the winter chill on the mainland. This assumption which associates the hearth with the Mycenaeans and their colder climate is found frequently in scholarship. ${ }^{73}$ Likewise, it is often assumed that pier and door partitions were developed by the Minoans at least in part to control the warmer climate in Crete. ${ }^{74}$ However, while hearths are found in Mycenaean contexts more often than Minoan, the Minoans did also use fixed hearths. Furthermore, pier and door partitions were also used on the mainland, at Tiryns and Gla. Like the Minoans, the Mycenaeans also incorporated open-air spaces into their buildings. There may have been more to these differences than a simple difference in temperatures, particularly as the climate in the Bronze Age was likely not the same as it is today.

Therefore, to determine whether the MHS and Mycenaean megaron-unit differed based on climate, the issue will be examined from two different angles. Firstly, whether or not the buildings in question were well adapted to the climate in question will be discussed. While they were suitable for one season, some of these climate control features may have made the hall uninhabitable in other parts of the year. Secondly, whether or not they were designed in the most effective manner to manipulate and manage this climate will be discussed.

To begin with, it is important to note that the climate in the Bronze Age would not have been the same as it is today. In a comprehensive study of the ancient climate, Moody (2005) determined that the Bronze Age was likely a period of fairly unstable climate conditions in the Aegean. Not only would the climate have been different to today, different periods would also have had different weather patterns.

The MHS were all built in the Neopalatial period in Greece, between $1700-1460 B C .^{75}$ The earliest were built in the MMIIIA period, while the last were built in the LMIA-LMIB periods. The earlier halls

\footnotetext{
72 Hazzidakis 1934:17.

73 Maeir and Hitchcock 2011:53.

${ }^{74}$ E.g. Graham 1962:96-7.

75 See Letesson 2009:303; 336-337.
} 
would have been built before the Theran eruption, and Moody (2005:471) states that at this time the climate would have been reasonably similar to the present. "Winters should have been as warm or warmer than the present, but cooling. Summers were cooler than the modern, but warming." ${ }^{176}$ On the other hand, during the latter part of the period, after the Theran eruption, there was "a period of especially cool winters and increased moisture". ${ }^{77}$

The Mycenaean palaces, on the other hand, were built later, and are generally dated to around LHIIIA-B. ${ }^{78}$ This period was one of dramatic changes in climate in the Bronze Age. While the period started during the cold weather mentioned above, from around 1300-1200BC a contrasting period of hot and dry weather would have seen temperatures increase and would likely have "exceeded those of the modern Aegean". ${ }^{79}$

Modern temperature data from Heraklion suggests that temperatures average up to 26.1 degrees in the summer and cool to an average of 12.1 degrees over the winter. ${ }^{80}$ While ventilation would have certainly been desirable in the summer, in the winter even if the MMIIIA winter temperatures were somewhat warmer than this, the temperature in the MHS would have likely been unpleasant without some way to warm it. During the cold winters after the Theran eruption, the MHS would have likely been even more unpleasant, and a fully enclosed room with central hearth would likely have been far more practical.

On the Peloponnese, by contrast, temperatures are slightly cooler. Over the summer, the average hovers around 24.5 degrees, while over the winter it drops to 5.1 degrees. ${ }^{81}$ Clearly during the period of colder winters following the Theran eruption heat from a hearth would have been very welcome, but during the summer, particularly after $1300 \mathrm{BC}$ when temperatures would likely have exceeded modern temperatures, this heat would have certainly been unwanted and unnecessary, rendering the megaron-unit a stifling environment.

It is interesting to note that the two different types of hall are constructed in a way that takes advantage of the most effective way to combat the humidity levels that would have been most prevalent around the time of their construction. While ventilation is most effective for moist, humid

\footnotetext{
${ }^{76}$ Moody 2005:471.

77 Moody 2005:471.

${ }^{78}$ E.g. Darcque 2005:38; Shelton 2010:143-4

${ }^{79}$ Moody 2005:471.

${ }^{80}$ Averages from 1957-1997 taken from the Hellenic National Meteorological Service at http://www.hnms.gr/hnms/english/climatology/climatology_region_diagrams_html?dr_city=Tripoli

${ }^{81}$ Averages in Tripoli between 1957-1997 from the Hellenic National Meteorological Service at http://www.hnms.gr/hnms/english/climatology/climatology_region_diagrams_html?dr_city=Heraklion
} 
climates, in dry, arid environments insulation is more effective. ${ }^{82}$ During the Neopalatial Period on Crete, it is likely that the climate was far more humid than it is today, making ventilation, such as that seen in the MHS, the most effective method of combatting the heat. ${ }^{83}$ On the other hand, conditions when the Mycenaean palaces were built would have likely been far more dry and arid, which is reflected in the way Mycenaean buildings were built, with fewer doors and windows for cross ventilation. ${ }^{84}$

While these two hall systems may have been effective during part of the year, it is likely that for at least part of the year the weather would have rendered the spaces unpleasant if not uninhabitable. While the MHS would have been effective and pleasant in the summer months, it would have been much less so in the colder winters, and the hearth of the Mycenaean megaron-unit would have provided unwanted heat in the summer. Furthermore, temperatures particularly over the summer likely were similar between the two locations. A closer investigation of these features which control the climate is needed to determine whether or not these buildings likely differed primarily based on climate. The remainder of this chapter will examine three different climatecontrolling features of the two different hall systems, open-air spaces, pier and door partitions and hearths, firstly in order to determine whether or not they were the most effective means of manipulating the climate in question. In each case similar features from each culture will also be compared to evaluate the similarities and differences between their forms and possible functions, both for climate control and otherwise.

\subsection{Open-Air Spaces}

As has already been seen in Chapter 2, both the MHS and Mycenaean Megaron-unit usually incorporate open-air spaces. In the case of the MHS, most suites include a light well of some description, with some opening onto open spaces outside of the building. On the other hand, only two of the suites studied in Mycenaean buildings did not include a porch open to an exterior space, and instead these were located near the entrances to the building. However, these open-air spaces vary considerably along with their possible functions.

On the one hand, the light wells found in the MHS are generally regarded as being used to provide light and air for the remainder of the hall, and from there potentially to the rest of the

\footnotetext{
${ }^{82}$ Moody 2009. See Table 2.3 (pg. 7).

${ }^{83}$ Moody 2005:470-471.

${ }^{84}$ Moody 2005:471.
} 
building. ${ }^{85}$ Using the polythyron, doors can be open or shut to provide the perfect climate for the individuals using the room. However, for several different reasons it should be noted that many of these so called 'light-wells' may have played more of a role than simply providing light and air.

Firstly, of the 35 MHS with an enclosed light well, 9 systems were also attached to another exterior space (Table 8). These were generally found in the palaces or in large palatial buildings. ${ }^{86}$ In these buildings, a canonical 'light well' was included in the interior of the building, and another part of the MHS (often the main hall) opened, sometimes through a polythyron, onto a courtyard or other exterior area. Whether the purpose of this other external area was to provide easy access, a view or otherwise, this larger open area would have provided significantly more light and air than the small light wells, which may have been several stories deep into the building and therefore distant from the open-air. To include both an exterior open space and an interior 'light well' seems entirely unnecessary, it may have therefore been another need that the interior light well was intended to fill.

Furthermore, of the 45 MHS studied, only four were not adjacent to the exterior at least in part (Table 8). If the only need was to provide light and air, it would therefore have been possible to build windows instead of a light well, which may have been easier to build and would have taken up less space. In these cases therefore it seems that it was not simply an opening for air and light that was needed, but rather an interior space which was open to the air.

Finally, 16 light wells were entirely isolated, with no doors or windows into any space other than the remainder of the MHS (Table 8). Instead of being placed centrally, where the light and air could be distributed to the largest area possible, this supply of light and air is a private one, intended for the users of the MHS only. While these 'light wells' would have provided light and air to the rest of the MHS, they were clearly not designed for maximum impact.

Because of the isolated nature of so many 'light wells' in MHS, Clairy Palyvou (2004:212) suggested that rather than being included simply as a way to introduce light and air to the building, these light wells should instead be seen as private open-air spaces. Palyvou uses Chermayeff and Alexander's hierarchy of privacy to compare different kinds of open-air spaces in Minoan Architecture, and as these 'light wells' are isolated at the end of MHS, she proposed that they should be considered 'Individual Private' spaces, the most private type of space, intended as a private space for the individual to withdraw. ${ }^{87}$ Chermayeff and Alexander's hierarchy of privacy consists of six

\footnotetext{
${ }^{85}$ E.g. Evans 1930:286; Graham 1962:96-7.

${ }^{86}$ Lloyd 1999:53-4.

${ }^{87}$ Chermayeff and Alexander 1963:121-2; also see Palyvou 2004:207.
} 
different levels of privacy: Urban Public, Urban Semi-Public, Group Public, Group Private, Family Private and Individual Private, with Urban Public as the most public and Individual Private as the most private. It was developed to be applied to modern Western architecture, and is only a rough guideline. Concepts of privacy and of ownership in the ancient world are extremely difficult to determine with any certainty and require much deeper discussion and analysis than can be accommodated here, however the hierarchy of privacy is a useful tool to compare accessibility of open-air spaces in MHS and megaron-units. ${ }^{88}$

Once again, while this may be true for many light wells in MHS, it is certainly not true for others. To begin with, many MHS were simply too public to be considered private spaces. In many buildings, such as those at Malia Z $\beta$ and Chania, the MHS is located near an entrance to the building. Although the light well itself may not be an important part of the circulation network within the building, as it is separated from a main circulation hub only by a series of columns it is certainly not an isolated space. At other halls such as at Gournia, the light well itself is an important circulatory nexus, providing access to several different spaces. These spaces would be considered 'Family Private' spaces, as they were only accessible to those invited into the building, but would have been readily accessible and visible to visitors to the building or matrix within the building.

Several light wells also may have had windows, either interior or exterior. Those at Tylissos House A and C, and Hagia Triada all had windows opening onto other interior spaces, meaning any activity taking place within the light well was not entirely private and could have had spectators in these adjoining spaces. In the MHS in the South House and House of the Frescoes at Knossos on the other hand, the light wells had windows opening onto the exterior, which would limit the privacy in the suite even more. As Lloyd (1999:69) points out, windows are common in both palatial and nonpalatial buildings, "suggesting that privacy was not a great concern or that the window openings could be closed off".

It must also be noted that some MHS lack a canonical light well and instead open directly on the exterior of the building. At Vathypetro this may still be a fairly isolated space, as the MHS opens onto a tripartite shrine, but at the other sites, this space is a public one. At Nirou Hani as well as three more fragmentary buildings at Pyrgos Myrtos, Amnissos and Archanes, the MHS was open to the exterior and may have been used as a main entrance to the building. While many of these systems are very fragmentary, the system at Nirou Hani opens onto an open court stretching across the front of the villa, and at Pyrgos Myrtos (Plan 41) the system opens onto a courtyard attached at one side to the main street of the settlement. In both cases, these are extremely public and likely

\footnotetext{
${ }^{88}$ See for example Clinton 2013 for a detailed discussion of privacy in Minoan architecture.
} 
easily accessible spaces. They would likely correspond to Urban Public spaces, the most public of all, which is in stark contrast to the isolated Individual Private light wells attached to other MHS. The small 'vestibules' at Pyrgos Myrtos and Nirou Hani with their two columns in antis resemble both the grand entrance to the Palace at Phaistos, and the porches of the Mycenaean Megaron-units far more than the more isolated MHS (Fig. 13). ${ }^{89}$

Finally, though by no means certain, it is possible that the MHS located on the edge of buildings may have been even less private than generally assumed. Based on the house model from Archanes, Lloyd (1999) suggested that MHS which were located on the edge of the building may only have had half walls, allowing a view of the exterior and a chance for even more air to flow through the MHS (Fig. 14). While this would decrease the privacy of the system significantly, she notes that the polythyron ensures that those occupying the MHS could still have as much privacy as required..$^{90}$ It should also be noted here that though this lower wall provides less privacy than a full wall, it remains marginally more private than a completely exterior space. The space would still only be accessible from inside the building, and therefore would be controlled by the occupants of the building, making it different from an entirely exterior space such as the court at Pyrgos Myrtos. Of the 21 canonical MHS which included a full light well, 13 had light wells located at the edge of the building, which could therefore have included a partial wall. ${ }^{91}$ The MHS in room 12 of Malia Z $\alpha$ could also have had a half wall. While the original excavators tentatively proposed an entrance to the building in this room, they also found the remains of a wall along the proposed entryway, the height of which could not be determined. ${ }^{92}$ While it may have been a full wall, it could also have been a half wall. While this theory is difficult to prove with any degree of certainty, due to the lack of preserved walls, it remains a possibility to be considered.

Whether or not some light wells in MHS featured lower walls, the open-air spaces incorporated in the suites clearly differ in their range of privacy. Suites in buildings such as Malia Z $\alpha$ and the South House at Knossos which are isolated at the end of the MHS with no connection of their own to the rest of the building are Individual Private spaces, far more private in terms of resident to resident or resident to visitor interactions than the Family Private halls in buildings such as at Chania or Malia $Z \beta$, where the MHS is located at the entrance and would have been accessible to visitors upon entry to the building. These interior open-air spaces are then still more private than the Urban Public exterior open-air spaces that MHS such as those at Nirou Hani and Pyrgos Myrtos opened onto,

\footnotetext{
89 The similarity between Nirou Hani and Phaistos was noted by Hitchcock 1994:22.

90 Lloyd 1999:68-9.

91 Lloyd 1999:73.

92 Demargne and Gallet de Santerre 1953:74; see also Letesson 2009:132.
} 
which likely would not have been controlled by the residents of the building in question but instead would have been open to the public at any time.

Furthermore, it should be clear that while a light well may have aided in bringing light and air to a space, climate cannot have been the only motivation for its inclusion. If bringing light and air into the building was the only concern, interior light wells would have been superfluous in MHS such as the Hall of the Double Axes at Knossos, which also open onto the exterior. A light well would have also taken up more space than simple windows, which would have had a similar effect. Finally, if these light wells were built to provide as much light and air to as large an area as possible, they would not have been built at the edges of buildings, but in the centre, and would not have been isolated but instead open to as many other spaces as possible to distribute the light and air throughout the building. While climate must have been a concern, it likely was not the sole concern.

If some of these light wells were, as Palyvou suggests, built as private open-air spaces, this again reinforces the idea that not all MHS were built for the same purpose. While in the isolated MHS a ritual, ceremony or other activity involving this open-air space could have been performed in privacy, in MHS such as those at Nirou Hani this would not have been possible, and the 'light well' in this case a public court yard - would have necessarily been used in a very different way.

On the other hand, the open-air spaces incorporated into Mycenaean megaron-units differed from many of the corresponding spaces included in MHS. Firstly, the suites in the palaces (Pylos, Mycenae, and the two suites at Tiryns), as well as Megaron A at Dimini and the West House at Mycenae all opened onto well-defined closed courtyards. In most cases, access to this courtyard from the exterior was controlled, with only one or two entrances. ${ }^{93}$ However, the courtyard was by no means isolated. Though generally the largest and most obvious route leads to the megaron-unit, in most cases, this courtyard acted as a circulatory nexus, providing access to multiple spaces, generally three or more. ${ }^{94}$ In this, these courtyards are remarkably similar to the central courts of the Minoan palaces. Though far more controlled in terms of access, the Mycenaean courts, like the Minoan Central courts, connected the different matrices of the palace to one another and could therefore host important circulation patterns. ${ }^{95}$ Some of these courts, such as those at Pylos and Dimini, provided the only access to several isolated matrices, providing their only link to the rest of the building. Most of these courts also are flanked with a portico, like the Minoan Central Court. ${ }^{96}$

\footnotetext{
${ }^{93}$ Except for the court of the smaller megaron-unit at Tiryns (16), which was isolated from the exterior and therefore had 4 different access routes.

${ }^{94}$ Except for the court at Mycenae, which only opened onto the porch of the megaron-unit.

95 Palyvou 2004:172-3.

${ }^{96}$ Except for the two courts at Mycenae - at the palace and at the West House.
} 
Like the portico around the Minoan central courts, the Mycenaean porticos are also very narrow, making it likely that they were transitional spaces, functioning generally more as covered walkways rather than hosting activity. ${ }^{97}$ In each case, this stoa connects two or more doorways allowing for access between them without crossing the uncovered courtyard. It should be noted also that the porch of the megaron-unit at Pylos and Tiryns differs from these other porticos only in its depth and the large entranceway into the vestibule. It is only considered part of the megaron-unit because it contains this entrance and is located on axis with the rest of the megaron-unit; it could just as easily be considered an extension of the courtyard, similar to the other surrounding stoa spaces.

What these courts should be labelled as in terms of Chermayeff and Alexander's hierarchy of privacy depends on the perceived use of the building they appear within. The courts were not accessible to the public and therefore cannot be considered public spaces, as access was carefully controlled through one or two entrances..$^{98}$ However, neither were they particularly secluded. The court in most cases was one of the first spaces reached upon entering the building and it would then be necessary to move through this space to access the majority of the building. As stated, they provided important links to isolated matrices that could only be accessed through the court space. They are therefore spaces that would be frequented by any visitors to the building. At best, they should then be seen as at least semi-public, but under the control of the elites or individuals who owned the building. These courts are therefore potentially similar to the semi-public central courts of Minoan palaces, classified as Urban Semi-Public. However, access to the Mycenaean palaces is even more controlled than to the Minoan equivalents, so these halls also could have been at a similar level of privacy to the Family Private light wells located near the entrances to buildings such as at Chania and Malia Z $\beta$.

At Phylakopi, instead of a controlled courtyard incorporated into the building, the Megaron suite opened directly onto a large public courtyard, which was surrounded by other buildings. ${ }^{99}$ The court was located at the junction of several roads, with multiple entrances on all sides. It also contained a well to one side. Its highly accessible and centralized nature is in stark contrast to the controlled access to the 'great courts' of the palaces. It should be seen as an Urban Public space, and may have been used for public community gatherings and events. Opening from this public court, the porch of

\footnotetext{
97 Palyvou 2002:172 states that the stoas at the Minoan central courts are generally 2.2-2.5m wide. The stoa at Pylos is wider with an average depth of $3.325 \mathrm{~m}$ (to cover the double doors to rooms 54 and 45 , each $1.05 \mathrm{~m}$ wide)(Blegen and Rawson 1966:190, 195). The portico in the great court (4) at Tiryns is narrower, 1.6-1.9m wide (Schliemann 1885:204-206). I could find no information on the depth of the porticos at Megaron A in Dimini or the stoa in court 16 at Tiryns, but as each space is rather small - 9.2x18.45m at Tiryns (Schliemann 1885:327); $8 \times 8 \mathrm{~m}$ at Dimini (Adrimi-Sismani 2003:75) - it is likely that the stoa in each case was also narrow. ${ }^{98}$ Cavanagh 2001:130.

${ }^{99}$ Atkinson 1904:55-58.
} 
the megaron-unit is also conspicuously public and could have been accessed by anyone at any time. However, as Pantou (2010:84) notes, though the porch is an open space which combines roofed and open-air space, its impressive threshold marks this transition and emphasizes the transition between public and more private space. Though the court is a community space, the Corridor Building itself is conspicuous, monumental, and potentially controlled by elites.

Finally, the remaining megaron-units studied opened onto an undefined, unbuilt open space. In some cases, these buildings are at the edge of the excavated space, or the surrounding space is too fragmentary and eroded for any certainty, so it is entirely possible in some cases that some kind of walls did enclose these spaces, but from the available evidence these buildings seem considerably more accessible than the previous examples. The difference between these buildings and the palaces in particular is stark. While to access the megaron-unit at Tiryns, for example, it would be necessary to first gain entry through four separate gateways, on approaching these buildings it would be immediately possible to enter the porch. At Menelaion the megaron-unit itself was accessed through a $2.8 \mathrm{~m}$ doorway, and the flanking corridor which provided access to the smaller spaces was immediately accessible from the exterior also. ${ }^{100}$ In House He at Gournia and Megaron B at Dimini, as already seen, this corridor was more private, accessible only through the porch or vestibule itself, but in both cases the area immediately preceding the building appears unrestricted. This was by no means a private open-air space and again should be seen as Urban-Public, accessible at any time to any individual.

The open, unrestricted courts that these megaron-units open onto correspond to some degree to the open courtyards found at sites such as Nirou Hani and Pyrgos Myrtos, all of which feature an unrestricted Urban Public nature. Many also are entered through a porch or roofed area that would possibly have been accessible to the public at any time. In contrast, the 'Great Courts' at the Mycenaean palaces and the courts found in Megaron A at Dimini and the West House at Knossos with their more restricted access correspond to the semi-public Minoan Central Courts, and the megaron-units attached to these courts are similar to MHS such as Phaistos 63-64 and the two halls at Zakros which open from the courts. They are also remarkably similar to MHS such as those at Chania, Mochlos and Malia $Z \beta$, where the hall is located at the entrance to the building and provides access to much of the remainder of the building. On the other hand, there seems to be no parallel in Mycenaean 'megaron' suites for the isolated, private light wells with an Individual Private nature.

In terms of climate, the light and air provided by these courtyards would not have been distributed into the megaron-unit as well as in the MHS. Even at Tiryns, which boasts a pier and

${ }^{100}$ Catling et al. 2009:24. 
door partition system very similar to those found in the MHS, a further door separates the main hall itself from the exterior. With an entire extra roofed space in the megaron-units, far less light and air would have reached the main hall itself. Many of the thresholds in the Corridor Buildings have not been well preserved, so their width is difficult to determine, but the doors leading into the palatial megaron-units were generally large. At Tiryns, the door into the main hall measured $2 \mathrm{~m}$, but as the hall was around $9.75-9.86 \mathrm{~m}$ wide, the door would have only taken up around $20 \%$ of the wall. ${ }^{101}$ The doors between the porch and vestibule, and vestibule and main hall at Pylos were larger at $3.48 \mathrm{~m}$ wide, and took up around $30 \%$ of the wall. ${ }^{102}$ The door between the porch and vestibule at Mycenae was $1.8 \mathrm{~m}$ wide, and while the width of the suite can only be approximately determined this was likely only around $15 \%$ of the wall. ${ }^{103}$ Therefore, while these courts would have provided some air and light into the surrounding spaces, this would have been far more limited than in Crete. Even where the door to the main hall may have had no physical door to close (at Tiryns and Mycenae) the system would have still been easily isolated from the weather by closing the door(s) from the porch. ${ }^{104}$ At Tiryns and Pylos, where these 'Great Courts' opened onto other spaces, these doorways were generally small and tucked away under sheltered porticos or small foyer-like spaces. ${ }^{105}$ Windows to provide extra light and air were rare. It therefore seems likely that these courts were not designed to bring in the maximum amount of light and air into the surrounding rooms.

Both the MHS and the Mycenaean megaron-unit included exterior spaces in their plans, but while light and air may have been a consideration in both cases, the architecture suggests other motivations. Mycenaean 'Great Courts' were not designed for leading light and air into the building, while many light wells of MHS were isolated, ensuring that only the rest of the MHS would have gained light and air. Furthermore, other methods for ventilation and lighting could have been - and indeed were - used by the Minoans. While open-air spaces by definition let in light and air, this does not seem to be the only motivation in their inclusion into both Minoan and Mycenaean buildings.

\subsection{Pier and Door Partitions}

Pier and door partitions, also known as polythyra, are one of the diagnostic features of the MHS. They were used heavily in Minoan architecture but were also found in Akrotiri in Thera, and in two Mycenaean sites on the mainland. Pier and door partitions are a system of multiple double

\footnotetext{
101 Schliemann 1885:216.

102 Blegen and Rawson 1966:71, 76-77.

103 Wace 1949:76-77.

104 Schliemann 1885:216; Wace 1949:77.

105 Such as spaces 11 and 44 at Pylos.
} 
doorways which extend across a given room, replacing a wall. Between each set of double doors, a small pier wall was placed, with a niche for the door to be folded into when not in use (Fig. 4). The pier and door partition has been much discussed in Minoan scholarship, so this discussion should serve only to briefly summarize these previous arguments and discuss how it pertains to the question at hand.

As has been often noted, the salient feature of the pier and door partition is its flexibility. Essentially, as pointed out by Palyvou, the pier and door partition can function in three different ways: as a doorway, as a wall or as a void (Fig. 5). ${ }^{106}$ When all doors are closed, the feature becomes a wall. When only one or two doors are opened, it is a doorway, still attached to a wall. When all doors are opened, the wall disappears and the feature becomes instead a void, joining the two adjacent spaces. This flexibility gives the room's occupiers the ultimate flexibility both in terms of permitting or blocking access but also in controlling the climate. The room can be opened up to allow in all visitors and be used as one larger space, or closed off entirely. When attached to an open-air area, doors can be opened or closed to allow in light and air or block unsavoury weather. While only one polythyron wall is required for a space to be considered a MHS, in some suites two or three walls of the main hall or vestibule are replaced with pier and door partitions.

However, for a few reasons it is unlikely that the pier and door partition system was developed solely to be flexible in terms of climate. Firstly, as discussed in the consideration of the light well or open-air space, there would have been much more simple and economical ways to add climate control into a space. Windows could have been built and blocked in adverse weather, or one door could have sufficed. More importantly, pier and door partitions have been found without any openair space adjacent, such as in Xeste 3 on Thera. ${ }^{107}$ They must therefore have had another purpose.

In their 1986 study, Nanno Marinatos and Robin Hägg pointed out that pier and door partitions were often found in relation to other ritual spaces, frequently the lustral basin or adyton. From their analysis of the possible circulation patterns around these spaces, they postulated that the pier and door partition hall was often used as an area of transit before admittance to the shrine proper, rather than as a destination in its own right. The pier and door partitions themselves would have been passed through on the way into the ritual space.

While this theory has its merits, there are several different points to take into consideration. Firstly, as Marinatos and Hägg noted, some halls could not have functioned as transitory spaces. ${ }^{108}$

\footnotetext{
106 Palyvou 1997:198.

107 Marinatos and Hägg 1986:58.

108 Marinatos and Hägg 1986:65-8.
} 
As has already been noted, some MHS such as those at Malia $\Delta \alpha$ and $Z \alpha(12)$ are entered and exited through the same door, making it impossible for them to be used as a passage or transitory space before the main shrine. These halls may have been used for related ceremonies, but the purpose of their pier and door partitions was not as an entranceway to a ritual space.

Secondly, though many pier and door partitions are found near areas of ritual significance, this is certainly not the case in all instances. At the palace of Phaistos, similar double doors separated by a pillar opened onto the storage magazines (Fig. 15), and though some ceremony or ritual may have been involved in the use of this area, it seems likely that these doors would have been entered and exited for more domestic or every day purposes as well. At Hagia Triada, Hitchcock (1994:33) recognized a secondary MHS of sorts incorporating rooms $16,46 \& 47$. This area of the building was not associated with ritual but instead more mundane activities, and Hitchcock proposed that this hall "was used for storage activities, to facilitate access, and may have been associated with food preparation through its relationship with room 45 to the south." ${ }^{109}$ In these cases, it is likely the pier and door partitions were included for ease of access more than for a ritual purpose.

Finally, it is possible that in many Minoan buildings the lustral basin was filled in before the pier and door partitions were added. Though it is often difficult to be certain about the exact dates, in many cases lustral basins may have been filled in during LMIA, at which time many MHS were being built. ${ }^{110}$ If this is indeed the case and the lustral basins went out of use before pier and door partitions were added, then any ceremonies involving the lustral basin would clearly not have involved the pier and door partitions.

However, it is still entirely possible that pier and door partitions were created for some kind of ritual, ceremonial or monumental purpose. Marinatos and Hägg also pointed out that the incorporation of an open-air space into the MHS would make it possible to use the pier and door partitions for a dramatic interplay of light and darkness. ${ }^{111}$ Opening all the doors at once would have the potential to suddenly flood the dark main hall with light and air in a dramatic display. In Xeste 3 in Akrotiri, the doors of room 4 lined up perfectly with the frescoes in the adyton or lustral basin (room 3), giving potential for another dramatic reveal. ${ }^{112}$ The use of pier and door partitions in the place of a single door also makes the space appear more spacious and impressive, giving the room

\footnotetext{
109 Hitchcock 1994:33.

110 Driessen 1982.

111 Marinatos and Hägg 1986:72.

112 Marinatos and Hägg 1986:60.
} 
an even more monumental appearance. It is therefore clearly possible that this feature had more than a simply mundane use.

Pier and door partitions have been found only twice in Mycenaean architecture, once at the palace at Tiryns and once at Gla between rooms $2 \& 3$. At Tiryns, this connects the porch of the megaron-unit to the vestibule, creating a total space of $93.93 \mathrm{~m}^{2}$, larger than most MHS (see Tables 1-4). From the vestibule, the main hall can be reached through a large door, $2 \mathrm{~m}$ wide. ${ }^{113}$ No pivot holes were found on the threshold, leading the excavators to conclude that there may never have been a physical door to close the space off. ${ }^{114}$ If this was the case, the pier and door partitions here also could have had an important use as climate control, to let light and air into the main hall or keep out the cold in the winter months. Either way, the pier and door partitions connect a large space making it a flexible and useful area for people processing in towards the main hall, or gathering before entrance.

At Gla, the two spaces connected by the pier and door partitions are not open to the air, making it impossible that the system was used for climate control. However, it does create a large space of $107.25 \mathrm{~m}^{2}$, again much larger than most MHS (Tables 1-4). The partitions could be opened to create more space when the space in the main hall was insufficient, or like at Tiryns, they could have been used for processing into the hall, with a grand reveal as the doors opened not unlike that proposed for Minoan pier and door partitions.

While these practical uses are entirely possible, it is also very likely that pier and door partitions were incorporated into these buildings for their monumental and ceremonial value. Both suites are extremely large and monumentally designed, making it very likely that they were used for official occasions, ceremonies or ritual activity. Participants in a ceremony taking place in either suite could gather out in the porch or courtyard at Tiryns, or in rooms 1 and 2 at Gla and make their way through into the main hall once the pier and door partitions had been opened. As in the MHS, the pier and door partitions could have been opened for dramatic effect, and passed through in order to gain access to the ceremonial or ritual space. Though it is true that these two instances of pier and door partitions lack the elaboration of some Minoan buildings, they are incorporated in a very similar way to the pier and door partitions such as those at Nirou Hani, Palaikastro X1-17 or Malia $Z \alpha$, all of which include only one pier and door partition in a very linear arrangement. ${ }^{115}$

\footnotetext{
113 Schliemann 1885:216.

114 Schliemann 1885:216.

115 See Palyvou 2009:118.
} 
In terms of climate, it should be abundantly clear that this was not the only reason for the inclusion of pier and door partitions. Pier and door partitions were used in sites such as Gla which were not attached to open-air space, eliminating the possibility for climate control. Furthermore, climate control could have been achieved in far less elaborate ways. It is far more likely that the motivation for including pier and door partitions in a structure was due to other considerations, whether this be for their monumentality or dramatic potential in a ritual or ceremonial setting.

\subsection{Hearths}

In Bronze Age literature, hearths have frequently been associated with the Mycenaeans, and more specifically with the Mycenaean palaces. However, while it is true that the hearths found in the Mycenaean megaron-units were significantly larger than most hearths found anywhere in the Bronze Age Aegean, the Mycenaeans were not the only ones to build hearths or to use them as the centrepiece of rooms. In Crete from the Prepalatial to Neopalatial periods rooms with central hearths likely acted as a central living space in houses. ${ }^{116}$ Circular clay hearths with central cavities similar to those found at the Mycenaean palaces have been found in Crete and beyond, in Syria and Palestine, for example (Fig. 16). ${ }^{117}$ Furthermore, hearths were not found in the main hall of all megaron-type buildings in Mycenaean Greece, and even where they were, the largest of these nonpalatial hearths were less than half the size of the three palatial examples. ${ }^{118}$

However, despite this, the massive hearth of the palatial megaron-unit remains its most prominent feature. Whether or not this massive hearth was included in the Mycenaean megaronunit and excluded from the MHS due to climate is key to the comparison of the two spaces. Therefore, the three palatial Mycenaean hearths will be discussed and compared with hearths firstly from the Corridor Buildings, and secondly with the average Mycenaean hearth. Next, the question of the function of these hearths will be raised. Finally, Minoan hearths from buildings containing MHS will be compared, and the absence of hearths in the MHS will be discussed.

Taking up close to $20 \%$ of the total area of the megaron-unit's main hall, the monumental hearths of the megaron-units at Tiryns, Pylos and Mycenae and the columns that surround them are the focal point and most prominent aspect of the megaron-unit. The three hearths in question were found in differing states of repair, but the best preserved by far was that of the palace at Pylos (Fig. 17). The monumental hearth at Pylos is $4.02 \mathrm{~m}$ in diameter $\left(12.69 \mathrm{~m}^{2}\right)$, and like the others is located

\footnotetext{
116 Letesson 2014:24-5.

117 Muhly 1984:109, 111.

118 See Darcque 2005:171-173.
} 
approximately in the centre of the main hall, surrounded by four columns. ${ }^{119}$ It is described by the excavators as being circular with a wide, flat border, around 0.32 to $0.36 \mathrm{~m}$ in width running around the outer edge. This border was coated with five layers of fine, smooth stucco and decorated with painted patterns. The layers represent successive phases of decoration, and the motifs employed include spirals, triangles, notches and flame patterns, in various combinations of red, orange, yellow and black. The interior was $3 \mathrm{~m}$ in diameter and $0.05 \mathrm{~m}$ lower than the border, which rose to $0.17 \mathrm{~m}$ above the ground. The interior was paved with rough stucco.

Unlike the hearth at Pylos, only a small proportion of the hearth at Mycenae was preserved (Fig. 18). From what remains the estimated total diameter is $3.7 \mathrm{~m}\left(10.75 \mathrm{~m}^{2}\right) .{ }^{120}$ What remains of the hearth is very similar to the hearth at Pylos. It was likewise framed by a moulded rim, which was decorated with ten layers of painted stucco. All ten layers represented variations of wave patterns similar to the flame patterns on the hearth at Pylos in black, red, blue, white and yellow. The hearth itself was "built up on a ring of poros enclosing a clay centre". ${ }^{121}$

The hearth at Tiryns is unfortunately very poorly preserved. What remains is a circular gap in the pavement of the floor surrounded by part of a plaster rim. ${ }^{122}$ The gap measured $3.3 \mathrm{~m}$ in diameter, giving the hearth a total area of around $8.55 \mathrm{~m}^{2}$. The excavators presumed that this gap would have once been filled with a core of clay or clay-brick. ${ }^{123}$ There is no detail given of any painted decoration on what remained by the excavators.

Of the Corridor Buildings studied, on the other hand, only two contained hearths in the main hall of the megaron-unit. ${ }^{124}$ At Phylakopi, the hearth was simply an area of the floor that was left unpaved. ${ }^{125}$ It was rectangular in shape and took up $3.96 \mathrm{~m}^{2}$. Traces of burning were found in the area. In room 8 of Megaron A at Dimini, a smaller rectangular hearth was found covering $2.73 \mathrm{~m}^{2} .{ }^{126}$ Few details about this hearth were given, but it was described as a clay hearth, of good construction, with a rim. ${ }^{127}$ Both hearths were placed approximately in the centre of the room.

\footnotetext{
${ }^{119}$ Blegen and Rawson 1966:85-87.

120 Wace et al. 1921-1923:241-243.

${ }^{121}$ Wace et al. 1921-1923:241.

122 Schliemann 1885:222.

123 Schliemann 1885:222.

124 The main halls of other Corridor Buildings were reconstructed with central hearths, or their floors had been disturbed in antiquity, making it difficult to know for certain, but these two buildings were the only ones for which a hearth could be reconstructed with any real certainty. (e.g. Pantou 2010:60, 246)

125 Renfrew 2007:20.

126 Pantou 2010:209.

${ }^{127}$ Adrimi-Sismani 2004:13.
} 
At 3-4m in diameter, the hearths of the Mycenaean palaces are by far the largest hearths found in Mycenaean Greece, more than twice the size of those in the Corridor Buildings. Darcque (2005) surveys 88 hearths from Mycenaean contexts in 18 sites (including the monumental hearths of Pylos, Tiryns and Mycenae); of these, half have complete measurements provided by the excavators. ${ }^{128}$ While the three monumental hearths have areas totalling between $8.5-12.7 \mathrm{~m}^{2}$, the 41 nonmonumental hearths have areas of between 0.2 and $2.78 \mathrm{~m}^{2}$, with an average size of $1 \mathrm{~m}^{2}$. As the three palatial hearths average at more than ten times the size of the average Mycenaean hearth, it is clear that they stand apart.

37 of the 88 surveyed hearths were placed centrally, while 21 were placed along walls, and 9 were placed in corners. Aside from those in the palaces there are only two secure examples of hearths surrounded by four columns, one at Malthi (B85) and one at a newly discovered site at Iklaina ( $\left\lceil 3\right.$, not included in Darcque's survey), measuring $0.71 \mathrm{~m}^{2}$ and $0.87 \mathrm{~m}^{2}$ respectively. ${ }^{129} \mathrm{~A}$ few hearths appear between two columns, but this is still relatively rare. ${ }^{130}$

The average Mycenaean hearth is constructed far more simply than the palatial hearths. ${ }^{131}$ Many were built with a clay or stone foundation, sometimes with a layer of sherds (Fig. 19). Many others were simply unbuilt areas of charred remains on the ground. Aside from the hearth in the 'Queen's Megaron' at Pylos, none were decorated, in stark contrast to the elaborately decorated monumental hearths in the palatial megarons.

It should be clear then from this comparison that that the monumental hearths found in the megaron-units of Tiryns, Pylos and Mycenae differ greatly to the average Mycenaean hearth, making these hearths an extremely interesting and important aspect of the megaron-unit. The purpose of these hearths has been much debated, and there are many different possibilities that are difficult to prove or disprove. These monumental hearths may have been used simply for lighting and warmth, they could have been used for cooking or crafts, and they could have been sacred or objects of worship.

The most obvious possible use of these monumental hearths is as a source of light and warmth. While both light and warmth would have undoubtedly been a factor in their use, it is unlikely that this was the sole reason they were built, or built in the way that they were. As such a large hearth

\footnotetext{
128 Darcque 2005:170-177.

${ }^{129}$ Malthi: Valmin 1938:174; Iklaina: Cosmopoulos 2009:103-105. The megaron-unit at Midea has been reconstructed with four columns, but only two remain in situ. The hearth itself was disturbed and remains only as a "crescent-shaped area of ashes". Walberg 2007:65.

${ }^{130}$ Such as at Nichoria Unit IV-A, Tiryns Megaron W, Mycenae Panagia House II, and Korakou House M \& L. See Darcque 2005 for plans.

${ }^{131}$ Darcque 2005:173-174.
} 
with a similarly large border, it would have been difficult to use. ${ }^{132}$ Light could have been - and in fact was - provided much more simply through lamps. Numerous fragments of stone lamps have been found in and around the megaron-unit at Pylos. ${ }^{133}$ Similarly, in the winter months portable braziers could have been used to provide extra warmth. ${ }^{134}$ Though in the winter the hearth would likely be more effective than these braziers, during the summer it is likely the heat would have been unwanted and unnecessary. Even if the climate was cooler in antiquity, with modern temperatures averaging up to 24 degrees in the summer months a large fire would have been stifling. The choice to build a central hearth instead of using these portable, more convenient and more flexible solutions suggests that the hearth had another purpose or significance.

Shannon Lafayette (2011) and Emily Egan (2015) both argue there was not a clerestory and upper balcony above the megaron-unit at Pylos as suggested by Blegen and Rawson (1966:81-82). Lafayette argues that such an arrangement would not aid ventilation for the fire, and would render the chimney pots found useless. ${ }^{135}$ Egan, on the other hand, suggests that the artifactual evidence used to support an upper balcony has been misinterpreted. ${ }^{136}$ If they are correct, then the megaronunit would have been a very dark, windowless space. Incorporating a hearth and a ventilation system instead of using smaller, portable sources of fire greatly effects the atmosphere of the megaron-unit. The hearth would have been a central focus of the room and an impressive light source in the dimly-lit space. If the intention had been to create a well-lit room, this would not have been achieved. This suggests again that rather than being intended simply as a source of light, that the hearth was integral to the room and its purpose.

Whether or not the hearth in the megaron-unit was used for cooking has long been debated. Many scholars have argued that the hearth would not have been used for cooking based on the lack of pottery, cooking equipment or bones found on or near the hearths. ${ }^{137}$ While large bones would have been taken away, as noted by Géry de Pierpont, it seems unlikely that no smaller bones would be found either. ${ }^{138}$ Likewise, there is no archaeological evidence to suggest any kind of eating or cooking in the megaron-units. ${ }^{139}$ While it is still possible these hearths were used for cooking of some kind, there is no real evidence to support this.

\footnotetext{
132 de Pierpont 1990:262.

133 Egan 2015:160.

134 de Pierpont 1990:257.

135 Lafayette 2011:17-19.

136 Egan 2015:105-107.

137 e.g. Knox 1973:3-4.

138 de Pierpont 1990:258.

139 de Pierpont (1990:258) argues against this based on the large quantities of sherds found in the megaronunit at Pylos. However, these sherds were extremely small and none could be reconstructed into complete
} 
On top of these practical uses, de Pierpont also points out that despite the elaborate location and monumental nature of these hearths, more domestic uses of such fires are still possible. While there is no evidence to support such uses, it is still entirely possible that the central hearth was intended as a hub for domestic tasks and was used "dans certains travaux artisanaux par exemple, ou pour chauffer l'eau d'un bain". ${ }^{140}$ However, none of these practical uses can explain the size and monumentality of the hearth. As de Pierpont states, the size of the hearth would have made it extremely impractical and difficult to use. ${ }^{141}$ Likewise, as argued by Michael Nelson, any fire in the hearth would necessarily be much smaller than the hearth itself so as not to endanger the wooden columns surrounding it. ${ }^{142}$ Therefore, the elaborate size and decoration must have had a specific purpose or significance.

It has often been suggested that the monumental hearth may have had some kind of ritual significance or have been an object of worship in itself. James Wright (1994) suggests that the hearth was symbolically the centre of the Mycenaean state, and linked with the Wanax or ruler who occupied the throne. ${ }^{143}$ It has also been suggested that the hearth may have served a similar role as that of the fire of the Prytanaeion in classical Greece - as the eternal flame, symbolic of the city. ${ }^{144} \mathrm{~A}$ number of scholars have also suggested that the hearth was sacred based on interpretations of the motifs consistently repainted around the edge of the hearths. The excavators of Mycenae in 1921 linked these motifs to those on Minoan offering tables, saying that this indicated that the hearth should be interpreted as a "large immovable altar". ${ }^{145}$ More recently Egan (2015) linked these motifs to motifs found on Mycenaean offering tables, and suggested that these tables should be considered a continuation of the cult relating to the main hearth in the palatial megaron-unit. ${ }^{146}$

While all of these theories are entirely plausible and it is likely the hearth had some symbolic significance, it must be noted that there is no concrete artifactual evidence that the hearth was used as an object of worship itself. No evidence of votive offerings were found at any of the hearths. ${ }^{147}$ The presence of other ritual objects in the megaron-unit do not necessarily indicate that the hearth was a ritual object itself, it is entirely possible that these indicate that the focus of ritual activity in

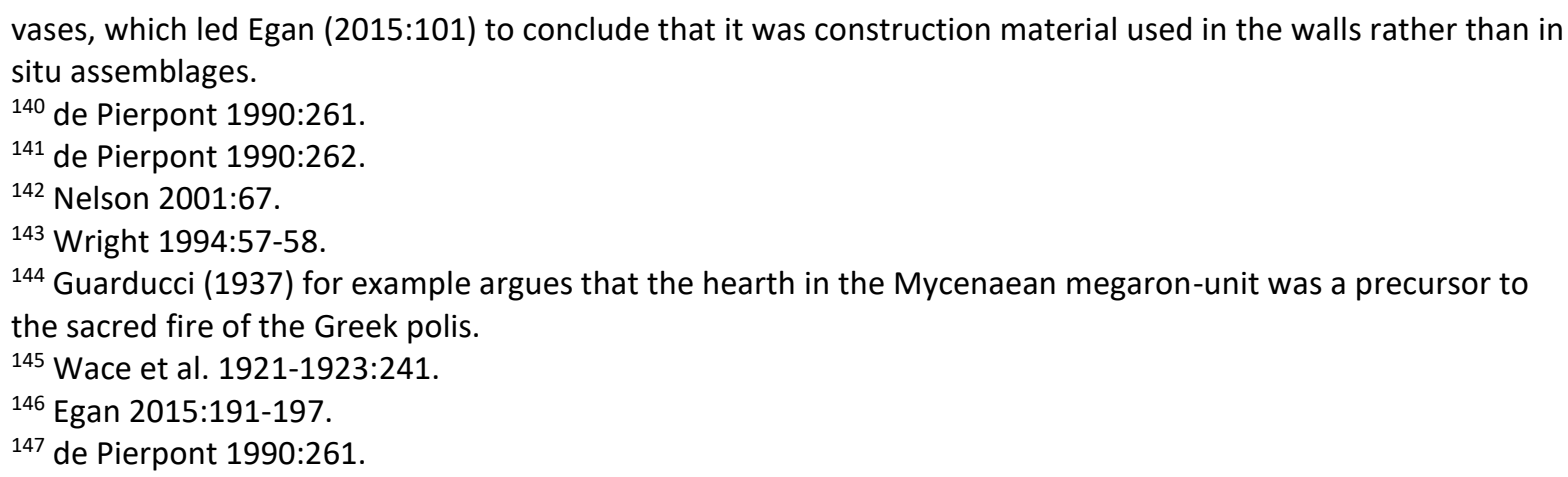


the megaron-unit lay elsewhere. ${ }^{148}$ The palatial hearth may have been so large and well decorated simply because it was located in such an important setting. ${ }^{149}$ Any interpretation of the monumental hearth as an object of worship in itself must remain theoretical.

In the winter, it is likely that rooms with central hearths in simple settlements acted as living rooms or hubs in which the household came together to socialize, keep warm, cook and perform other day to day activities requiring the fire. As such, the hearth would have become the central focus of household. It is possible that the central hearth in the palaces took on a similar role, becoming symbolically the central focus of the palace, and the symbolic core of Mycenaean society. ${ }^{150}$

The hearth area of the megaron-units at Tiryns, Pylos and Mycenae and the columns that surround them were clearly an important and dominant aspect of the megaron-unit's use. While the hearths themselves took up around $7-8 \%$ of the floor space in the main hall, the area enclosed by the columns was closer to $20 \%$, making it clear that the hearth was a dominant structure and focal point of any activity that took place inside. At such a large size, these hearths were impractical and difficult to use, and far less flexible than a system of windows, torches and braziers that could have been utilized instead. The heat of the fire would have likely been intense during the summer. All this suggests, therefore, that while the monumental hearths could have been used for practical purposes, this was likely not their only significance. Contrary to Hazzidakis' suggestion, it is therefore unlikely that a hearth was utilized simply as an alternative to a light well in a colder climate. It seems far more likely that the hearth had some other ceremonial, symbolic or ritual significance, but it is extremely difficult to know now for certain exactly what that may have been.

Hearths are much less common in Crete than on the mainland, but they are by no means absent. Though not contemporary with MHS, clay hearths similar in form to those found in the Mycenaean palaces were also attested in Crete in the Middle Minoan period. ${ }^{151}$ They were significantly smaller, at $0.65-0.85 \mathrm{~m}$ in diameter, but were frequently decorated with incised or painted patterns. ${ }^{152}$ While hearths have not been found within MHS, they do coexist in the same buildings. From the Middle Minoan period through to the Neopalatial period on Crete there was a tradition of central hearths in rooms used as the central living space of the house. ${ }^{153}$ These are found less often in the Neopalatial

\footnotetext{
148 de Pierpont 1990:261.

${ }^{149}$ As suggested by de Pierpont (1990) in the abstract of his article. "La dimension et le décor de ces larges

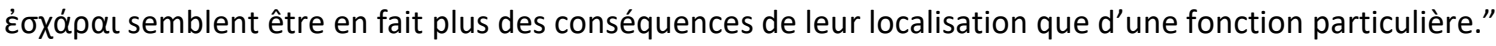

${ }^{150}$ As suggested by de Pierpont (1990:259).

151 Muhly 1984:109.

152 Muhly 1984:109.

${ }^{153}$ Letesson 2014:721.
} 
period, but are attested in several buildings also containing MHS, such as at Chania, Galatas and Malia Z $\beta$.

At Galatas, a large rectangular hearth was found in a shallow recess in the floor and surrounded by four pillars. ${ }^{154}$ Very little is said about its construction other than that it contained ash and carbonized wood. ${ }^{155}$ While this hearth has been called monumental, it should be noted that at $3 \times 1.5 \mathrm{~m}$ it is around half the size of the monumental Mycenaean hearths. While the Galatas hearth measures $4 \mathrm{~m}^{2}$, the Mycenaean monumental hearths measure between $8.5-12.7 \mathrm{~m}^{2} .156$ The hearth was found in a paved room immediately adjacent to the central court, through which it would be necessary to pass to access most of the east wing of the palace.

At Chania, an approximately square hearth was found at the centre of room $M$, which measured $1.25 \times 0.83 \mathrm{~m}\left(1.03 \mathrm{~m}^{2}\right) .{ }^{157}$ It was reported as being built with a clay bedding and coated with stucco. ${ }^{158}$ Based on finds from the rest of the room, such as cooking pots and a grindstone, the excavators concluded that the room would likely have had a domestic function. ${ }^{159}$ Room $\mathrm{M}$, where the hearth was found, was one of the largest rooms in the building $(4.9 \times 4.15 \mathrm{~m})$, and functioned in part as the access to several rooms in the northern part of the house. ${ }^{160}$

Most interestingly, at Malia Z $\beta$, the hearth was found in the central room adjoining the MHS. It consisted of four flat bricks laid together to form a rectangle $1 \times 0.71 \mathrm{~cm}\left(0.71 \mathrm{~m}^{2}\right) .{ }^{161}$ It was identified as a hearth as the bricks showed signs of being exposed to heat. ${ }^{162}$ The excavators recognised a kitchen in another part of the building, so proposed that this hearth would have been used instead to light and heat the room. ${ }^{163}$ The hearth was placed near the centre of the room, towards the east wall. This central room was accessible from the outside through spaces a and I, or through the small foyer $b$ and the MHS (VII). It provided the only access to the south-east section of the building. Most notably, the central room opens onto the MHS without a doorway, instead with an opening of $1.85 \mathrm{~m}$, over half the width of the MHS. ${ }^{164}$ While the MHS was paved with limestone, the floor of the central room was clay. ${ }^{165}$

\footnotetext{
154 Rethemiotakis 1999:723.

155 Rethemiotakis 1999:723.

156 Rethemiotakis 1999:723, Darcque 2005:171-173.

157 Hallager and Tzedakis 1984:5.

158 Hallager and Tzedakis 1984:5.

159 Hallager and Tzedakis 1984:5.

${ }^{160}$ Hallager and Tzedakis 1984:5.

161 Deshayes and Dessenne 1959:12.

162 Deshayes and Dessenne 1959:12.

163 Deshayes and Dessenne 1959:12.

164 Deshayes and Dessenne 1959:18-19.

165 Deshayes and Dessenne 1959:12, 19.
} 
These three rooms are all variations of a type of room considered by some scholars to have functioned as the central living space of the house, where residents would have naturally gathered and visitors could be received. ${ }^{166}$ While some contained a hearth, the room has been connected to other large rooms with a central column but no hearth. ${ }^{167}$ As spaces that were centrally placed and which connected a large amount of other rooms, they would have been key to the circulation in the surrounding building. Their large size would have also allowed for the meeting of large numbers of people. Letesson (2014:724-725) states:

"Such a room would therefore have been at the very center of domestic life, hosting household daily practices such as food processing and consumption, family gatherings, guest receptions, as well as small craft activities. [...] They were the functional core and central focus of the household or social group in charge of the building."

As such, the hearth contained within such rooms would have been a focal point for social and communal gatherings. It would have certainly served to light and heat the space when necessary, and could also have been used for food preparation or craft, particularly in domestic buildings. ${ }^{168}$ The hearth room at Galatas, on the other hand, retained a social and communal function throughout the duration of its use. No evidence of food preparation or craft was found in the room, making it all the more likely that the hearth was used to light and heat the room as an area for social gatherings. ${ }^{169}$

If these rooms did in fact function as social spaces for gatherings of people, the absence of a hearth in the MHS cannot be explained simply by a warmer climate. The presence of a hearth in rooms that would have been frequented by many people and used as a gathering place indicates that there was a desire for fire and warmth in such spaces at least during some parts of the year. The absence of hearths in the MHS therefore must have had another explanation.

Before any such conclusion is drawn, it should be noted that while no hearth has been found in a MHS, other receptacles for fire have been found. Stone lamps were found in Malia Z $\beta$ and in the Royal Villa at Knossos, fireboxes were found in the Hall of the Double Axes at Knossos and in Malia

\footnotetext{
${ }^{166}$ E.g. Letesson 2014:724-725.

167 Letesson 2014:742.

168 Letesson 2014:724-725.

169 Rethemiotakis 1999:723.
} 
$Z \beta$ and an incense burner was found at Mochlos. ${ }^{170}$ Other such portable items could have been brought in to heat the MHS from elsewhere when necessary.

Based on this evidence, it is therefore not possible to consider the lack of a central hearth in MHS the result of a milder climate alone. If this was the case, there would not be evidence for central hearths in social spaces where individuals likely gathered. At Malia Z $\beta$, the MHS was open to the room with the central hearth by a gap of $1.85 \mathrm{~m}$, meaning the former would have been warmed by the hearth when it was lit. The lack of a hearth in the hall itself cannot therefore be because the heat was not needed or wanted. In the winter months, the light well of the MHS would be exposed to the wind and rain, and this would likely have made the hall itself an unpleasant environment. With temperatures dropping to an average of 12 degrees in Crete over the winter and likely colder in the latter half of the Neopalatial period, these rooms would have been almost uninhabitable without some heating. It is entirely possible that these rooms were primarily used during the summer months and left vacant once the weather worsened.

This tradition of hearths as the central focus of the community and social gatherings is remarkably similar to the model proposed for the Mycenaeans for the inclusion of the hearth in the megaron-unit. If both communities likely had a similar focus on the hearth then its absence from one set of rooms and inclusion in the other is notable. In her examination of the room with the central columns, Anna Michailidou (1987) proposed that the MHS may have been developed to take over some but not all of the functions of this room, which was found at Malia Z $\beta$ and Chania also with a central hearth. She suggested that the MHS with pier and door partitions would have been used as a reception hall, while the room with the central column continued to be used as a central living space by the residents. ${ }^{171}$ While not all of these rooms with central columns contained hearths, many did, and from their similarity it is possible that those without hearths may have instead been fitted with portable braziers. ${ }^{172}$ If Michailidou is correct, then it is interesting to note that the hearth was not transferred into the MHS as it was developed. It is possible the hearth was not considered an essential part of the room, but if the Minoans had placed any symbolic importance on the hearth as the centre of their social gatherings, this was not considered necessary in the newly developed space for the reception of guests.

\footnotetext{
170 Deshayes and Dessenne 1959:19 (Malia Z $\beta$ ); Evans 1928:404 (Royal Villa); Evans 1930:347 (Hall of the D. Axes); Soles and Davaras 1996:189 (Mochlos). See Letesson 2013:336-7 (Table 2) for an overview of items found in MHS.

171 Michailidou 1987:522.

172 Letesson 2014:741-742.
} 
It seems clear that the central hearth was included in the Mycenaean megaron-unit not simply as a source of light and air but in a symbolic capacity that had meaning to the occupants and was essential to the use of the megaron-unit. It was not climate alone but more intangible, symbolic considerations that led to the inclusion of a hearth in the megaron-units of the Mycenaean palaces. On the other hand, whether or not symbolism was attached to fire or hearths in Neopalatial Crete, no such fixed hearth was necessary in the use of the MHS. Again, it is clear that the Minoans used hearths in similar ways and in similar contexts to the Mycenaeans, making it likely that the exclusion of hearths in the MHS was not due to a different climate alone but because of a difference in culture and ideology. While the climate certainly would have had an effect on the way in which these two different spaces developed, it should certainly not be considered the only factor in the presence or lack of hearths in these two spaces.

\subsection{Conclusions}

Several conclusions can be drawn from this study. Firstly, the three features of MHS and Mycenaean megaron-units discussed are not the most effective or simplest method of climate control. Light wells and pier and door partitions could have easily been replaced in MHS by single doors or windows. The monumental hearths in the Mycenaean megaron-units on the other hand were too large to be practical to use, and were surrounded by wooden columns which would have necessitated smaller fires. It was likely not climate alone, therefore, that influenced the development of these features.

All three features must therefore have had some other significance or use for the occupants of the building. Some light wells may have been designed as a private open-air space, intended for the use of the occupants of the MHS alone. Pier and door partitions may have been used in a ceremonial sense to create a dramatic opening or reveal, allowing access for participants into the main suite. The monumental hearths likely had some kind of ritual, ceremonial, or sacred character, probably in relation to the status of the Wanax or ruler. However, it is also possible that these three features were intended to be lavish, elaborate and monumental, adding to the monumentality and prestige of the suites they were found in. Whatever the case, they were designed not as simple, practical features for the manipulation of climate but as refined and impressive architectural features.

Secondly, all three features were in fact used in both cultures. While the light well and pier and door partitions are features associated with the MHS, both have been used in the Mycenaean 
megaron-unit also. Open-air space was an important part of the megaron-unit, with the porch almost always opening onto a court of some description, similar to MHS such as at Nirou Hani and Pyrgos Myrtos. On the other hand, two Mycenaean buildings incorporated pier and door partitions into megaron-units. While these suites were more linear than some more elaborate MHS, they were very similar to the more linear MHS such as Malia Z $\beta$ or the South House at Knossos. They also joined spaces which together equalled around $100 \mathrm{~m}^{2}$, larger than most entire MHS. Though certainly pier and door partitions are far more characteristic of the Minoans, neither feature is unheard of in Mycenaean contexts. Furthermore, while hearths the size of those in the Mycenaean palaces are unattested outside of these three sites, the Minoans also used hearths in some of their important social spaces. No artifacts for the preparation or consumption of food or for craft of any kind were found around the hearth at Galatas, suggesting that it functioned as a focus of social gatherings, rather than having a more practical use. As fixed hearths are attested in social Minoan contexts, it seems clear that the differences between MHS and Mycenaean megaron-units could not have been simply due to dramatically different climates. Both cultures required hearths for warmth in the winter, both used pier and door partitions and both incorporated open-air spaces into their architecture. These differences must be explained by other means.

As both cultures employed similar climate control features into their architecture, it should not be surprising that the climate may not have been very different between Crete and mainland Greece in the Bronze Age. In the modern day, while average temperatures over the winter are much colder in the Peloponnese than on Crete, both do get cold enough to require some kind of heating or insulation from the elements. Bronze Age weather estimates indicate that the temperatures over winter may have also been even colder than the present after the Theran eruption, while MHS were likely still being built. Furthermore, modern summer temperatures in both locations are similarly high, and the heat from a hearth would have been very unwelcome even in the Peloponnese. Temperatures in the LHIII period may have even exceeded those in the Minoan Neopalatial period, further reducing the need for heating.

It is possible that instead of being adapted to higher or lower temperatures, climate control in Minoan and Mycenaean buildings differed due to a change in humidity levels in the Aegean region. While earlier in the Bronze Age the climate may have been much more humid and moist than it is today, around $1300 \mathrm{BC}$ the climate may have changed to be a lot more dry and arid. ${ }^{173}$ Regardless of temperatures, in moist climates the best climate control involves ventilation, which is generally seen in Minoan buildings, with multiple doors, windows and open-air areas. In dry or arid environments,

${ }^{173}$ Moody 2005:470-471. 
on the other hand, whether hot or cold, insulation is more appropriate. This, again, is reflected in Mycenaean building design. Buildings are more linear, with less entrances eliminating the possibility for cross ventilation. Doorways from the open-air 'Great Courts' in the Mycenaean palaces are hidden away from direct sunlight under porticos. Buildings generally have fewer open-air spaces, with fewer doors and windows. Though Minoan features like the pier and door partition are used, they are more easily isolated from the weather. While this may explain some differences between MHS and Mycenaean megaron-units, the three features in question remain more elaborate and monumental than can be explained simply by this difference in humidity. The differences between the MHS and Mycenaean megaron-unit seem to combine differences in culture, religion and function as well as differences in climate. 


\section{Chapter 4: Conclusions}

Several different conclusions can be drawn from this comparison of the MHS and Mycenaean megaron-unit, based on the three research aims of the study. Firstly, it should be apparent that neither the MHS nor the Mycenaean megaron-unit is a uniform system. Both were constructed and located in such different ways in the different sites that it is unlikely that every suite could have functioned in the same way. This is particularly evident in the case of the MHS, but is true for the Mycenaean megaron-unit also.

The MHS varies a great deal in its spatial structure in relation to the surrounding building. Some halls are located near an entrance to the building, or matrix within the palace, where others are distant from the entrance. Some halls provide the only access to many different spaces, making them integral to the use of the building, while others were isolated, dead-end spaces. MHS vary considerably in their access from the exterior, in their locations within the building and in their connections to other spaces within the building. These variations seem to suggest that these different systems would have functioned in different ways. While there are many suggestions as to the use of the MHS, it is difficult to conceive of a single function that could explain this variety.

One of the most prominent aspects of the MHS, the variety of the light well highlights the differences between the suites. While light wells in isolated suites such as at Malia Z $\alpha$ and the South House at Knossos were extremely private, others such as at Chania or Malia Z $\beta$ would have been accessible by any visitor to the building due to their location near the entrance. Still more public, these contrast with the open-air spaces incorporated into MHS such as at Nirou Hani and Pyrgos Myrtos, where the light well is replaced by an open court, accessible to the public at any time of day. While a private ceremony could take place in the isolated light wells at Malia Z $\alpha$ and the South House, any activity in the equivalent open-air space at Nirou Hani or Pyrgos Myrtos would have been in full view of any passers-by. This necessitates a different dynamic and function to any activity involving the open-air attached to these spaces.

On the other hand, while the megaron-unit is more uniform in spatial structure as it related to the surrounding buildings, as noted already it differs in many ways from site to site. Firstly, while the three palatial megaron-units measure more than $200 \mathrm{~m}^{2}$, the megaron-units in the Corridor Buildings are much smaller, measuring between $46-83 \mathrm{~m}^{2}$. Likewise, the two isolated megaron-units studied are both far smaller than the palatial examples at $63 \mathrm{~m}^{2}$ and $132 \mathrm{~m}^{2}$ respectively. Furthermore, while the three palatial megaron-units include hearths, only two Corridor Buildings certainly contained hearths, and likewise the isolated megaron-unit at Thermos and both suites at 
Gla revealed no traces of a hearth. While the three palatial megaron-units and all the Corridor Buildings featured main halls that were type ' $a$ ' dead-end spaces, the isolated megaron-units at Korakou and Thermos both included back rooms, and the main hall (23) of the smaller suite at Gla was a type ' $c$ ' space, acting to some extent as a circulatory nexus. Unlike the isolated non-palatial megaron-units such as Korakou House $L$ and Thermos Megaron A, the palatial megaron-units were not isolated but instead an integral part of a larger building, with the vestibule as one of the most integrated spaces in the building. The Corridor Buildings, while being linked due to their spatial similarity, also vary considerably, leading Pantou to conclude that they were used for different purposes. While some she suggested would have been private houses, others would have had a public function.

Finally, like the light well of the MHS, the open-air spaces attached to the Mycenaean buildings studied also varied considerably. While the palatial suites at Pylos, Mycenae and Tiryns as well as Megaron A at Dimini and the West House at Mycenae all had enclosed courtyards included within the building, the other Mycenaean buildings in contrast had far more open courts. The contrast between the two different types of court is considerable. While at Tiryns an individual would have to make their way through four separate gateways to enter the court in front of the megaron-unit, at the remaining sites on approaching the buildings it would immediately be possible to enter the porch at any time. The use of these spaces would necessarily have differed to some degree from site to site.

It should be clear, therefore, that both the MHS and the Mycenaean megaron-unit likely had a variety of different functions from site to site. Rather than being completely uniform architectural forms, both differed considerably, meaning not every system would have been suited to the same purposes. One single function should therefore not be assumed for every example based on comparative material from other sites but should instead be examined individually. The presence of a Corridor Building does not necessarily indicate a Mycenaean palatial centre, for example.

In comparing the MHS with the Mycenaean megaron-unit, there are some major differences that are immediately apparent. In terms of their place within the building, in the case of the Mycenaean megaron-unit, it is the porch, attached to the open-air space, the court, which is the first space accessible from the exterior. The main hall, on the other hand, is the most isolated space, distant from the exterior. The opposite is true of the MHS. Though it differs from building to building, the main hall is often the first space accessible from the exterior, and it is never an isolated type ' $a$ ' space as it is in the megaron-unit. The light well, on the other hand, is generally the most isolated 
space, and is often a type ' $a$ ' space. While many MHS provide essential access routes to other spaces, in general this is not the case with megaron-units.

The two also differ in their approach from the exterior. The megaron-unit is generally a prominent aspect of the building it is included in, and is easily accessible from a monumental porch, near the exterior of the building. In contrast, many MHS are distant from the entrance to the building, with little in the spatial structure to indicate that an important space was located in this direction. The main entrance to the megaron-unit was generally located on its shorter side, while the MHS was generally entered from the longer side, giving a broken-axis entrance.

The use of the three features studied also varies between the two different types of suite. Though some Minoan light wells bear a resemblance to the courts included in the Megaron-units, there is no parallel for the isolated light wells included in isolated MHS such as at Malia $\Delta \alpha$. Similarly, though pier and door partitions were included into Mycenaean buildings, an extra internal space ensures that the main hall of the Mycenaean megaron-unit would have been more isolated from the weather than the main hall of the MHS. This difference is reflected more generally in the architecture of the two cultures. While Minoan architecture includes many entrances, multiple doorways such as pier and door partitions and windows, Mycenaean architecture in general incorporates fewer of these features, suggesting that air would have been distributed through the building less effectively than in Minoan buildings.

Finally, the MHS, as is immediately obvious, does not include a hearth. However, hearths were included in other contemporary Minoan buildings in places where individuals would have gathered, suggesting that the lack of a hearth in the MHS was not due just to a warmer climate but instead because it was not needed or wanted in the use of the MHS.

However, despite this, in many ways the megaron-unit and MHS are remarkably similar. Both incorporate three spaces, as well as an open-air space. Both are often among the largest and most elaborate spaces in the buildings they were included in. Although more characteristic of the Minoans than the Mycenaeans, both were also known to incorporate pier and door partitions. Though the pier and door partitions would have provided less light and air to the main hall of Tiryns than those included in the MHS, these pier and door partitions and those at Gla joined spaces equivalent to or larger than most MHS. While many MHS included far more elaborate pier and door partition systems, the Mycenaean examples were incorporated in a similar way to those at Nirou Hani, Palaikastro X1-17 or Malia Z $\alpha$, which were likewise incorporated in a linear arrangement. 
Both also include open-air spaces, though many of these differ in some ways. As noted, there is no parallel for the more isolated Minoan light wells in Mycenaean buildings, but in both types of suite some buildings open directly onto public open-air spaces. MHS such as at Nirou Hani and Pyrgos Myrtos bear a striking resemblance to many Corridor Buildings and the isolated megaronunits which open onto public courts. On the other hand, the slightly more private courts included in the palaces and both the West House at Mycenae and Megaron A at Dimini bear a resemblance to the slightly more private light wells located near the entrances to buildings such as at Chania, or the MHS that open from the Central Courts of the palaces. Though they do differ in many ways, it is important to note that the two types of suite do have similarities and may have had similar uses.

As for climate, the theory that the two types of suite differed mainly based on climate is unlikely, firstly because the climate likely was rather similar between Crete and the Mainland in the Bronze Age. Though in the past 50 years temperatures on the mainland over winter averaged far lower than in Crete, summer temperatures were remarkably similar, meaning the heat from a central hearth would have been just as unwanted on the mainland as in Crete. Over the winter on Crete, the pier and door partitions would likely have rendered the MHS too cold without some kind of heating, particularly in the cold period following the Theran eruption. Central hearths in rooms where people gathered are attested in Neopalatial Crete, therefore the lack of a hearth in the MHS cannot be explained by warmer temperatures in Crete. Furthermore, during the time the megaronunits would have been built, temperatures were increasing in the Aegean region, further reducing the need for the heat from a hearth on the mainland. It is unlikely, therefore, that differences in temperatures would have been extreme enough to cause this difference alone.

Secondly, as has been stated it is unlikely that the two suites differed because of climate as the features in question were not the most effective method for climate control. They instead likely had some kind of other ritual, ceremonial or monumental significance. On the one hand, light wells and pier and door partitions were not the only means of light and air circulation available to Minoans, they also frequently used windows and single doors as a means to open a room up to light. The light well and pier and door partition system is not the simplest or the most effective method of light and air circulation which the Minoans used, but it is one of the most elaborate. On the other hand, the monumental hearths found in the Mycenaean megaron-units were far too large to be practical to use, in surrounding them by wooden columns the architects ensured that the fire would necessarily not be particularly large in order to prevent these columns from catching fire. Furthermore, in using the chimney system of ventilation, the room would necessarily have been dark and enclosed, which would have likely been rather unpleasant in the summer. In using these methods of heating and 
ventilation, then, instead of simpler and more flexible systems, both the Minoans and the Mycenaeans likely had other motivations than simply the control of climate conditions.

All three features may have been included in the suites for their impressive, monumental character. In good weather, the light and air from the light well would have made the MHS a pleasant place to retire, and the pier and door partitions add monumentality to the area, allowing for a large, spacious area to be joined together. The monumental hearth in the megaron-unit would have provided more warmth than portable braziers in the winter months, and made an impressive centrepiece for the megaron-unit. However, it is also possible that more significance was placed on these features. Some Minoan light wells may have been designed as private open-air spaces, and the pier and door partitions may have been used to create a dramatic reveal during some kind of ceremony or ritual. The monumental hearths may have had some kind of ritual or sacred character, in relation to the Wanax. Whatever the case, it is likely that culture and religious significance, as well as the desire to create an impressive space, had a large influence on the development of both the MHS and the Mycenaean megaron-unit.

This desire for an impressive, monumental space is also possibly what influenced the Mycenaeans to adopt Minoan pier and door partitions at Tiryns and Gla. In their study of why and how Minoan elements were added to Mycenaean architecture at Pylos, Joshua Englehardt and Donna Nagle (2011) concluded that Mycenaean elites likely adopted Minoan architectural elements as well as Minoan objects as a bid for the prestige attached to such foreign luxurious items and features. ${ }^{174}$ They proposed that these were then changed or phased out in a later period as these new Mycenaean elites created their own architectural tradition. ${ }^{175}$ While this new, changed tradition included the megaron-unit, the same formation process could easily be true for the inclusion of the pier and door partitions at Tiryns and Gla. Though cultural influences are rarely straightforward, it is also possible that some of the similarities between MHS and Mycenaean megaron-units may have been due in part to Mycenaean exposure to Minoan architecture, such as the monumental entrance to Phaistos or MHS in the palaces.

The difference in temperatures between Crete and the mainland cannot therefore explain why the MHS lacks a hearth and the Mycenaean megaron-unit contains one, as Hazzidakis (1934:17) suggested. However, some of the differences between Minoan and Mycenaean architectural design may have been due to differences in humidity levels between the two periods. Earlier in the Late Bronze Age, around the time of the Neopalatial Period in Crete, humidity levels were much higher

\footnotetext{
${ }^{174}$ Englehardt and Nagle 2011:365.

175 Englehardt and Nagle 2011:366-368.
} 
than in the present day, making ventilation the more effective method of temperature control. On the other hand, later in the period, humidity levels dropped, making the climate far more dry and arid than earlier. Insulation from the heat is far more effective than ventilation in arid climates, lessening the need for cross ventilation in Mycenaean buildings. This may help to explain the lack of emphasis on ventilation in Mycenaean architecture in comparison with Minoan architecture. However, as stated, this still does not sufficiently explain the monumental Mycenaean hearth.

As should be clear, both the MHS and the Mycenaean megaron-unit were extremely varied in design, size and elaboration, making it very difficult to determine what their function may have been. However, based on this study some cautious conclusions can be drawn. Firstly, as has been noted in relation to the climate, the features and design of both the MHS and the Mycenaean megaron-unit are in general more elaborate than necessary, or in some case than practical. They were not created simply for climate control but to be impressive and monumental. It is likely therefore that they were generally not created simply for domestic purposes but instead had some kind of ritual, ceremonial or official purpose. Pier and door partitions would have been useful to create a dramatic reveal, and the monumental hearth and light well would have created dramatic lighting of some kind of ceremony.

However, as has been stated, these features may have been created simply to make the megaron-unit and MHS more elaborate and impressive than the surrounding spaces. Pier and door partitions were used to create a MHS of sorts at Hagia Triada which was used for food storage. The monumental hearth may have been so large and well decorated simply to create an impressive atmosphere in the megaron-unit. These features need not have necessarily had a higher significance.

In the past, scholars have proposed that both the MHS and the Mycenaean megaron-unit may have functioned as reception areas for guests, where the residents of the building could receive and welcome visitors. While it is not the case for all MHS, as has been stated many MHS and megaronunits would be appropriately placed for some kind of welcoming ceremony or ritual before the visitor gained access to the rest of the building or matrix within the Minoan palaces. In the Mycenaean Corridor-Buildings the flanking rooms were likely service areas for whatever activity took place in the larger main suite, but in the palaces the visitor was directed by the architecture to the megaron-unit upon arrival. The visitor could be welcomed there before making their way into the rest of the palace. Many MHS could have functioned in a very similar way. Systems at sites such as Chania, Nirou Hani, Mochlos and Malia Z $\beta$ were located at an entrance to the building, and visitors would have been directed by the architecture towards the MHS. Once they had been accepted into 
the MHS, they could then move from there onwards into the rest of the building. A similar system could have been in place at the palaces, where the MHS was often the first space accessible in the isolated matrices they were found within. However, as already noted, this function would not be possible in the more isolated MHS such as at Malia Z $\alpha$ and $\Delta \alpha$, Tylissos House C and the South House at Knossos. These systems were more isolated in the buildings they were found within, distant from the entrance and with only one entrance and exit. They were not transitory spaces that could be passed through to access other areas. A different type of activity must have taken place in MHS such as these.

It should be clear that neither MHS nor Mycenaean megaron-units are uniform entities. MHS occur in vastly different buildings and vary wildly in size, from $14.5 \mathrm{~m}^{2}$ to $159 \mathrm{~m}^{2}$. They are found in different parts of the building and while some are integral to the circulation of the buildings others are isolated and cut off from the rest of the building. The Mycenaean structures often called 'megarons' on the other hand range from $4.9 \mathrm{~m}^{2}$ to $243 \mathrm{~m}^{2}$. They are range from the integral, identical suites included in the three palaces, to more isolated buildings with flanking rooms, to finally isolated suites. Though similar in form, these buildings did not all contain hearths and may have been used for a wide range of different purposes. In determining the function of these suites, therefore, it is important to consider each case separately.

Likewise, though they may have differed in many ways, there is no reason why some MHS could not have functioned in very similar ways to some Mycenaean megaron-units. While some more unique halls and features from each culture contrast wildly from the other, more simple forms of each MHS are extremely similar. Though conclusions about cultural influence are difficult, it is entirely possible that features such as the 'Great Courts' of the Mycenaean palaces and the pier and door partitions at Tiryns and Gla may have been incorporated into the Mycenaean palaces in imitation of the Minoan palaces. Although the two cultures had very different architectural traditions, these features were used in remarkably similar ways on the mainland to those in Crete. Though any symbolic significance may have been changed, lost, or adapted to Mycenaean culture, it is entirely possible that these similar structures and features had similar functions in both cultures.

Both the MHS and the Mycenaean megaron-unit may have been built to fulfil various different roles at different sites and in different buildings. Though the two types of hall served different cultural traditions, some may have hosted rituals or ceremonies which filled a similar role in the two different cultures. As the two cultures differed greatly in their social organisation, these likely looked rather different, but it is possible such an activity may have had a similar role in relation to the function of the building these MHS were located in. Though the cultures may be different, the 
relationship between some MHS and Mycenaean megaron-units with the structures they were located in may have been similar. 


\section{Works Cited}

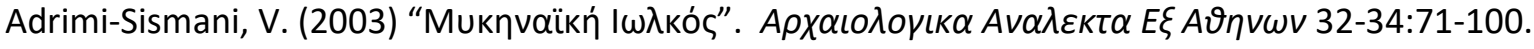

Adrimi-Sismani, V. (2004) "Le palais de lolkos et sa destruction". Bulletin de Correspondance Hellénique 128-129.1:1-54.

Ames, K., Raetz, D., Hamilton, S., and McAfee, C. (1992). "Household Archaeology of a Southern Northwest Coast Plank House". Journal of Field Archaeology 19.3:275-290.

Atkinson, T. (1904). "The architecture". In Atkinson, T, Bosanquet, R., Edgar, C., Evans, A., Hogarth, D., Mackenzie, D., Smith, C. and Welch, F. (eds), Excavations at Phylakopi in Melos. (Society for the Promotion of Hellenic Studies Suppl. Paper 4; London), pp. 25-69.

Baldwin Smith, E. (1942). "The Megaron and its Roof". American Journal of Archaeology 46.1:99118.

Barber, R. (1987). The Cyclades in the Bronze Age. (London: Gerald Duckworth \& Co. Ltd.).

Blegen, C. W. (1921). Korakou: A Prehistoric Settlement near Corinth. (Boston and New York: The American School of Classical Studies at Athens).

Blegen, C. W., and M. Rawson. (1966). The Palace of Nestor at Pylos in Western Messenia I: The Buildings and Their Contents. (Princeton: Princeton University Press).

Boëthius, C. (1919). "Mycenaean Megara and Nordic Houses". The Annual of the British School at Athens 24:161-184.

Cadogan, G. (1977-1978). "Pyrgos, Crete, 1970-7". Archaeological Reports 24:70-84.

Catling, H., Hughes-Brock, H. et al. (2009) Sparta: Menelaion I: The Bronze Age. (London: British School at Athens).

Cavanagh, W. (2001). "Empty Space? Courts and Squares in Mycenaean Towns." In Branigan, K. (ed) Urbanism in the Aegean Bronze Age. (Sheffield: Sheffield Academic Press).

Chapin, A, and Shaw, M. (2006). "The Frescoes from the House of the Frescoes at Knossos: A Reconsideration of Their Architectural Context and a New Reconstruction of the Crocus Panel". The Annual of the British School at Athens 101:57-88.

Chermayeff, S. and Alexander, C. (1963). Community and Privacy: Toward a New Architecture of Humanism. (New York: Doubleday \& Company, Inc.).

Clinton, Miriam. (2013). "Access and circulation pattern analysis in Neopalatial architecture on Crete: A methodology for identifying private spaces" (Ph.D. dissertation, University of Pennsylvania).

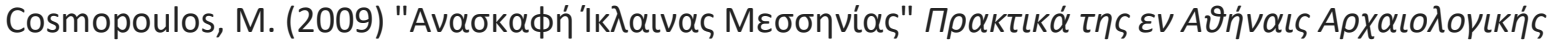

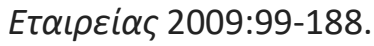

Darcque, P. (2005). L'habitat mycénien: Formes et fonctions de l'espace bâti en Grèce continentale à la fin du lle millénaire avant J.-C. (Athens: École française d'Athènes). 
de Pierpont, G. (1990). "Le rôle du foyer monumental dans la grand salle du palais mycénien," in L'habitat égéen préhistorique. Actes de la Table ronde internationale organiseé par le Centre national de la recherche scientifique, I'Université de Paris l et l'École française d'Athènes, Athènes 23-25 juin 1987 (BCH Suppl. 19), ed. P. Darcque and R. Treuil, Athens, pp. 255-262.

Demargne, P., and Gallet de Santerre, H. (1953). Fouilles exécutées à Mallia. Exploration des maisons et quartiers d'habitation (1921-1948). (Paris: Paul Geuthner).

Deshayes J., and Dessenne, A. (1959). Fouilles exécutées à Mallia. Exploration des maisons et quartiers d'habitation (1948-1954). (Paris: Paul Geuthner).

Driessen, J. (1982). "The Minoan Hall in Domestic Architecture on Crete: To be in Vogue in Late Minoan IA?" Acta Archaeologica Lovaniensia 21:27-92.

Driessen, J., and MacDonald, C. (1997). The Troubled Island: Minoan Crete Before and After the Santorini Eruption. (Liège: Université de Liège).

Driessen, J., and Sakellarakis, J. (1997). "The Vathypetro-Complex: Some Observations on its Architectural History and Function". In R. Hägg and N. Marinatos (eds) The Function of the Minoan Palaces: Proceedings of the Fourth International Symposium at the Swedish Institute in Athens, 1016 June, 1984. (Stockholm: Paul Aströms Förlag), pp. 63-77.

Duinker, H. (2014). "The reciprocity between architecture and man: Power representation in the Mycenaean megaron palaces". (Masters dissertation, University of Groningen).

Egan, E. (2015). Nestor's Megaron: Contextualizing a Mycenaean Institution at Pylos (diss. University of Cincinnati).

Englehardt, J., and Nagle, D. (2011). "Variations on a Theme: Dual-Processual Theory and the Foreign Impact on Mycenaean and Classic Maya Architecture". American Journal of Archaeology 115.3:355-382.

Evans, A. (1900-1901). "The Palace of Knossos". The Annual of the British School at Athens. 7:1-120.

Evans, A. (1921). The Palace of Minos at Knossos. Vol. I. (London: MacMillain and co. Ltd.).

Evans, A. (1928). The Palace of Minos at Knossos. Vol. II. (London: MacMillain and co. Ltd.).

Evans, A. (1930). The Palace of Minos at Knossos. Vol. III. (London: MacMillain and co. Ltd.).

Fotou, V. (1997). "Éléments d'analyse architecturale et la question des fonctions de trois bâtiments «villas»: la Royal Villa, le «Mégaron» de Nirou et le "Mégaron» de Sklavkambos". In R. Hägg and N. Marinatos (eds) The Function of the Minoan Palaces: Proceedings of the Fourth International Symposium at the Swedish Institute in Athens, 10-16 June, 1984. (Stockholm: Paul Aströms Förlag), pp. 33-50.

Gercke, P., and Hiesel, G. (1971). "Grabungen in der Unterstadt von Tiryns von 1889 bis 1929". Tiryns: Forschungen und Berichte 5:1-23.

Graham, J. (1959). "The Residential Quarter of the Minoan Palace". American Journal of Archaeology 63.1:47-52.

Graham, J. (1962). The Palaces of Crete. (Princeton: Princeton University Press). 
Guarducci, M. (1937) "La 'eschara' del tempio Greco arcaico". Studi e Materiali de Storia delle Religioni 13:159-65.

Hacıgüzeller, P., and Thaler, U. (2014). "Three tales of two cities? A comparative analysis of topological, visual and metric properties of archaeological space in Malia and Pylos". In Paliou, E; Lieberwirth, U. and Polla, S (eds) Spatial Analysis and Social Spaces. Topoi Berlin Studies of the Ancient World Vol. 18:203-262.

Hallager, E., and Tzedakis, Y. (1984). "The Greek-Swedish Excavations at Kastelli, Khania 1982-83)".

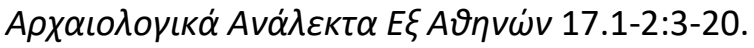

Hallager, E., and Tzedakis, Y. (1985). "The Greek-Swedish Excavations at Kastelli, Khania 1984)".

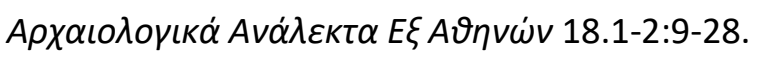

Hatzaki, E. (2005). Knossos: The Little Palace. (British School at Athens Supplementary Volume 38).

Hazzidakis, J. (1934). Les Villas Minoennes de Tylissos. Chapouthier, F. and Joly, R. (trans.). (Paris: Geuthner).

Hellenic National Meteorological Service. (n.d.) The Climatology of Greece. Retrieved February 27, 2017 from http://www.hnms.gr/hnms/english/climatology/climatology_html

Hillier, B., and J. Hanson. (1984). The Social Logic of Space. (Cambridge: Cambridge University Press).

Hitchcock, L. (1994). "The Minoan Hall System: Writing the Present out of the Past". In M. Locock (ed.), Meaningful Architecture: Social Interpretations of Buildings (Aldershot, Hampshire: Avebury), pp. 14-43.

Hitchcock, L. (2000). Minoan Architecture: A Contextual Analysis. (Jonsered: Paul Åströms Förlag).

lakovidis, S. (2001). Gla and the Kopais in the $13^{\text {th }}$ Century B.C. (Athens: Archaeological Society of Athens).

Knox, M. O. (1973). "Megarons and MEГAPA: Homer and Archaeology". The Classical Quarterly 23:121.

LaFayette, S. L. (2011). The Destruction and Afterlife of the Palace of Nestor at Pylos: The Making of a Forgotten Landmark (diss. University of Cincinnati).

Letesson, Q. (2009). Du phénotype au génotype: Analyse de la syntaxe spatiale en architecture minoenne (MMIIIB-MRIB). Aegis 2. (Louvain-la-Neuve: Presses Universitaires de Louvain).

Letesson, Q. (2013). "Minoan Halls: A Syntactical Genealogy". American Journal of Archaeology 117.3:303-351.

Letesson, Q. (2014). "Fire and the Holes: an Investigation of Low-Level Meanings in the Minoan Built Environment". Journal of Archaeological Method and Theory 22.3:713-750.

Lloyd, J. (1998). "The Minoan hall system and the problem of an entrance to the South House at Knossos". Opuscula Atheniensia 22-23:117-140. 
Lloyd, J. (1999). "The Three-Dimensional Form of the Light Area of the Minoan Hall System and the Southeast Corner of the South House at Knossos". Opuscula Atheniensia 24:51-77.

Lloyd, J. (2011). "The South House at Knossos: More than a House?" In ITEГA: The Archaeology of Houses and Households in Ancient Crete. Hesperia Supplements 44:163-175.

Mackenzie, D. (1898/1899). "Excavations in Melos, 1899, A. The Season's Work". The Annual of the British School at Athens 5:3-10.

Maeir, A., and Hitchcock, L. (2011). "Absence Makes the Hearth Grow Fonder: Searching for the Origins of the Philistine Hearth". Eretz-Israel 30:46-64.

Marinatos, N., and R. Hägg. (1986). "On the Ceremonial Function of the Minoan Polythyron." Opuscula Atheniensia 16:57-73.

McEnroe, J. (2010). Architecture of Minoan Crete. (Austin: University of Texas Press).

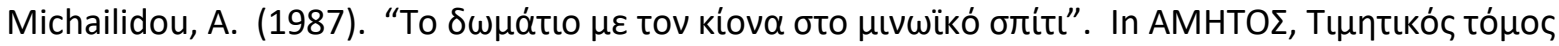

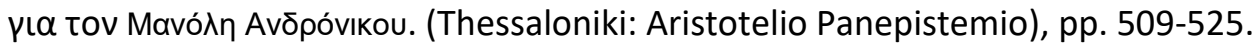

Moody, J. (2005). "Unravelling the threads: climate changes in the Late Bronze III Aegean". In A. L. D'Agata, J. Moody, and E. Williams (eds.), Ariadne's Threads: Connections between Crete and the Greek Mainland in Late Minoan III (LM IIIA2 to LM IIIC) (Athens 2005), pp. 443-71.

Moody, J. (2009). "Changes in vernacular architecture and climate at the end of the Aegean Bronze Age". In Bachhuber, C and Roberts, R. (eds) Forces of Transformation: The End of the Bronze Age in the Mediterranean. (Oxford: Oxbow Books), pp. 6-20.

Muhly, P. (1984). "Minoan hearths". American Journal of Archaeology 88.2:107-122.

Mylonas, G. (1983). Mycenae Rich in Gold. (Athens: Ekdotike Athenon).

Nelson, M. C. (2001). The Architecture of Epano Englianos, Greece (diss. University of Toronto).

Noble, A. (2007). Traditional Buildings: A Global Survey of Structural Forms and Cultural Functions. (London \& New York: I. B. Tauris \& Co Ltd).

Otswald, M. (2011). "The Mathematics of Spatial Configuration: Revisiting, Revising and Critiquing Justified Plan Graph Theory". Nexus Network Journal 13.2:445-470.

Palyvou, C. (1997). "Circulatory Patterns in Minoan Architecture." In R. Hägg and N. Marinatos (eds) The Function of the Minoan Palaces: Proceedings of the Fourth International Symposium at the Swedish Institute in Athens, 10-16 June, 1984. (Stockholm: Paul Aströms Förlag), pp. 195-203.

Palyvou, C. (2002). "Central Courts: The Supremacy of the Void." In J. Driessen, I. Schoep, and R. Laffineur (eds) Monuments of Minos: Rethinking the Minoan Palaces. Proceedings of the International Workshop "Crete of the Hundred Palaces?" Held at the Université Catholique de Louvain, Louvain-la-Neuve, 14-15 December 2001. (Liège and Austin: University of Texas at Austin), pp. 167-78.

Palyvou, C. (2004). "Outdoor space in Minoan architecture: community and privacy". British School at Athens Studies 12:207-217. 
Palyvou, C. (2009). "The Comparative Analysis of Spatial Organization as a tool for Understanding Aegean Bronze Age Architecture: Minoan and Mycenaean". In Proceedings of the Symposium 'Bronze Age Architectural Transitions in the Eastern Mediterranean: Diffusion and Diversity', 07. 08. 05. 2008 in Munich. (Weilheim: Verein zur Förderung der Aufarbeitung der Hellenischen Geschichte e.V.), pp.115-124.

Pantou, P. (2010). Mycenaean Society Outside the Palaces: A Study of Late Helladic IIB-IIIB1 Corridor Buildings. (Diss. University at Buffalo).

Pernier, L. (1951). II Palazzo Minoico di Festòs: I/ secondo palazzo. (Rome: Libreria dello Stato).

Platon, L. (1997). "The Minoan "Villa" in Eastern Crete: Riza, Akhladia, and Prophetes Elias, Prassos: Two Different Specimens of One Category?". ." In R. Hägg and N. Marinatos (eds) The Function of the Minoan Palaces: Proceedings of the Fourth International Symposium at the Swedish Institute in Athens, 10-16 June, 1984. (Stockholm: Paul Aströms Förlag), pp. 187-202.

Platon, N. (1971). Zakros: The Discovery of a Lost Palace of Ancient Crete. (New York: Charles Scribner's Sons).

Preziosi, D. (1983). Minoan Architectural Design: Formation and Signification. (Berlin: Mouton).

Renfrew, C. (2007). Excavations at Phylakopi in Melos 1974-77. (London: The British School at Athens).

Rethemiotakis, G. (1999). "The Hearths of the Minoan Palace at Galatas". In Betancourt, P., Karageorghis, V., Laffineur, R., and Niemeier, W. (eds) Melemata: Studies in Aegean Archaeology Presented to Malcolm H. Wiener as He Enters his 65th Year. (Liège: Université de Liège), pp. 721728.

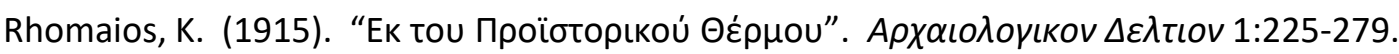

Romanou, D. (2007). "Residence design and variation in residential group structure: a case study, Mallia". British School at Athens Studies 15:77-90.

Schliemann, H. (1885). Tiryns: The Prehistoric Palace of the Kings of Tiryns. The Results of the Latest Excavations. (New York: Charles Scribner's Sons).

Shelton, K. (2010). "Mainland Greece". In Cline, E. (ed) The Oxford Handbook of the Bronze Age Aegean. (Oxford: Oxford University Press).

Soles, J. (1991). "The Gournia Palace". American Journal of Archaeology 95.1:17-78.

Soles, J., and Davaras, C. (1996). "Excavations at Mochlos, 1992-1993". Hesperia 65.2:175-230.

Thaler, U. (2005). "Narrative and Syntax: New Perspectives on the Late Bronze Age Palace of Pylos, Greece". In Space Syntax. 5th International Symposium, pp 323-339.

Thaler, U. (2015). "Movement in between, into and inside Mycenaean palatial megara". In Schallin, A-L., and Tournavitou, I. (eds) Mycenaeans Up to Date: The Archaeology of the NE Peloponnese Current Concepts and New Directions. (Athens: Swedish School) pp. 339-360.

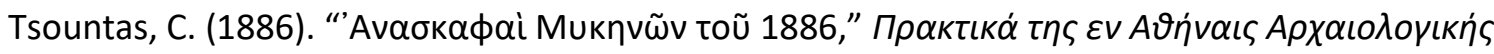

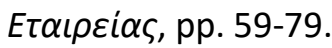


Valmin, M. (1938). The Swedish Messenia Expedition. (Lund: C. W. K. Gleerup).

Wace, A. (1949). Mycenae: An Archaeological History and Guide. (Princeton: Princeton University Press).

Wace, A. J. B., Heurtley, W. A., Lamb, W., Holland, L. B., and Boethius, C. A. (1921-1923). "The Report of the School Excavations at Mycenae, 1920-1923," Annual of the British School at Athens 25:1-434.

Walberg, G. (2007). Midea: The Megaron Complex and Shrine Area. Excavations on the Lower Terraces 1994-1997 (Philadelphia: INSTAP Academic Press).

Werner, K. (1993). "The Megaron during the Aegean and Anatolian Bronze Age: A study of occurrence, shape, architectural adaption, and function". Studies in Mediterranean Archaeology Supplementary Volume 108.

Wright, J. C. (1994). "The Spatial Configuration of Belief: The Archaeology of Mycenaean Religion," in Alcock, S., and R. Osbourne, R. (eds) Placing the Gods: Sanctuaries and Sacred Space in Ancient Greece. (Oxford: Clarendon Press) pp. 37-78. 


\section{Appendix 1: Space Syntax Analysis of Mycenaean Megaron-units}

The tables and figures that follow provide details of the Space Syntax Analysis of 12 Mycenaean buildings. A justified graph is included for each building, and the table details the cell type (CT), Total Depth (TD), Mean Depth (MD), and Real Relative Asymmetry (RRA) or Relative Asymmetry (RA) figures for each space in the building. Spaces in the megaron-unit are shaded in grey. For a detailed explanation of Space Syntax Analysis, see Chapter 2.2. For an overview of these findings, see Table 7.

Table 1.1: Phylakopi, Megaron

\begin{tabular}{l|lrrr} 
& CT & TD & MD & RRA \\
\hline Outside & & 15 & 1.875 & 0.789 \\
2 & c & 14 & 1.75 & 0.676 \\
14 & $\mathrm{c}$ & 20 & 2.5 & 1.352 \\
13 & $\mathrm{~b}$ & 20 & 2.5 & 1.352 \\
\hline 12 & $\mathrm{~b}$ & 17 & 2.125 & 1.013 \\
3 & $\mathrm{c}$ & 19 & 2.375 & 1.239 \\
1 & $\mathrm{a}$ & 27 & 3.375 & 2.141 \\
15 & $\mathrm{a}$ & 24 & 3 & 1.803 \\
7 & $\mathrm{a}$ & 24 & 3 & 1.803 \\
\hline Average & & & 2.5 & 1.352
\end{tabular}

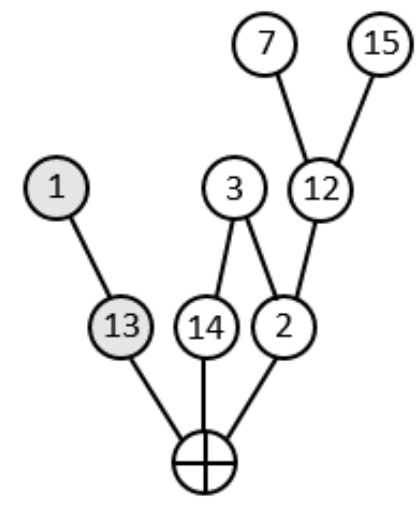

Figure 1.1: Justified Graph of the Megaron at Phylakopi

Table 1.2: Mansion 1, Menelaion

\begin{tabular}{|c|c|c|c|c|}
\hline & CT & & TD MD & RRA \\
\hline Outside & & 24 & 1.846 & 0.528 \\
\hline 9 & c & 32 & 2.462 & 0.912 \\
\hline 10 & c & 22 & 1.692 & 0.432 \\
\hline 4 & a & 36 & 2.769 & 1.104 \\
\hline 5 & $b$ & 32 & 2.462 & 0.912 \\
\hline 8 & c & 30 & 2.308 & 0.816 \\
\hline 15 & $a$ & 34 & 2.615 & 1.008 \\
\hline 14 & $a$ & 34 & 2.615 & 1.008 \\
\hline 13 & a & 34 & 2.615 & 1.008 \\
\hline 12 & a & 34 & 2.615 & 1.008 \\
\hline 11 & a & 34 & 2.615 & 1.008 \\
\hline 2 & $b$ & 42 & 3.231 & 1.392 \\
\hline 7 & $a$ & 42 & 3.231 & 1.392 \\
\hline 1 & $a$ & 54 & 4.154 & 1.969 \\
\hline Average & & & 2.659 & 1.036 \\
\hline
\end{tabular}

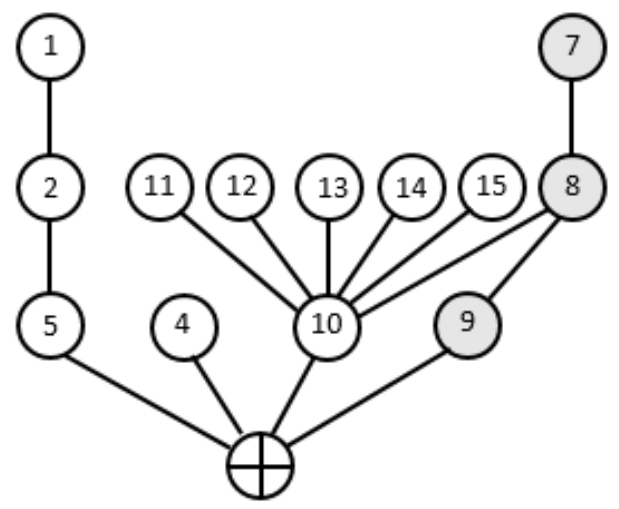

Figure 1.2: Justified Graph of Mansion 1, Menelaion 
Table 1.3: House He, Gournia

\begin{tabular}{l|lrrr} 
& CT & TD & MD & RRA \\
\hline Outside & & 22 & 2.75 & 1.577 \\
31 & $\mathrm{~b}$ & 15 & 1.875 & 0.789 \\
33 & $\mathrm{~b}$ & 12 & 1.5 & 0.451 \\
32 & $\mathrm{a}$ & 22 & 2.75 & 1.577 \\
35 & $\mathrm{~b}$ & 17 & 2.125 & 1.014 \\
37 & $\mathrm{~b}$ & 17 & 2.125 & 1.014 \\
38 & $\mathrm{a}$ & 19 & 2.375 & 1.239 \\
34 & $\mathrm{a}$ & 24 & 3 & 1.803 \\
36 & $\mathrm{a}$ & 24 & 3 & 1.803 \\
\hline Average & & & 2.389 & 1.252
\end{tabular}

Table 1.4: Megaron A, Dimini

\begin{tabular}{l|rrrr} 
& CT & TD & MD & RRA \\
\hline Outside & & 43 & 2.867 & 1.062 \\
2 & c & 29 & 1.933 & 0.531 \\
7 & d & 28 & 1.867 & 0.493 \\
C & d & 21 & 1.4 & 0.228 \\
1 & $\mathrm{a}$ & 43 & 2.867 & 1.062 \\
10 & $\mathrm{a}$ & 42 & 2.8 & 1.024 \\
6 & $\mathrm{c}$ & 31 & 2.067 & 0.607 \\
13 & $\mathrm{a}$ & 35 & 2.333 & 0.759 \\
17 & $\mathrm{a}$ & 35 & 2.333 & 0.759 \\
18 & $\mathrm{a}$ & 35 & 2.333 & 0.759 \\
9 & $\mathrm{~b}$ & 33 & 2.2 & 0.683 \\
5 & $\mathrm{a}$ & 35 & 2.333 & 0.759 \\
3 & $\mathrm{~b}$ & 33 & 2.200 & 0.683 \\
4 & $\mathrm{a}$ & 47 & 3.133 & 1.214 \\
8 & $\mathrm{a}$ & 45 & 3 & 1.138 \\
19 & $\mathrm{a}$ & 47 & 3.133 & 1.214 \\
\hline Average & & & 2.425 & 0.811
\end{tabular}

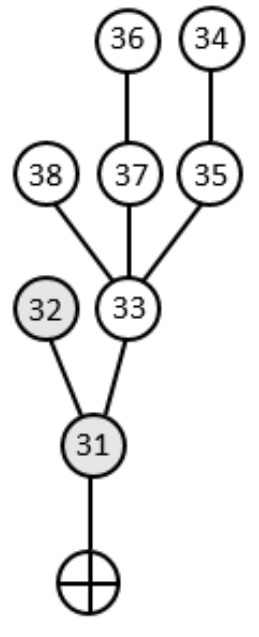

Figure 1.3: Justified Graph of House He, Gournia

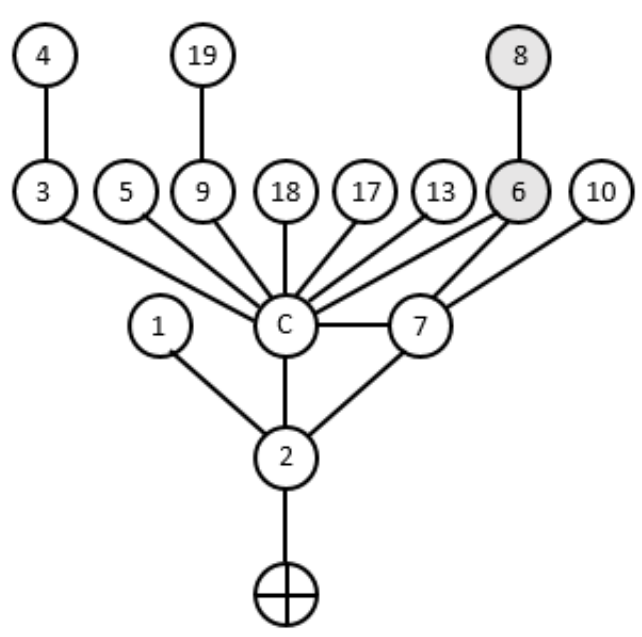

Figure 1.4: Justified Graph of Megaron A, Dimini 
Table 1.5: Megaron B, Dimini

\begin{tabular}{l|rrrr} 
& CT & TD & MD & RRA \\
\hline Outside & & 15 & 2.5 & 1.765 \\
3 & $\mathrm{~b}$ & 10 & 1.667 & 0.784 \\
$\mathrm{C}$ & $\mathrm{b}$ & 9 & 1.5 & 0.588 \\
2 & $\mathrm{a}$ & 15 & 2.5 & 1.765 \\
6 & $\mathrm{a}$ & 14 & 2.333 & 1.569 \\
5 & $\mathrm{~b}$ & 12 & 2 & 1.176 \\
4 & $\mathrm{a}$ & 17 & 2.833 & 2.157 \\
\hline Average & & & 2.19 & 1.401
\end{tabular}

Table 1.6: House of the Sphinxes, Mycenae

\begin{tabular}{l|rrrr} 
& CT & TD & MD & RRA \\
\hline Outside & & 12 & 1.714 & 0.726 \\
C & b & 8 & 1.143 & 0.145 \\
3 & $\mathrm{a}$ & 18 & 2.571 & 1.597 \\
1 & $\mathrm{a}$ & 14 & 2 & 1.016 \\
2 & $\mathrm{a}$ & 14 & 2 & 1.016 \\
4 & $\mathrm{a}$ & 14 & 2 & 1.016 \\
6 & $\mathrm{a}$ & 14 & 2 & 1.016 \\
8 & $\mathrm{a}$ & 14 & 2 & 1.016 \\
\hline Average & & & 1.929 & 0.944
\end{tabular}

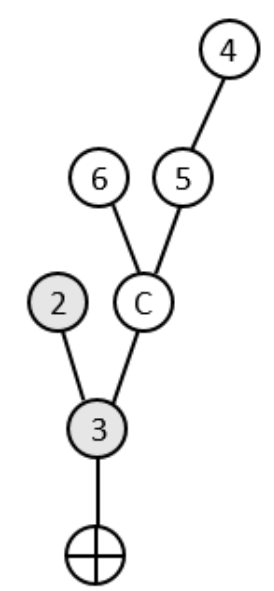

Figure 1.5: Justified Graph of Megaron B, Dimini

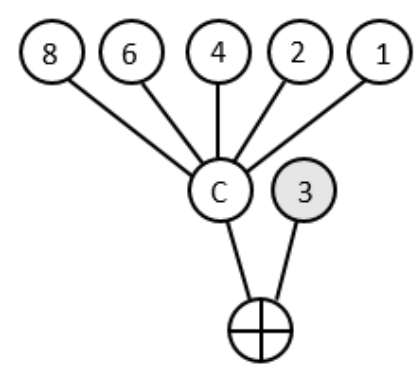

Figure 1.6: Justified Graph of the House of the Sphinxes, Mycenae 
Table 1.7: West House, Mycenae

\begin{tabular}{l|lrrr} 
& CT & TD & MD & RRA \\
\hline Outside & & 24 & 2.4 & 1.055 \\
C & $\mathrm{b}$ & 15 & 1.5 & 0.377 \\
M1 & $\mathrm{b}$ & 20 & 2 & 0.753 \\
6 & $\mathrm{a}$ & 24 & 2.4 & 1.055 \\
5 & $\mathrm{a}$ & 24 & 2.4 & 1.055 \\
4 & $\mathrm{a}$ & 24 & 2.4 & 1.055 \\
2 & $\mathrm{~b}$ & 20 & 2 & 0.753 \\
3 & $\mathrm{a}$ & 29 & 2.9 & 1.431 \\
1 & $\mathrm{a}$ & 29 & 2.9 & 1.431 \\
M2 & $\mathrm{b}$ & 27 & 2.7 & 1.281 \\
M3 & $\mathrm{a}$ & 36 & 3.6 & 1.959 \\
\hline Average & & & 2.473 & 1.109
\end{tabular}

Table 1.8: Megaron A, Thermos

\begin{tabular}{l|rrrr} 
& CT & TD & MD & RA \\
\hline Outside & & 6 & 2 & 1 \\
1 & $\mathrm{~b}$ & 4 & 1.333 & 0.333 \\
2 & $\mathrm{~b}$ & 4 & 1.333 & 0.333 \\
3 & $\mathrm{a}$ & 6 & 2 & 1 \\
\hline Average & & & 1.667 & 0.667
\end{tabular}

Table 1.9: House L, Korakou

\begin{tabular}{l|lrrr} 
& CT & TD & MD & RA \\
\hline Outside & & 10 & 2.5 & 1 \\
Porch & $\mathrm{b}$ & 7 & 1.75 & 0.5 \\
Vestibule & $\mathrm{b}$ & 6 & 1.5 & 0.333 \\
Hall & $\mathrm{b}$ & 7 & 1.75 & 0.5 \\
Back Room & $\mathrm{a}$ & 10 & 2.5 & 1 \\
\hline \multicolumn{1}{c}{ Average } & & & 2 & 0.667
\end{tabular}

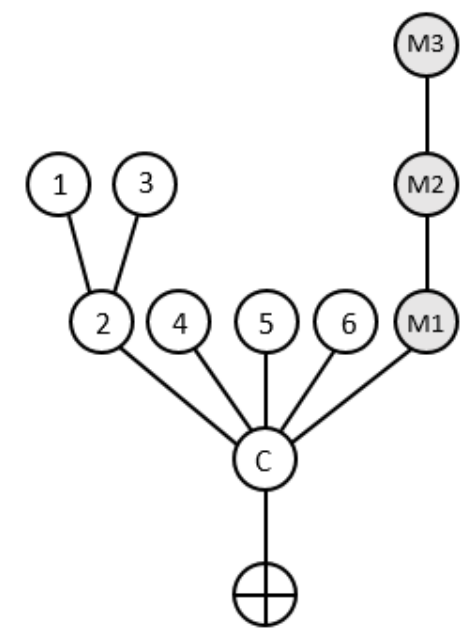

Figure 1.7: Justified Graph of the West House, Mycenae

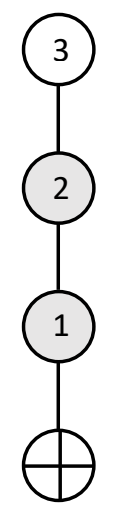

Figure 1.6: Justified Graph of Megaron A, Thermos

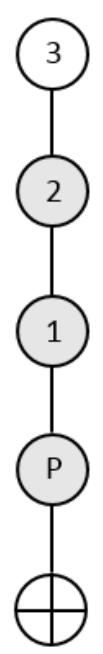

Figure 1.6: Justified Graph of House L, Korakou 
Table 1.10: Gla

\begin{tabular}{|c|c|c|c|c|c|c|c|c|c|}
\hline & CT & TD & $\mathrm{MD}$ & RRA & & CT & TD & $M D$ & RRA \\
\hline Outside & & 185 & 4.744 & 1.288 & N4 & $d$ & 162 & 4.154 & 1.085 \\
\hline 1 & $d$ & 181 & 4.641 & 1.253 & P1 & $b$ & 223 & 5.718 & 1.623 \\
\hline 01 & $d$ & 171 & 4.385 & 1.164 & 20 & $b$ & 225 & 5.769 & 1.641 \\
\hline 2 & c & 197 & 5.051 & 1.394 & 22 & a & 241 & 6.179 & 1.782 \\
\hline 1 & $d$ & 179 & 4.59 & 1.235 & 6 & $a$ & 241 & 6.179 & 1.782 \\
\hline 02 & c & 149 & 3.821 & 0.97 & $M$ & $a$ & 237 & 6.077 & 1.746 \\
\hline 24 & c & 207 & 5.308 & 1.482 & 4 & $b$ & 235 & 6.026 & 1.729 \\
\hline $\mathrm{T}$ & c & 207 & 5.308 & 1.482 & 10 & c & 180 & 4.615 & 1.244 \\
\hline 3 & a & 235 & 6.026 & 1.729 & N5 & c & 191 & 4.897 & 1.341 \\
\hline K1 & $d$ & 157 & 4.026 & 1.041 & 15 & a & 261 & 6.692 & 1.958 \\
\hline 14 & c & 147 & 3.769 & 0.953 & 16 & $b$ & 259 & 6.641 & 1.94 \\
\hline 13 & $b$ & 167 & 4.282 & 1.129 & 18 & b & 261 & 6.692 & 1.958 \\
\hline 23 & c & 243 & 6.231 & 1.799 & 5 & $a$ & 273 & 7 & 2.064 \\
\hline N2 & c & 167 & 4.282 & 1.129 & 8 & $b$ & 216 & 5.538 & 1.561 \\
\hline $\mathrm{K} 2$ & $d$ & 143 & 3.667 & 0.917 & 11 & c & 211 & 5.410 & 1.517 \\
\hline P2 & $b$ & 191 & 4.897 & 1.341 & 17 & $a$ & 297 & 7.615 & 2.276 \\
\hline 21 & $b$ & 203 & 5.205 & 1.447 & 19 & $a$ & 299 & 7.667 & 2.293 \\
\hline 7 & b & 203 & 5.205 & 1.447 & 9 & $a$ & 254 & 6.513 & 1.896 \\
\hline N1 & $b$ & 199 & 5.103 & 1.411 & 12 & a & 249 & 6.385 & 1.852 \\
\hline \multirow[t]{2}{*}{ N3 } & $d$ & 153 & 3.923 & 1.006 & 13 & $\mathrm{a}$ & 249 & 6.385 & 1.852 \\
\hline & & & & & Average & & & & 1.519 \\
\hline
\end{tabular}

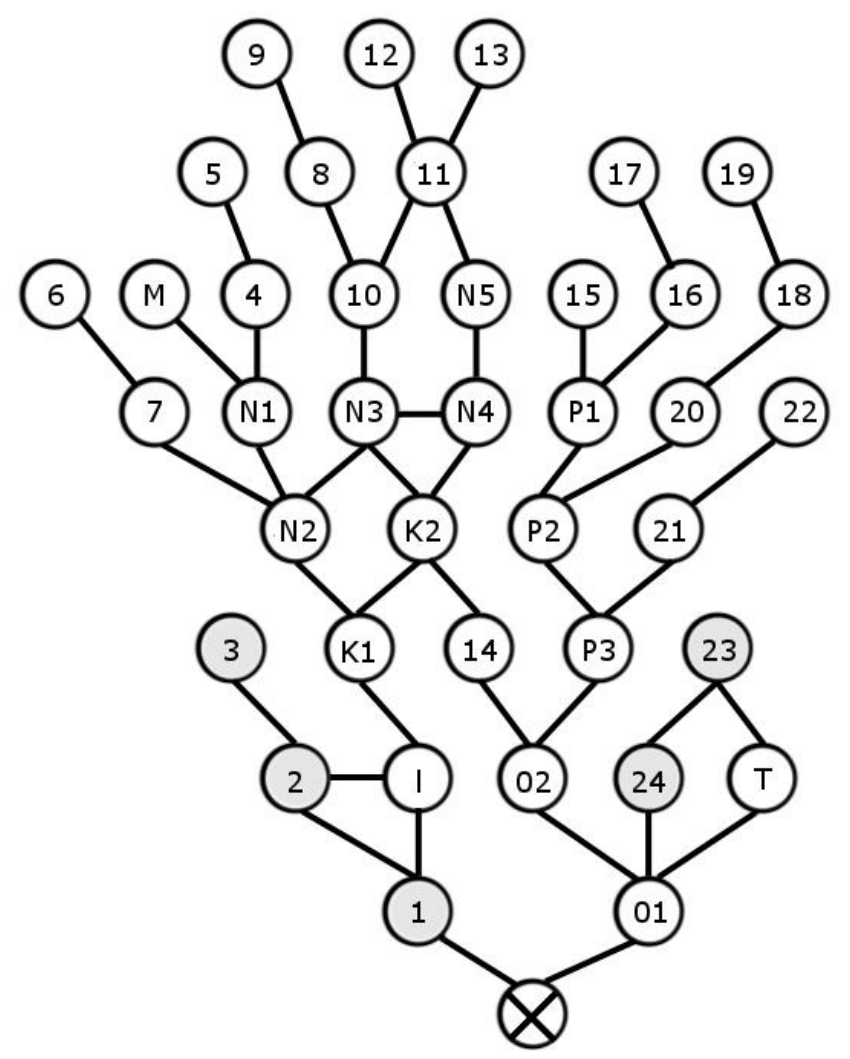

Figure 1.10: Justified Graph of the Residence at Gla 
Table 1.11: Tiryns

\begin{tabular}{|c|c|c|c|c|}
\hline & $\mathrm{CT}$ & TD & MD & RRA \\
\hline Outside & & 406 & 6.881 & 1.704 \\
\hline $1 a$ & $b$ & 348 & 5.898 & 1.419 \\
\hline $1 b$ & c & 292 & 4.949 & 1.144 \\
\hline 2 & $d$ & 293 & 4.966 & 1.149 \\
\hline 36 & c & 293 & 4.966 & 1.149 \\
\hline $3 a$ & c & 309 & 5.237 & 1.228 \\
\hline$A$ & a & 351 & 5.949 & 1.434 \\
\hline B & $a$ & 351 & 5.949 & 1.434 \\
\hline C & $d$ & 301 & 5.102 & 1.189 \\
\hline 31 & c & 290 & 4.915 & 1.135 \\
\hline $38 a$ & $b$ & 347 & 5.881 & 1.414 \\
\hline $3 b$ & $d$ & 311 & 5.271 & 1.238 \\
\hline 35 & $d$ & 307 & 5.203 & 1.218 \\
\hline 34 & $d$ & 307 & 5.203 & 1.218 \\
\hline 37 & c & 359 & 6.085 & 1.473 \\
\hline 32 & a & 348 & 5.898 & 1.419 \\
\hline 30 & $d$ & 278 & 4.712 & 1.076 \\
\hline 38 & $b$ & 403 & 6.831 & 1.69 \\
\hline 4 & $d$ & 305 & 5.169 & 1.208 \\
\hline 33 & $b$ & 363 & 6.153 & 1.493 \\
\hline $30 a$ & $a$ & 336 & 5.695 & 1.36 \\
\hline 16 & $d$ & 276 & 4.678 & 1.066 \\
\hline 28 & c & 299 & 5.068 & 1.179 \\
\hline $29 b$ & $b$ & 332 & 5.627 & 1.341 \\
\hline 39 & a & 461 & 7.814 & 1.974 \\
\hline 9 & $d$ & 294 & 4.983 & 1.154 \\
\hline 5 & c & 359 & 6.085 & 1.473 \\
\hline $33 a$ & a & 421 & 7.136 & 1.778 \\
\hline 19 & $d$ & 277 & 4.695 & 1.071 \\
\hline 17 & c & 306 & 5.186 & 1.213 \\
\hline $25 a$ & $b$ & 355 & 6.017 & 1.454 \\
\hline 26 & a & 357 & 6.051 & 1.464 \\
\hline $27 a$ & $b$ & 355 & 6.017 & 1.454 \\
\hline $29 a$ & $b$ & 388 & 6.576 & 1.616 \\
\hline 12 & c & 284 & 4.814 & 1.105 \\
\hline 8 & a & 352 & 5.966 & 1.439 \\
\hline 6 & c & 348 & 5.898 & 1.419 \\
\hline 15 & c & 284 & 4.814 & 1.105 \\
\hline 20 & $a$ & 335 & 5.678 & 1.356 \\
\hline 21 & $b$ & 329 & 5.576 & 1.326 \\
\hline 18 & $a$ & 364 & 6.169 & 1.498 \\
\hline $25 b$ & a & 413 & 7 & 1.739 \\
\hline $27 b$ & a & 413 & 7 & 1.739 \\
\hline 29 & a & 446 & 7.559 & 1.901 \\
\hline
\end{tabular}

\begin{tabular}{l|lrrr} 
& CT & TD & MD & RRA \\
\hline $12 \mathrm{c}$ & $\mathrm{b}$ & 338 & 5.729 & 1.37 \\
$11 \mathrm{a}$ & $\mathrm{b}$ & 340 & 5.763 & 1.38 \\
$13 \mathrm{~b}$ & $\mathrm{~b}$ & 340 & 5.763 & 1.38 \\
$13 \mathrm{a}$ & $\mathrm{a}$ & 342 & 5.797 & 1.39 \\
14 & $\mathrm{c}$ & 286 & 4.847 & 1.115 \\
7 & $\mathrm{a}$ & 406 & 6.881 & 1.704 \\
$14 \mathrm{~b}$ & $\mathrm{c}$ & 287 & 4.864 & 1.12 \\
22 & $\mathrm{a}$ & 387 & 6.559 & 1.611 \\
23 & $\mathrm{~b}$ & 385 & 6.525 & 1.601 \\
$12 \mathrm{~b}$ & $\mathrm{~b}$ & 394 & 6.678 & 1.645 \\
$11 \mathrm{~b}$ & $\mathrm{a}$ & 398 & 6.746 & 1.665 \\
13 & $\mathrm{a}$ & 398 & 6.746 & 1.665 \\
$10 \mathrm{~b}$ & $\mathrm{~b}$ & 342 & 5.797 & 1.39 \\
24 & $\mathrm{a}$ & 443 & 7.508 & 1.886 \\
$12 \mathrm{a}$ & $\mathrm{a}$ & 452 & 7.661 & 1.93 \\
$10 \mathrm{a}$ & $\mathrm{a}$ & 400 & 6.780 & 1.675 \\
\hline Average & & & & 1.42
\end{tabular}




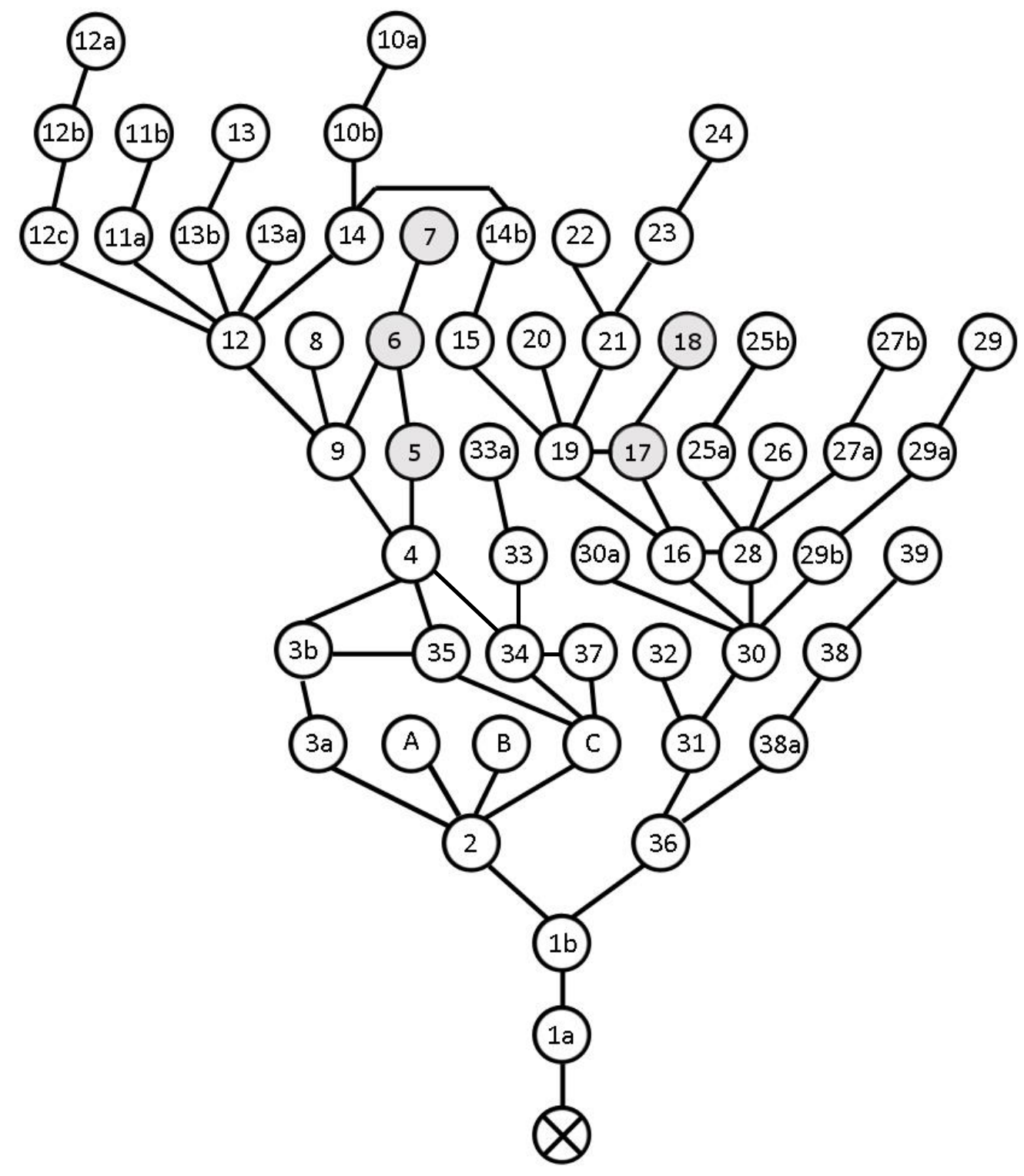

Figure 1.11: Justified Graph of the Upper Citadel at Tiryns 
Table 1.12: Pylos

\begin{tabular}{|c|c|c|c|c|c|c|c|c|c|}
\hline & CT & TD & $M D$ & RRA & & CT & TD & $\mathrm{MD}$ & RRA \\
\hline Outside & & 403 & 6.5 & 1.568 & 18 & $d$ & 359 & 5.79 & 1.366 \\
\hline 58 & c & 432 & 6.968 & 1.701 & 17 & $a$ & 379 & 6.113 & 1.458 \\
\hline 1 & c & 352 & 5.677 & 1.334 & 25 & c & 322 & 5.194 & 1.196 \\
\hline 57 & $a$ & 464 & 7.484 & 1.849 & 29 & $b$ & 332 & 5.355 & 1.242 \\
\hline 59 & c & 427 & 6.887 & 1.678 & 40 & a & 419 & 6.758 & 1.642 \\
\hline 7 & $b$ & 411 & 6.629 & 1.605 & 42 & $a$ & 419 & 6.758 & 1.642 \\
\hline 2 & c & 305 & 4.919 & 1.117 & 53 & a & 469 & 7.565 & 1.872 \\
\hline 61 & c & 380 & 6.129 & 1.462 & 49 & $b$ & 461 & 7.435 & 1.835 \\
\hline 8 & $a$ & 472 & 7.613 & 1.885 & 20 & c & 415 & 6.694 & 1.623 \\
\hline 3 & $d$ & 258 & 4.161 & 0.901 & 22 & $d$ & 393 & 6.339 & 1.522 \\
\hline 63 & c & 333 & 5.371 & 1.246 & 24 & c & 365 & 5.887 & 1.393 \\
\hline 11 & c & 283 & 4.565 & 1.016 & 26 & $b$ & 381 & 6.145 & 1.467 \\
\hline 4 & c & 265 & 4.274 & 0.933 & 30 & a & 393 & 6.339 & 1.522 \\
\hline 44 & c & 253 & 4.081 & 0.878 & 31 & $b$ & 391 & 6.306 & 1.513 \\
\hline 12 & $d$ & 282 & 4.548 & 1.012 & 33 & $b$ & 391 & 6.306 & 1.513 \\
\hline 10 & $b$ & 342 & 5.516 & 1.288 & 50 & a & 522 & 8.419 & 2.115 \\
\hline 5 & $d$ & 252 & 4.065 & 0.874 & 19 & a & 476 & 7.677 & 1.904 \\
\hline 37 & c & 248 & 4 & 0.855 & 88 & c & 461 & 7.435 & 1.835 \\
\hline 54 & $b$ & 310 & 5 & 1.14 & 21 & c & 450 & 7.258 & 1.784 \\
\hline 45 & c & 298 & 4.806 & 1.085 & 23 & c & 388 & 6.258 & 1.499 \\
\hline 13 & $d$ & 275 & 4.435 & 0.979 & 27 & $a$ & 442 & 7.129 & 1.747 \\
\hline 9 & a & 403 & 6.5 & 1.568 & 32 & a & 452 & 7.29 & 1.793 \\
\hline 6 & a & 313 & 5.048 & 1.154 & 34 & $a$ & 452 & 7.29 & 1.793 \\
\hline 35 & $d$ & 247 & 3.984 & 0.851 & Average & & & & 1.414 \\
\hline 38 & $b$ & 299 & 4.823 & 1.09 & & & & & \\
\hline 55 & $b$ & 369 & 5.952 & 1.412 & & & & & \\
\hline 51 & c & 349 & 5.629 & 1.32 & & & & & \\
\hline 46 & c & 351 & 5.661 & 1.329 & & & & & \\
\hline 14 & $b$ & 334 & 5.387 & 1.251 & & & & & \\
\hline 16 & c & 318 & 5.129 & 1.177 & & & & & \\
\hline 28 & c & 281 & 4.532 & 1.007 & & & & & \\
\hline 36 & a & 308 & 4.968 & 1.131 & & & & & \\
\hline 39 & $b$ & 358 & 5.774 & 1.361 & & & & & \\
\hline 41 & $b$ & 358 & 5.774 & 1.361 & & & & & \\
\hline 43 & a & 360 & 5.806 & 1.37 & & & & & \\
\hline 56 & a & 430 & 6.935 & 1.692 & & & & & \\
\hline 52 & $b$ & 408 & 6.581 & 1.591 & & & & & \\
\hline 48 & c & 402 & 6.484 & 1.563 & & & & & \\
\hline 47 & a & 412 & 6.645 & 1.609 & & & & & \\
\hline 15 & a & 395 & 6.371 & 1.531 & & & & & \\
\hline
\end{tabular}




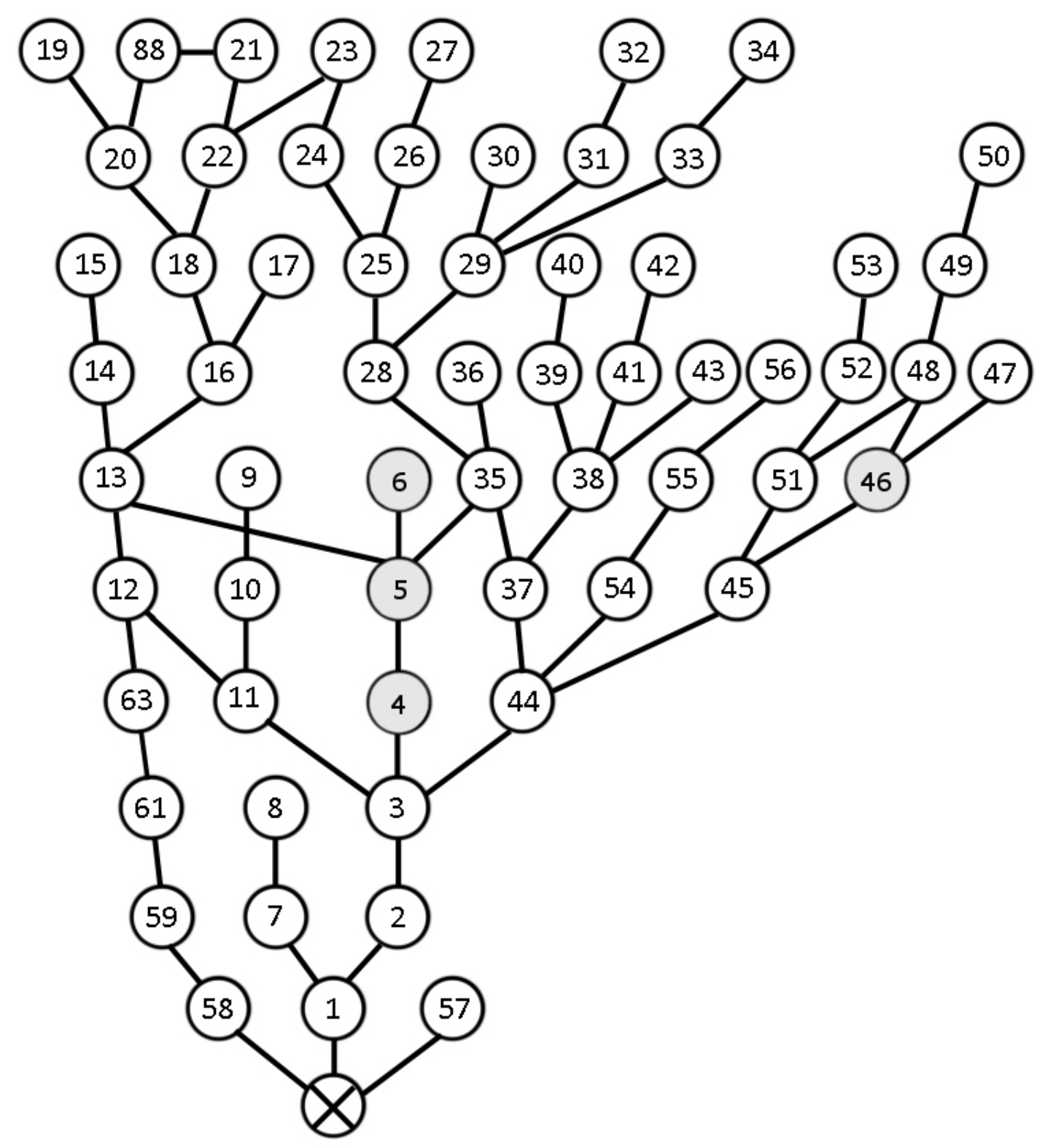

Figure 1.11: Justified Graph of the Main Building at Pylos 


\section{Tables}

Table 1: Minoan Hall Systems (studied by Letesson) $)^{176}$

\begin{tabular}{|c|c|c|c|}
\hline & $\begin{array}{l}\text { Rooms } \\
(\mathrm{MH} / \mathrm{VE} / \mathrm{LW})^{177}\end{array}$ & Area $\left(\mathrm{m}^{2}\right)$ & Plan \\
\hline Akhladia, Building A* & $3 / 2 b / 2 a$ & 58.5 & 1 \\
\hline Chania, House 1 & C, light well & 24.5 & 2 \\
\hline Gournia, Building G (Palace) * & $\mathrm{D} / \mathrm{II} / \mathrm{IV}$ & 90 & 3 \\
\hline Knossos, House of the Frescoes* & $\mathrm{H}-3 / \mathrm{F}-2 / \mathrm{G}-1$ & 27 & 4 \\
\hline Knossos, Little Palace & $9 / 8 / 7$ & 159 & 5 \\
\hline Knossos, Royal Villa & $\mathrm{Ca} / \mathrm{Cb} / \mathrm{Cc}$ & 46 & 6 \\
\hline Knossos, South House & $11 \mathrm{a} / \mathrm{b} / \mathrm{c}$ & 30 & 7 \\
\hline Malia, Palace & $1117 \mathrm{a} / \mathrm{b} / \mathrm{c}$ & 68 & 8 \\
\hline Malia, Maison $\Delta \alpha$ & 3 & 34 & 9 \\
\hline Malia, Maison Z $\alpha^{*}$ & 12,12 bis & 27.5 & 10 \\
\hline Malia, Maison Za* & $5 / 7-8$ & 21 & 10 \\
\hline Malia, Maison Z $\beta^{*}$ & VII & 20 & 11 \\
\hline Mochlos, Building B.2* & 2.2 & 33 & 12 \\
\hline Nirou Hani* & 2a/2/exterior & 32 & 13 \\
\hline Palaikastro, Building X1-17* & $4 / 4 / 6$ & 32 & 14 \\
\hline Phaistos, Palace & 63/64/exterior & 36 & 15 \\
\hline Phaistos, Palace & 79/77/78 & 78 & 16 \\
\hline Pseira, Building BC* & $2 / 3$ & 14.5 & 17 \\
\hline Tylissos, Building A & $6 / A-\delta / \Phi$ & 32 & 18 \\
\hline Tylissos, Building C & $15 / 15^{\prime} / 15^{\prime \prime}$ & 28 & 19 \\
\hline Vathypetro, West Building* & $26 / 25 / 24$ & 50 & 20 \\
\hline Zakros, Palace & 37 & 31 & 21 \\
\hline Zakros, Palace* & 36 & 57 & 21 \\
\hline
\end{tabular}

\footnotetext{
${ }^{176}$ Adapted from Letesson 2013:Table 1 (318); Table 2 (336-7). MHS marked with an asterisk are hypothetical. The four MHS which were altered in a later period are underlined.

${ }^{177} \mathrm{MH}=$ Main Hall; $\mathrm{VE}=$ Vestibule; $\mathrm{LW}=$ Light Well. Where possible the three types of room have been distinguished and matched to the provided plans, however due to the way rooms at some sites have been numbered this is not always possible.
} 
Table 2: Other Certain Minoan Hall Systems ${ }^{178}$

$\begin{array}{llll} & \text { Rooms (MH/VE/LW) } & \text { Area }\left(\mathbf{m}^{2}\right) & \text { Plan } \\ \text { Archanes, Villa } & 3 / 2 / 1 & \sim 59 & 22 \\ \text { Galatas, Palace } & 48 b, 54 & \sim 50.4 & 23 \\ \text { Hagia Triada, Villa Reale } & 3 / 12 / 4 \text { \&49 (double MHS) } & \sim 104.2 & 24 \\ \text { Hagia Triada, Villa Reale } & 1 & 34.32^{179} & 24 \\ \text { Hagia Triada, Villa Reale } & 21 / 22 / 22 & 21.12^{180} & 24 \\ \text { Knossos, Southeast House } & \text { K1/F1/F1 } & \sim 20.97 & 25 \\ \text { Knossos, Palace } & \text { Hall of the Double Axes 10/9/8 } & 132^{181} & 26 \\ \text { Knossos, Palace } & \text { Queen's Megaron 18/19/20 } & 69^{182} & 26 \\ \text { Phaistos, Palace } & 50 & \sim 63.3^{183} & 16\end{array}$

\section{Table 3: Other Hypothetical Minoan Hall Systems}

$\begin{array}{ll} & \text { Rooms } \\ \text { Amnissos, Villa of the Lilies } & 1 \\ \text { Hagia Triada, Villa Reale } & 16,46,47 \\ \text { Nirou Hani } & 12-13 \\ \text { Malia, Maison } \Delta \beta & 19 \\ \text { Malia, Maison } \Delta \gamma & 10-11 \\ \text { Malia, Maison Z } \gamma & \mathrm{Xb} \\ \text { Malia, Maison E } \alpha & 1,2,4,5 \\ \text { Malia, Maison de la Façade à Redans } & \mathrm{XVI-XVII} \\ \text { Mochlos, House D } & 9-11 \\ \text { Myrtos Pyrgos, Country House } & 3 \\ \text { Myrtos Pyrgos } & 13-14 \\ \text { Nerokourou, Building 1 } & \text { Building } 1 \\ \text { Palaikastro, Block M } & 3,9 a\end{array}$

\footnotetext{
${ }^{178}$ Adapted from Letesson 2013:Table 1 (318); Lloyd 1998:Table 2 (130), Table 4 (133). Areas marked with are approximate, calculated from scale plans where complete dimensions could not be found elsewhere.

179 Lloyd 1999:Table 4.

180 Lloyd 1999:Table 4.

181 Letesson 2013:Table 2.

182 Letesson 2013:Table 2.

183 Pernier 1951:258.
} 
Table 4: Mycenaean Megaron-Units

\begin{tabular}{|c|c|c|c|c|c|c|}
\hline & \multirow[b]{3}{*}{$\begin{array}{l}\text { Rooms } \\
(\mathrm{P} / \mathrm{V} / \mathrm{H})^{184}\end{array}$} & \multirow{2}{*}{\multicolumn{4}{|c|}{ Area $\left(\mathrm{m}^{2}\right)$}} & \multirow[b]{3}{*}{ Plan } \\
\hline & & & & & & \\
\hline & & Porch & Vestibule & Main Hall & Total & \\
\hline Mycenae $^{185}$ & $55 / 57 / 57$ & 43.7 & 50.6 & 149.04 & 243.34 & 27 \\
\hline Tiryns (main) ${ }^{186}$ & $5 / 6 / 7$ & 48.15 & 45.78 & 115.15 & 209.09 & 28 \\
\hline Pylos $^{187}$ & $4 / 5 / 6$ & 48.91 & 52.75 & 144.48 & 246.15 & 29 \\
\hline Tiryns (secondary) ${ }^{188}$ & $17 /-/ 18$ & 28.23 & - & 42.86 & 71.09 & 28 \\
\hline Gla $(A)^{189}$ & $1 / 2 / 3$ & 48.6 & 31.39 & 76.59 & 156.58 & 30 \\
\hline Gla $(B)^{190}$ & $-/ 23 / 24$ & - & 38.75 & 62.23 & 100.98 & 30 \\
\hline Corridor Buildings & & & & & & \\
\hline Dimini, Megaron $A^{191}$ & $-/ 6 / 8$ & - & 28.09 & 39.22 & 67.31 & 31 \\
\hline Dimini, Megaron $\mathrm{B}^{192}$ & $-/ 2 / 3$ & - & 38.16 & 45.05 & 83.21 & 32 \\
\hline Menelaion, Mansion $1^{193}$ & $9 / 8 / 7$ & 3.99 & 25.08 & 53.24 & 82.31 & 33 \\
\hline Mycenae, West House ${ }^{194}$ & $\mathrm{M} 1 / \mathrm{M} 2 / \mathrm{M} 3$ & $\sim 10.12$ & $\sim 17.08$ & $\sim 19.25$ & $\sim 46.45$ & 34 \\
\hline Phylakopi, Megaron ${ }^{195}$ & $13 /-/ 1$ & 27.6 & - & 53.32 & 80.92 & 35 \\
\hline Gournia, House He $\mathrm{e}^{196}$ & $31 /-/ 32$ & 21.45 & - & 34.65 & 56.1 & 36 \\
\hline $\begin{array}{l}\text { Mycenae, House of the } \\
\text { Sphinxes }^{197}\end{array}$ & $-/-/ 3$ & 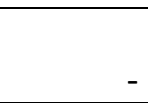 & - & 52.8 & 52.8 & 37 \\
\hline
\end{tabular}

\begin{tabular}{|l|c|r|r|r|r|r|}
\cline { 2 - 7 } \multicolumn{1}{c|}{} & \multicolumn{5}{c|}{ Area $\left(\mathbf{m}^{2}\right)$} & \\
\hline Isolated Megaron-Units & Porch & Vestibule & Main Hall & Back Room & Total & Plan \\
\hline Korakou, House $\mathrm{L}^{198}$ & 6.87 & 6.5 & 31.9 & 17.46 & 62.73 & 38 \\
\hline Thermos, Megaron $\mathrm{A}^{199}$ & 15 & - & 102 & $\sim 15$ & $\sim 132$ & 39 \\
\hline
\end{tabular}

\footnotetext{
${ }^{184} \mathrm{P}=$ Porch, $\mathrm{V}=$ Vestibule, $\mathrm{H}=$ Main Hall. Where one room is not included, this is indicated with a dash.

185 Mylonas 1983:98-100.

186 Schliemann 1885:209.

187 Blegen and Rawson 1966:65, 72, 77.

188 Schliemann 1885:239-40.

189 lakovidis 2001:33.

190 lakovidis 2001:36-7.

191 Pantou 2010:209.

192 Pantou 2010:210.

193 Catling, H, Hughes-Brock, H. et al. 2009:24.

${ }^{194}$ See Note 178 above.

195 Pantou 2010:78.

196 Pantou 2010:97.

197 Pantou 2010:127.

198 Blegen 1921:80-3.

199 Porch and main hall calculated from Rhomaios 1915:232; Back room estimated from overall area given by Darcque 2005:325.
} 


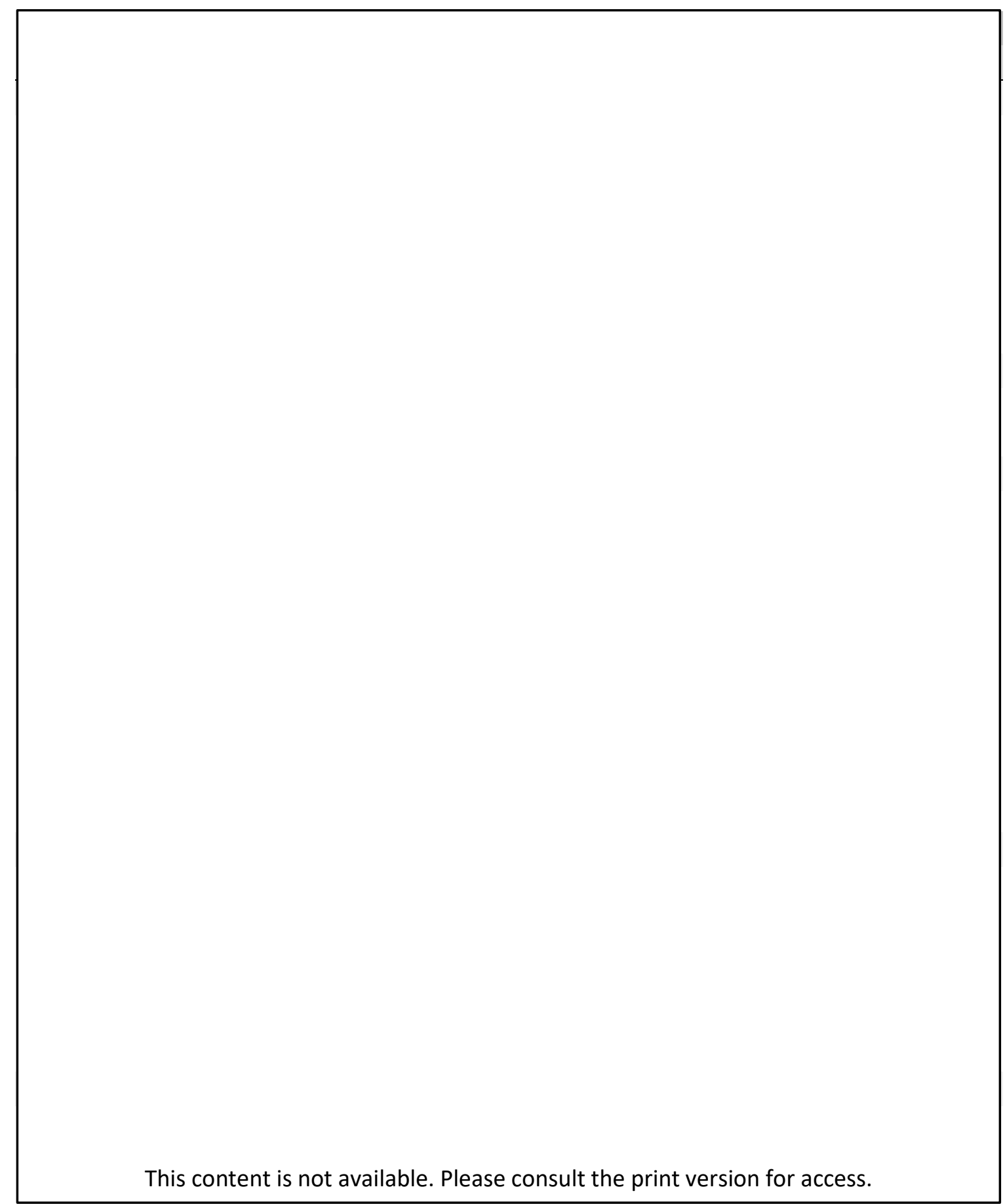

Adapted from Letesson 2013:Fig. 6. MH= Main Hall; VE= Vestibule; LW= Light Well, MDMH= Mean Depth of Minoan Hall; OMD= Overall Mean Depth (of the building); OMI= Overall Mean Integration (of the building). The first space accessible from the exterior has been italicised. 
Table 6: Minoan Hall System Connections

\begin{tabular}{|c|c|c|c|c|c|c|}
\hline & \multicolumn{2}{|c|}{ Spaces Accessed } & \multicolumn{4}{|c|}{ Spaces Connected } \\
\hline & Same Level & Overall & MH & VE & LW & Total \\
\hline Phaistos 63-64 & 2 & 2 & 2 & 0 & 0 & 2 \\
\hline Chania & 2 & 2 & 1 & 1 & 0 & 2 \\
\hline South House & 0 & 0 & 1 & 0 & 0 & 1 \\
\hline Malia Za 12 & 0 & 0 & 1 & 0 & 0 & 1 \\
\hline Malia Za 5-8 & 3 & 3 & 2 & 2 & 0 & 4 \\
\hline Palaikastro X1-17 & 1 & 1 & 1 & 1 & - & 2 \\
\hline Mochlos II & 14 & 14 & 4 & 1 & - & 5 \\
\hline Tylissos C & 0 & 0 & 2 & 0 & 0 & 2 \\
\hline Malia $\Delta \alpha$ & 0 & 0 & 3 & 0 & 0 & 3 \\
\hline Tylissos A & 13 & 8 & 4 & 3 & 0 & 7 \\
\hline Malia Palace I & 0 & 0 & 1 & 2 & 2 & 5 \\
\hline Malia Palace II & 4 & 4 & 1 & 2 & 2 & 5 \\
\hline Malia Z $\beta$ & 2 & 2 & 4 & - & 1 & 5 \\
\hline Phaistos 77-79 & 8 & 8 & 2 & 2 & 0 & 3 \\
\hline Gournia & 6 & 6 & 1 & 1 & 3 & 5 \\
\hline Zakros 36I & 0 & 0 & 4 & 2 & 1 & 4 \\
\hline Zakros 36 II & 0 & 0 & 4 & 2 & 1 & 4 \\
\hline Zakros 37I & 3 & 0 & 3 & 2 & 0 & 3 \\
\hline Zakros 37 II & 3 & 0 & 3 & 2 & 0 & 3 \\
\hline Royal Villa & 2 & 0 & 2 & 0 & 1 & 3 \\
\hline House of the & & & & & & \\
\hline Frescoes & 0 & 0 & 1 & 1 & 0 & 2 \\
\hline Little Palace & 1 & 1 & 3 & 1 & 4 & 6 \\
\hline Akhladia & 2 & 2 & 1 & 2 & 3 & 4 \\
\hline Pseira & 0 & 0 & 1 & 1 & - & 2 \\
\hline Mochlos I & 13 & 13 & 4 & 1 & - & 5 \\
\hline Nirou Hani & 9 & 0 & 3 & 0 & - & 3 \\
\hline Vathypetro & 0 & 0 & 1 & 0 & - & 1 \\
\hline
\end{tabular}

Spaces Accessed: Counts spaces which can only be accessed by passing through the Minoan Hall System, on the same level or overall including upper storeys. Spaces Connected: Counts spaces which are connected directly to the Minoan Hall System, not including other parts of the Minoan Hall System. Information gathered from Justified Graphs in Letesson 2009, and attached plans. 
Table 7: Space Syntax Analysis of Mycenaean Megaron-Units

\begin{tabular}{l|ccc|rr||cccc}
\multicolumn{1}{l}{} & \multicolumn{3}{c}{ Cell Type } & \multicolumn{3}{|c|}{ Depth } & \multicolumn{5}{c}{ Integration } \\
& P & VE & MH & MDM & OMD & P & VE & MH & OMI \\
\hline Tiryns (5-7) & c & c & a & 6.288 & 5.899 & 1.473 & 1.419 & 1.704 & 1.42 \\
Tiryns (17-18) & c & - & a & 5.678 & 5.899 & 1.213 & - & 1.498 & 1.42 \\
Pylos & c & d & a & 4.462 & 5.958 & 0.933 & 0.874 & 1.154 & 1.414 \\
& & & & & & & & & \\
Gla (1-3) & d & c & a & 5.239 & 5.415 & 1.253 & 1.294 & 1.729 & 1.519 \\
Gla (23-24) & - & c & c & 5.769 & 5.415 & - & 1.482 & 1.799 & 1.519 \\
& & & & & & & & & \\
Phylakopi, Megaron & b & - & a & 2.938 & 2.5 & 1.352 & - & 2.141 & 1.352 \\
Menelaion Mansion 1 & c & c & a & 2.667 & 2.659 & 0.912 & 0.816 & 1.392 & 1.036 \\
Gournia House He & b & - & a & 2.313 & 2.389 & 0.789 & - & 1.577 & 1.252 \\
Megaron A, Dimini & - & c & a & 2.533 & 2.425 & - & 0.607 & 1.138 & 0.811 \\
Megaron B, Dimini & - & b & a & 2.083 & 2.190 & - & 0.784 & 1.765 & 1.401 \\
House of the Sphinxes & - & - & a & 2.571 & 1.929 & - & - & 1.597 & 0.944 \\
West House, Mycenae & b & b & a & 2.767 & 2.473 & 0.753 & 1.281 & 1.959 & 1.109 \\
& & & & & & & & & \\
Megaron A, Thermos & b & - & a & 1.333 & 1.667 & 0.333 & - & 0.333 & 0.667 \\
House L, Korakou & b & b & b & 1.667 & 2 & 0.5 & 0.333 & 0.5 & 0.667
\end{tabular}

$\mathrm{P}=$ Porch. For other Abbreviations, see Table 5. 
Table 8: Light Wells in Minoan Hall Systems

\begin{tabular}{|c|c|c|c|c|}
\hline & LW & SES & AE & ISO \\
\hline \multirow{2}{*}{$\begin{array}{l}\text { Akhladia, Building A } \\
\text { Amnissos, Villa of the Lilies }\end{array}$} & Yes & No & Yes & No \\
\hline & No & No & Yes & - \\
\hline Archanes, Villa & No & Yes & Yes & - \\
\hline Chania, House 1 & Yes & No & Yes & Yes \\
\hline Galatas, Palace & * & $*$ & $*$ & $*$ \\
\hline Gournia, Building G (Palace) & Yes & No & Yes & No \\
\hline Hagia Triada, Villa Reale 3, 12, 49, 4 & Yes & Yes & Yes & No \\
\hline Hagia Triada, Villa Reale 1 & Yes & No & No & Yes \\
\hline Hagia Triada, Villa Reale 21,22 & Yes & No & No & Yes \\
\hline Hagia Triada, Villa Reale 16, 46, 47 & Yes & No & Yes & No \\
\hline Knossos, Hall of the Double Axes & Yes & Yes & Yes & No \\
\hline Knossos, House of the Frescoes & Yes & No & Yes & Yes \\
\hline Knossos, Little Palace & Yes & Yes & Yes & No \\
\hline Knossos, Queen's Megaron & Yes & Yes & Yes & No \\
\hline Knossos, Royal Villa & Yes & No & Yes & No \\
\hline Knossos, South House & Yes & No & Yes & Yes \\
\hline Knossos, Southeast House & Yes & No & Yes & Yes \\
\hline Malia, Palace & Yes & Yes & Yes & No \\
\hline Malia, Maison $\Delta \alpha$ & Yes & No & Yes & Yes \\
\hline Malia, Maison $\Delta \beta$ & Yes* & No* & Yes* & No* \\
\hline Malia, Maison $\Delta y$ & Yes & No* & Yes & Yes \\
\hline Malia, Maison E $\alpha$ & Yes & No & Yes & Yes \\
\hline Malia, Maison Za 12, 12bis & No & No & Yes & - \\
\hline Malia, Maison Za 5-8 & Yes & No & Yes & No \\
\hline Malia, Maison Z $\beta$ & Yes & No & Yes & No \\
\hline Malia, Maison Z $\gamma$ & Yes & No & Yes & Yes \\
\hline Malia, Maison de la Façade à Redans & No & No & Yes & - \\
\hline Mochlos, Building B.2 & No & No & Yes & - \\
\hline Mochlos, House D & Yes & No & Yes & No \\
\hline Myrtos Pyrgos, Country House & Yes & No & Yes & Yes \\
\hline Myrtos Pyrgos & No & Yes & Yes & - \\
\hline Nerokourou, Building 1 & Yes & No & Yes & No \\
\hline Nirou Hani 2-2a & No & Yes & Yes & - \\
\hline Nirou Hani 12-13 & Yes* & No & No & No* \\
\hline Palaikastro, Building X1-17 & Yes* & No & Yes* & Yes $* 200$ \\
\hline Palaikastro, Block M & Yes & No & Yes & No \\
\hline Phaistos, Palace 63-64 & Yes & Yes & Yes & Yes \\
\hline Phaistos, Palace 77-79 & Yes & Yes & Yes & Yes \\
\hline Phaistos, Palace 50 & Yes & No & No & No \\
\hline Pseira, Building BC & No & No & Yes & - \\
\hline Tylissos, Building A & Yes & No & No & No \\
\hline Tylissos, Building C & Yes & No & Yes & No \\
\hline Vathypetro, West Building & No & Yes & Yes & - \\
\hline Zakros, Palace 37 & Yes & Yes & Yes & Yes \\
\hline Zakros, Palace 36 & Yes & Yes & Yes & Yes \\
\hline
\end{tabular}

Key:

$\mathrm{LW}=$ Is there a Light Well space included in the hall system?

$\mathrm{SES}=$ Is there a secondary exterior space (as well as or instead of a formal light well)? $\mathrm{AE}=$ Is the Minoan Hall System adjacent to the exterior? $\mathrm{ISO}=$ Is the Light well isolated (i.e. with no doors or windows to other internal spaces)?

*= Answers marked with an asterisk concern spaces which are too fragmentary to be certain.

Information gathered from Lloyd 1998:Tables 2-4, Lloyd 1999:Table 1, Letesson 2013:319, and attached plans.

${ }^{200}$ Based on the reconstruction of room 6 as a light well (After Preziosi 1983:66). 


\section{Figures}

This content is not available. Please consult the print version for access.

Figure 1: Plan of Phylakopi showing the walls of the LCIII 'Megaron' and LCI 'Mansion' which it was built on top of (Barber 1987:Fig. 117).

This content is not available. Please consult the print version for access.

Figure 2: Middle Cycladic Building at Phylakopi with megaron-unit and flanking corridor. (Atkinson 1904:Fig. 32). 
This content is not available. Please consult the print version for access.

a)

b)

Figure 3: A) Plan and b) reconstruction of a typical Minoan hall system (Letesson 2013:Fig. 1).

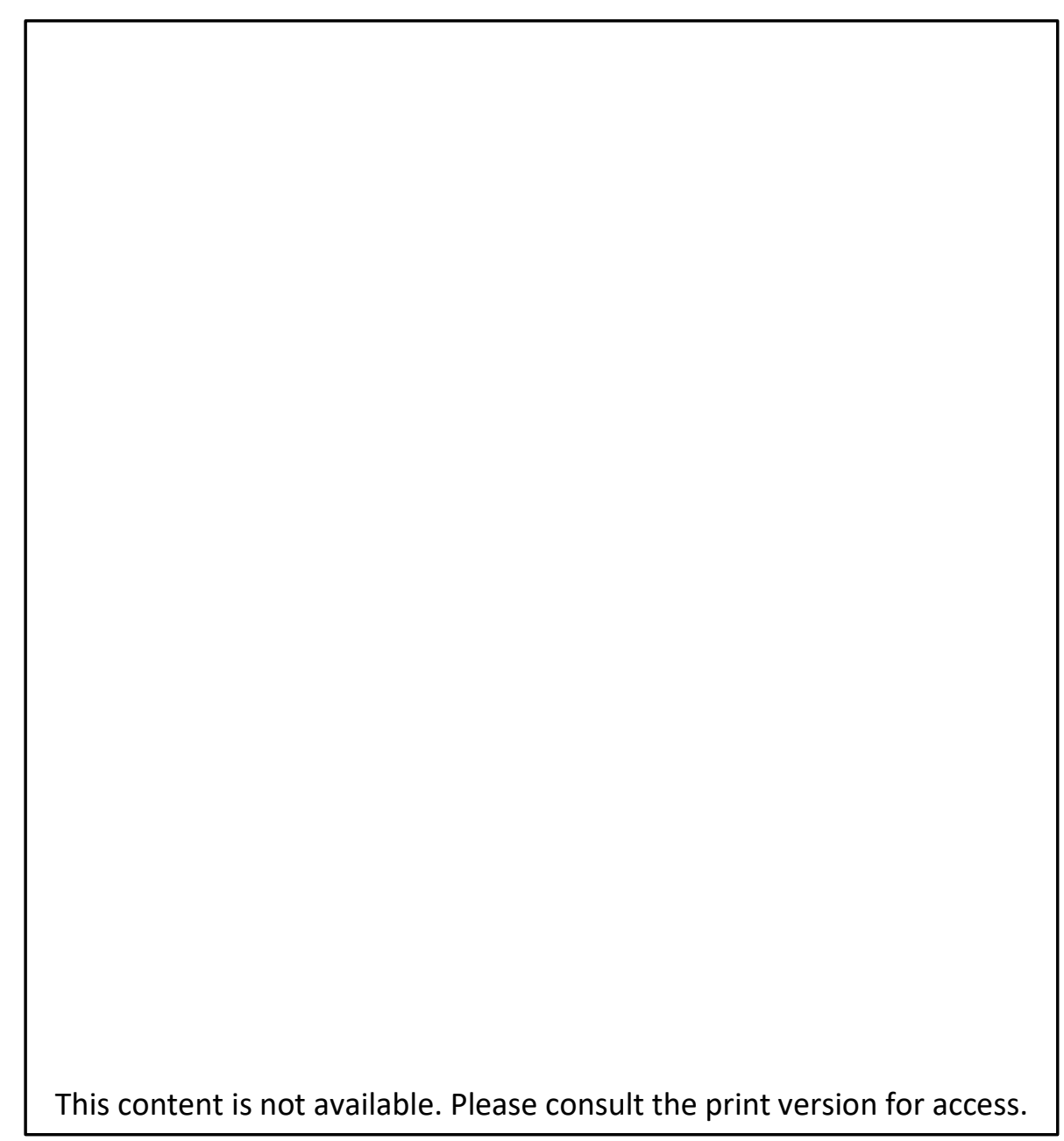

Figure 4: Pier and Door Partitions, reconstruction and plan (Preziosi 1983:Il.2, pg.231). 
This content is not available. Please consult the print version for access.

Figure 5: Pier and door partitions, showing the three ways they can be used - as a wall, door or void (Palyvou 1987:199).

This content is not available. Please consult the print version for access.

Figure 6: Comparison of the three palatial megaron-units from Mycenae, Tiryns and Pylos (Egan 2015:Fig. 1.2). 
This content is not available.

Please consult the print version for access.
This content

is not available.

Please consult the print version for access. a)

This content is not available.

Please consult the print version for access. b)

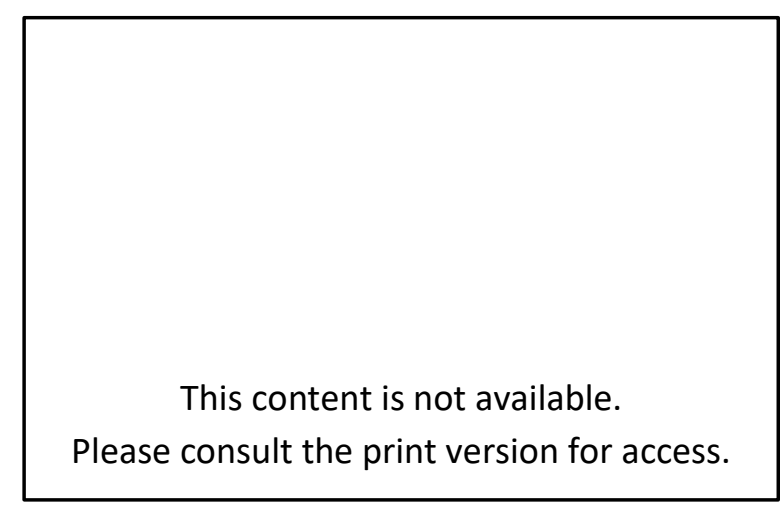

c)
This content is not available.

Please consult the print version for access.

Figure 7: Rectangular buildings with central hearths. a) Reconstructed EB I-II settlement at Demircihüyük, Turkey (Werner 1993:Fig. 3), b) Plan of a typical Chinook plank house with several central hearths based on remains from $14^{\text {th }}-15^{\text {th }}$ Century AD Oregon (Ames et. al. 1992:Fig. 2), c) Modern Central-hearth house from Dalecarlia, Sweden (Boëthius, 1920/1921:Fig. 5b), d) Reconstruction of a traditional Tlingit house from the North-West coast of North America (Noble 2007:Fig. 13-2). 


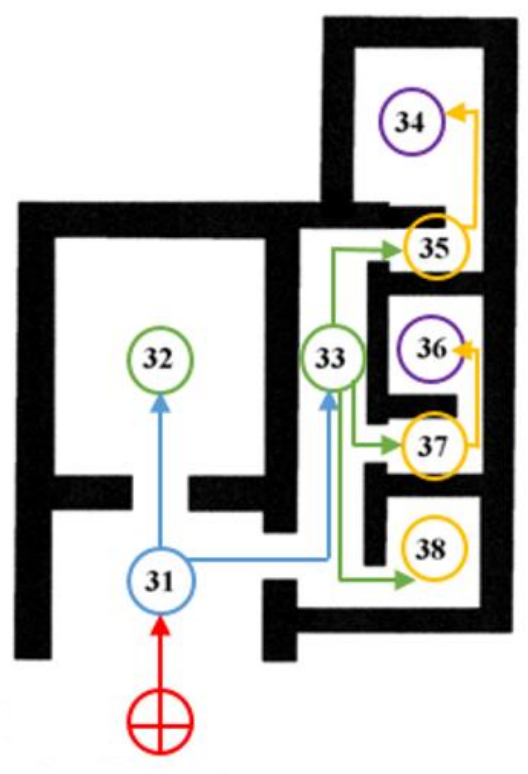

a)

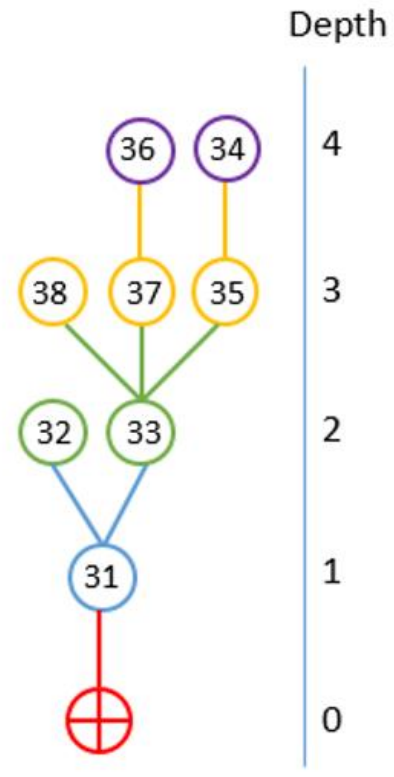

b)

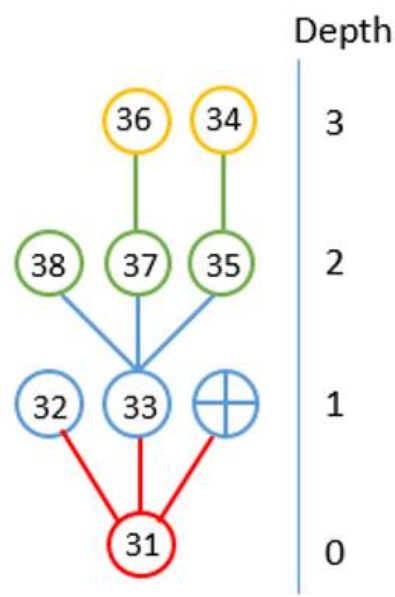

c)

\begin{tabular}{|l|l|l|l|l|l|l|l|}
\cline { 2 - 8 } \multicolumn{1}{c|}{} & \multicolumn{3}{c|}{ Depth } & \multicolumn{1}{c|}{} \\
\cline { 2 - 8 } \multicolumn{1}{c|}{} & 1 & 2 & 3 & 4 & Total Depth & Mean Depth & RRA \\
\hline Exterior & 1 & 2 & 3 & 2 & 22 & 2.75 & 0.5 \\
\hline 31 & 3 & 3 & 2 & 0 & 15 & 1.875 & 0.25 \\
\hline
\end{tabular}

d)

Figure $\mathbf{8}$ (a-d): Space Syntax Analysis of House He at Gournia. a) Connections between the various spaces as seen on the plan (after Pantou 2010:Fig. 6.2). b) The standard Justified Graph, with the exterior as carrier. c) Justified Graph with Space 31 as carrier. d) Depth and Integration figures for the exterior and space 31 of Gournia House He. 


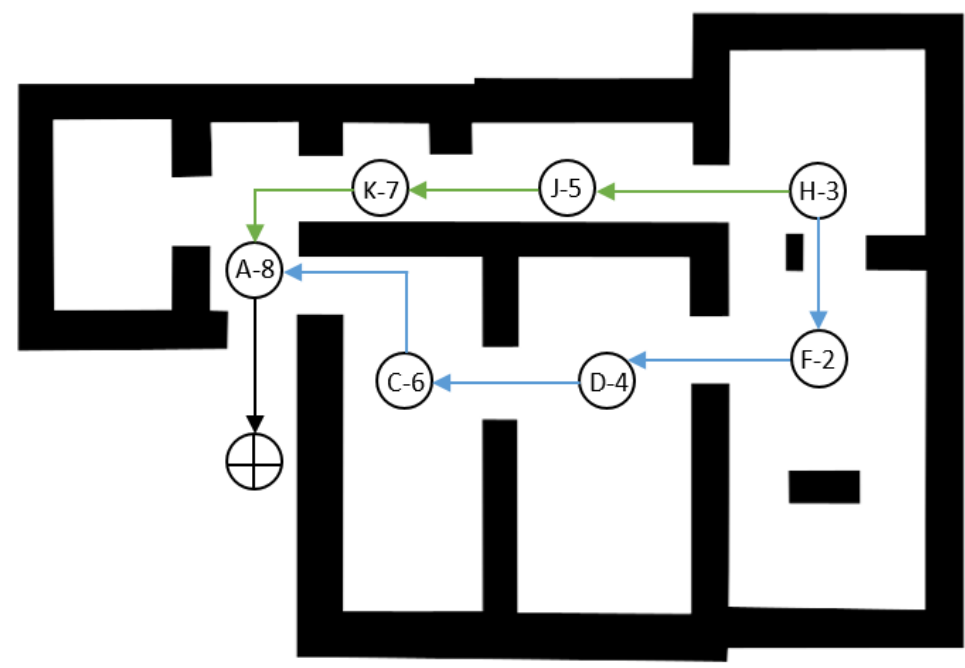

a)

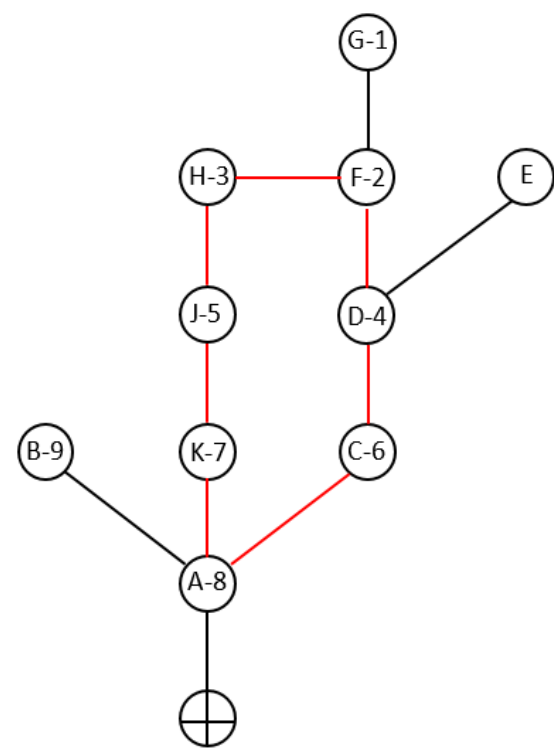

b)

Figure 9: Ringy system in the House of the Frescoes at Knossos, represented on a) a plan (after Chapin and Shaw, 2006:Fig. 1), and justified graph (b).

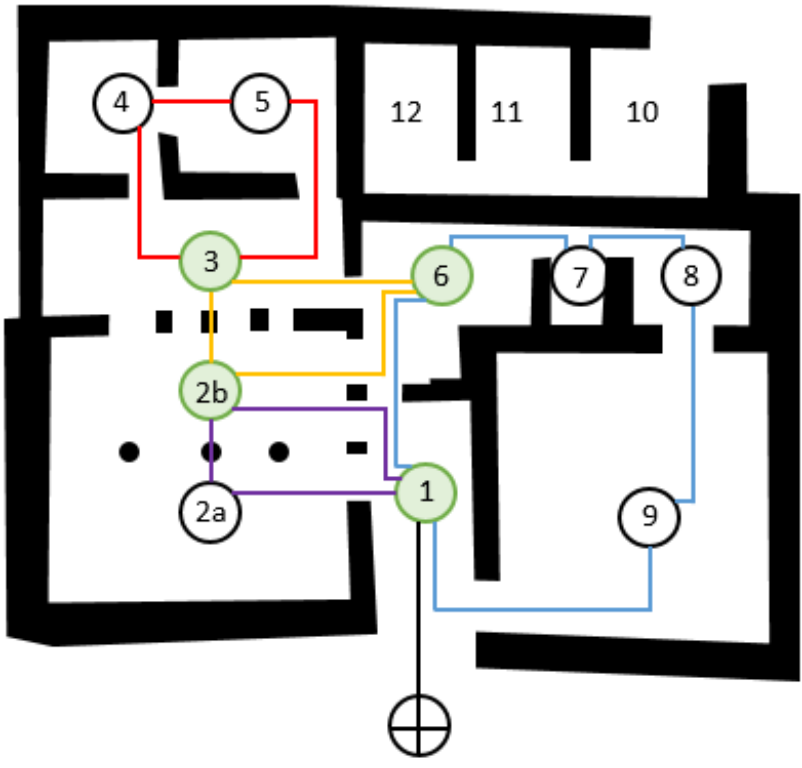

a)

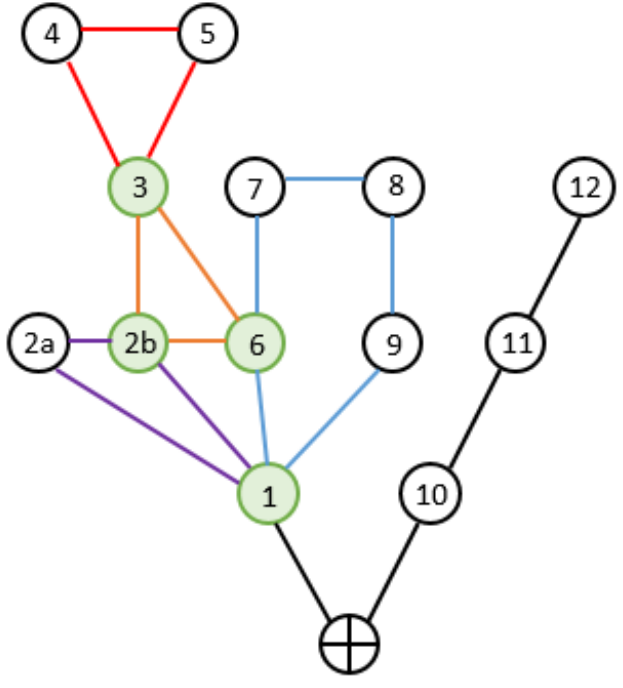

b)

Figure 10: Ringy systems in Akhladia, with type $d$ spaces shaded in green, represented on (a) a plan (After Platon, 1997:Fig. 4), and justified graph (b). 


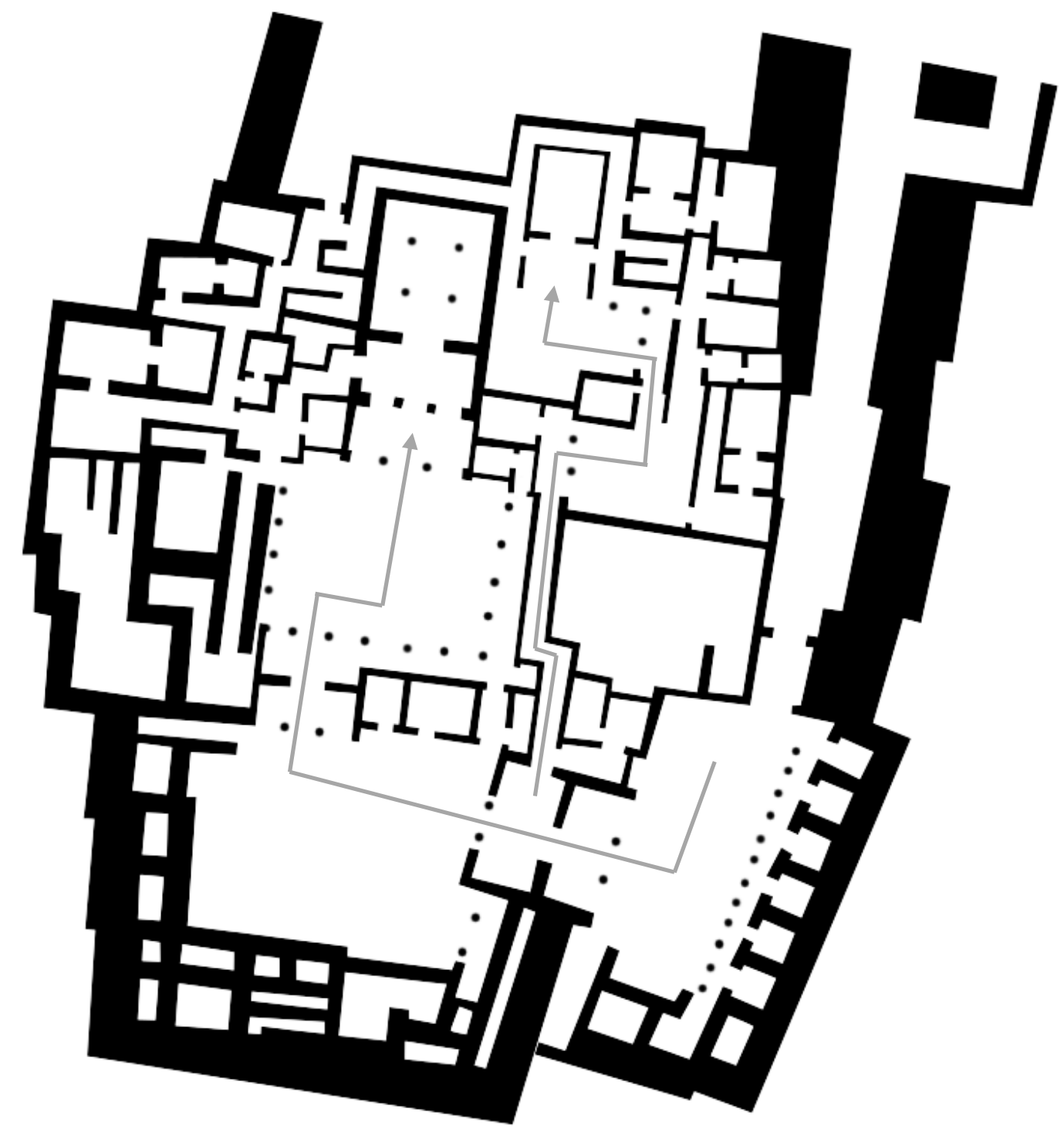

Figure 11: Plan of Tiryns showing bent axis approach to the two Megaron-units. (Plan by author, after Thaler 2015:Fig. 1). 


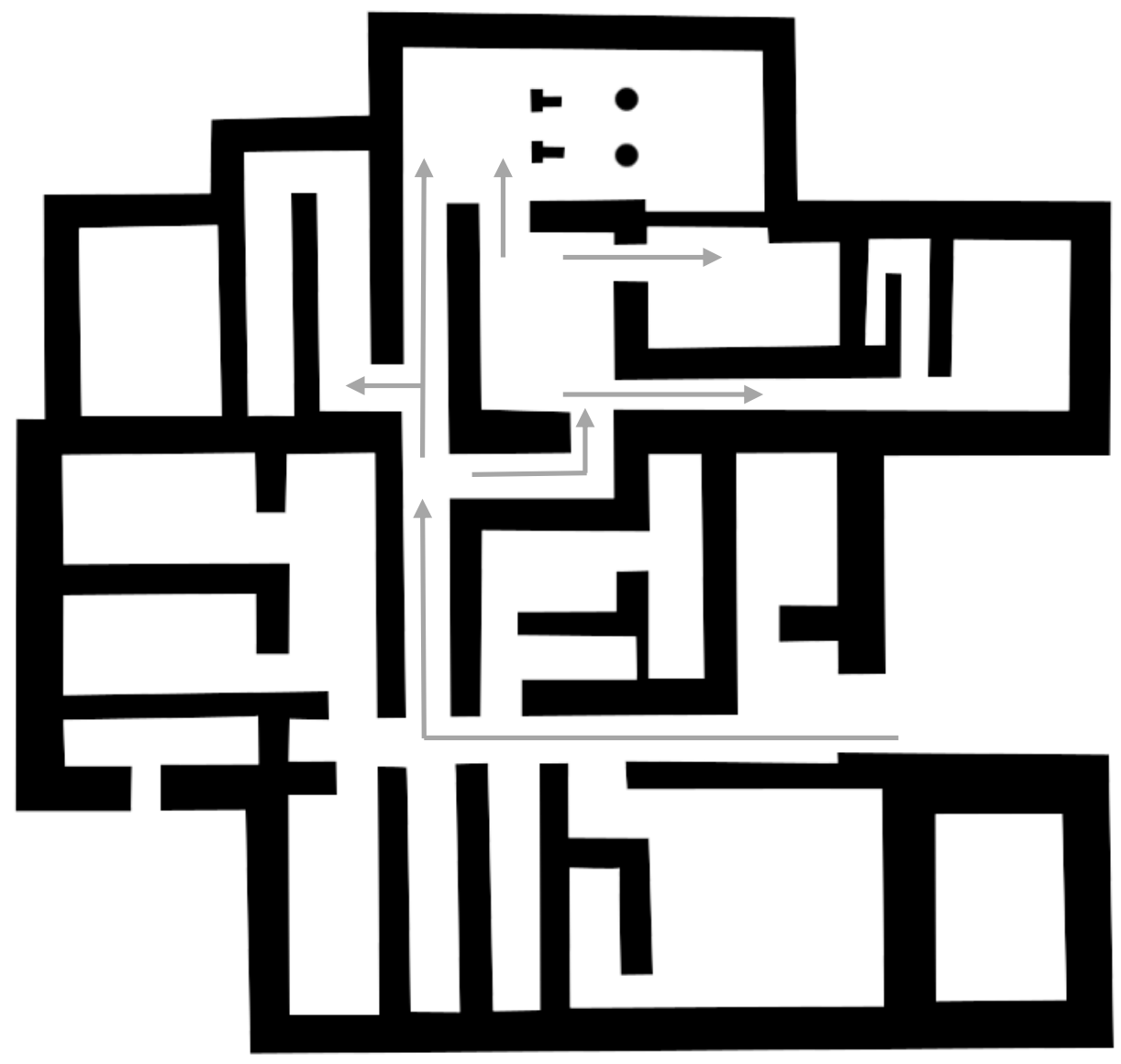

Figure 12: Tylissos House $C$ showing circulation patterns into the Minoan Hall System and surrounding matrix (after Letesson 2013:Fig. 8).
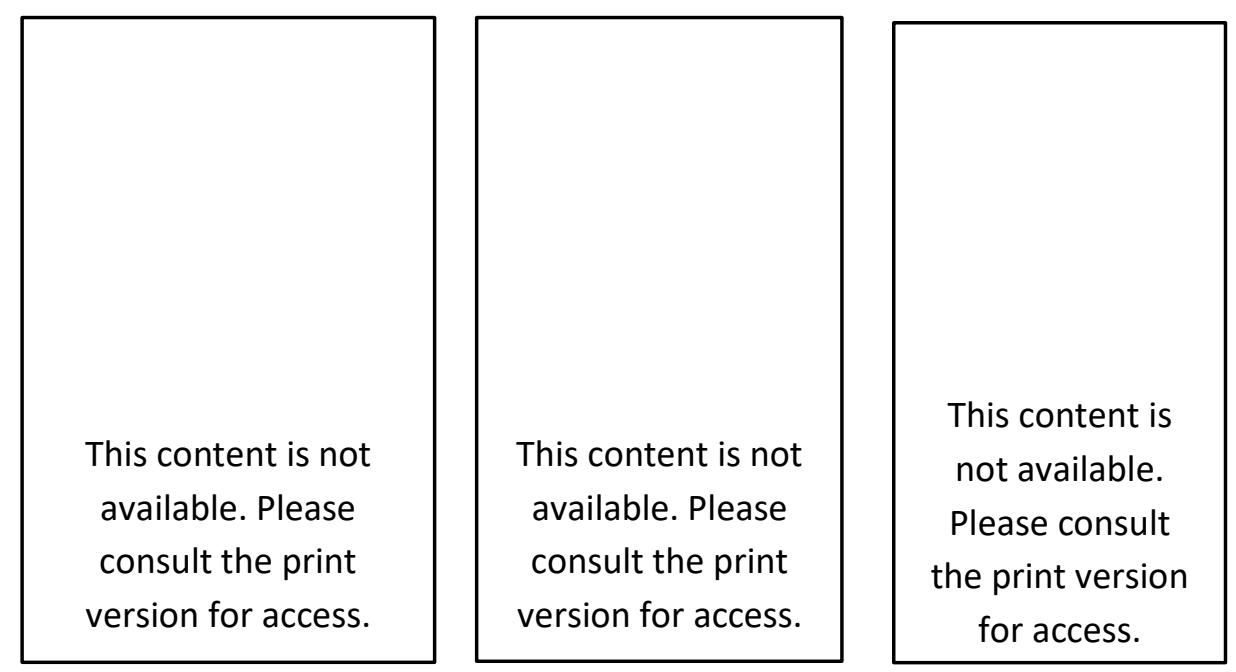

Figure 13: Comparison of the Minoan Hall System at a) Nirou Hani (Letesson 2013:Fig. 12) with b) the monumental entrance to the Palace at Phaistos (after Hitchcock 1994:Fig. 5) and c) the megaron-unit at Tiryns (Egan 2015:Fig. 1.2). Plans not to scale. 


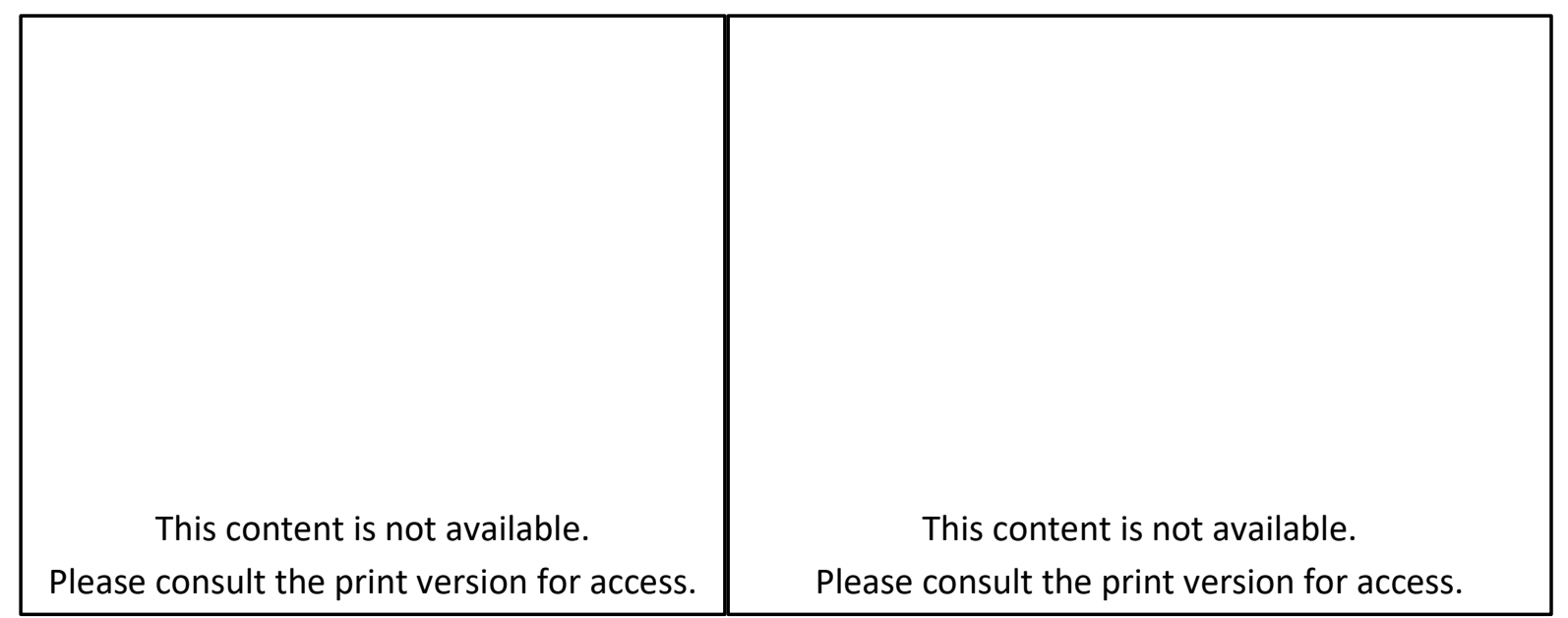

a)

b)

Figure 14: a) Archanes House Model, showing half wall of the Minoan Hall System (Palyvou 2004: Fig. 15.5), b) Reconstruction of the South House at Knossos with a half wall at the Minoan Hall System (Lloyd 1999:Fig. 17a).

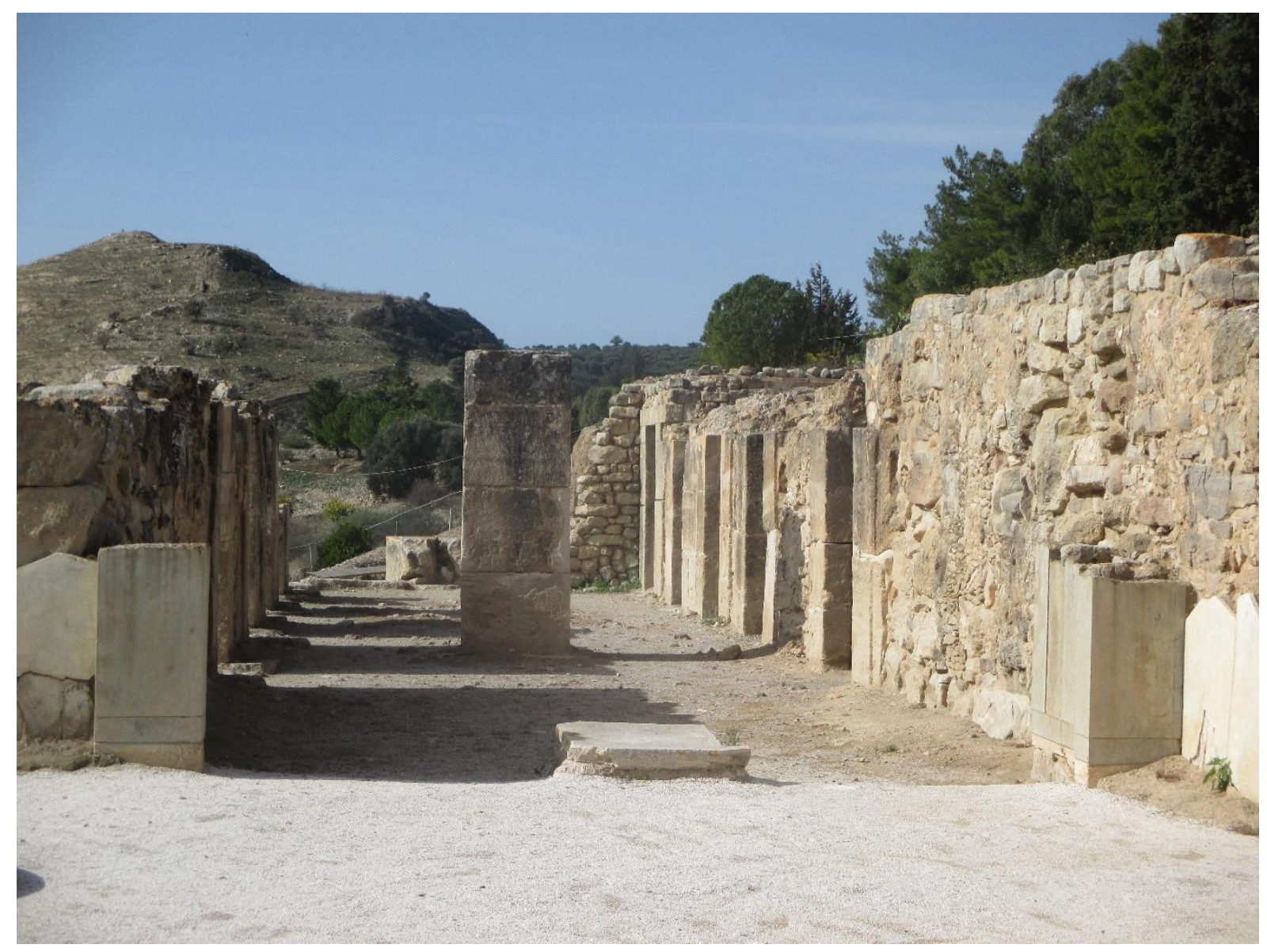

Figure 15: Double doors opening onto the Storage Magazines at Phaistos. Photo by Author. 
This content is not available.

Please consult the print version for access.

Figure 16: Circular hearth from Tell Judeideh, Syria (Muhly 1984:111 (III. 4)).

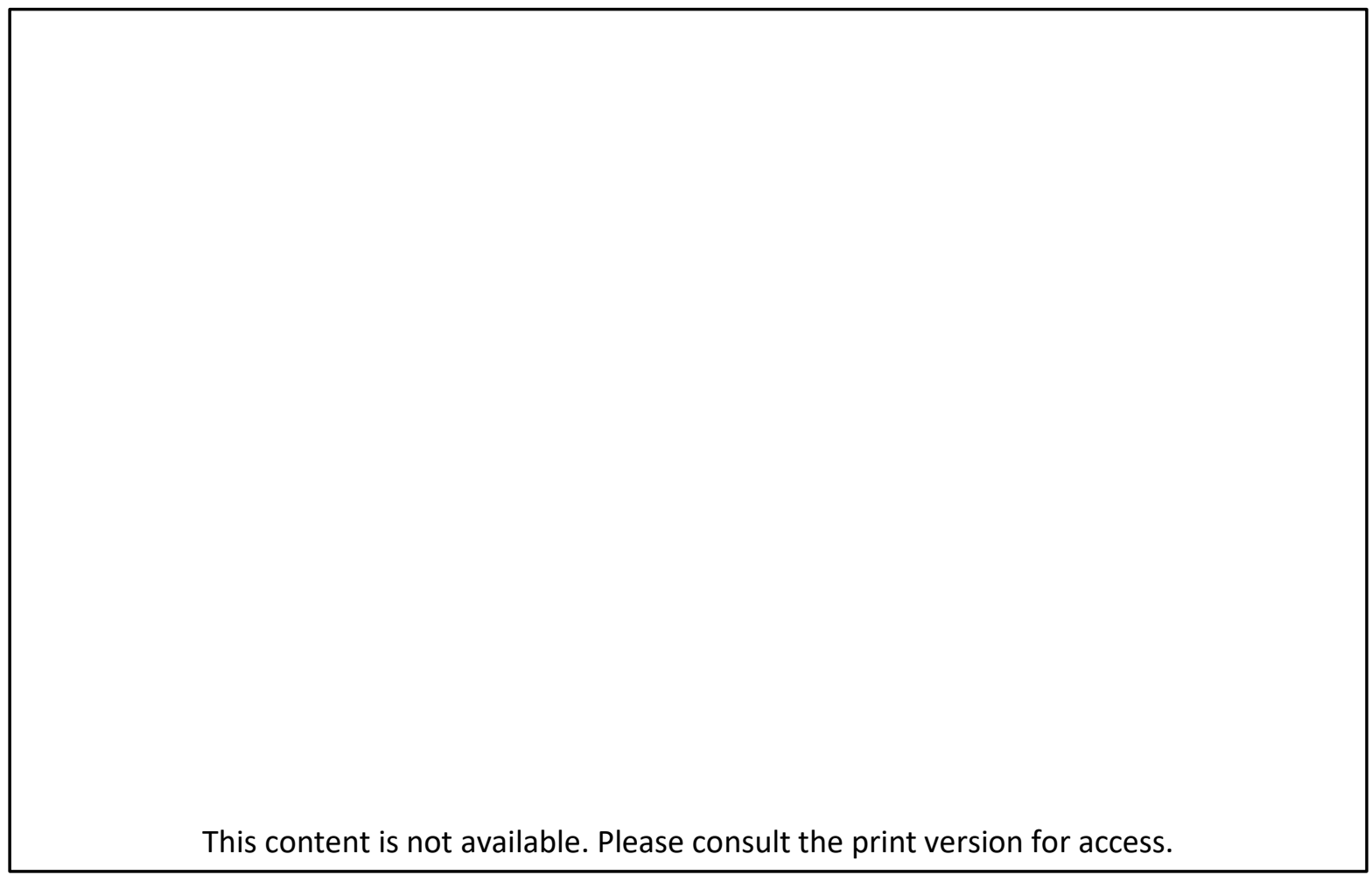

Figure 17: Rim of the Hearth at Pylos showing painted decoration (Blegen and Rawson 1966:Plate 66). 
This content is not available.

Please consult the print version for access.

a)

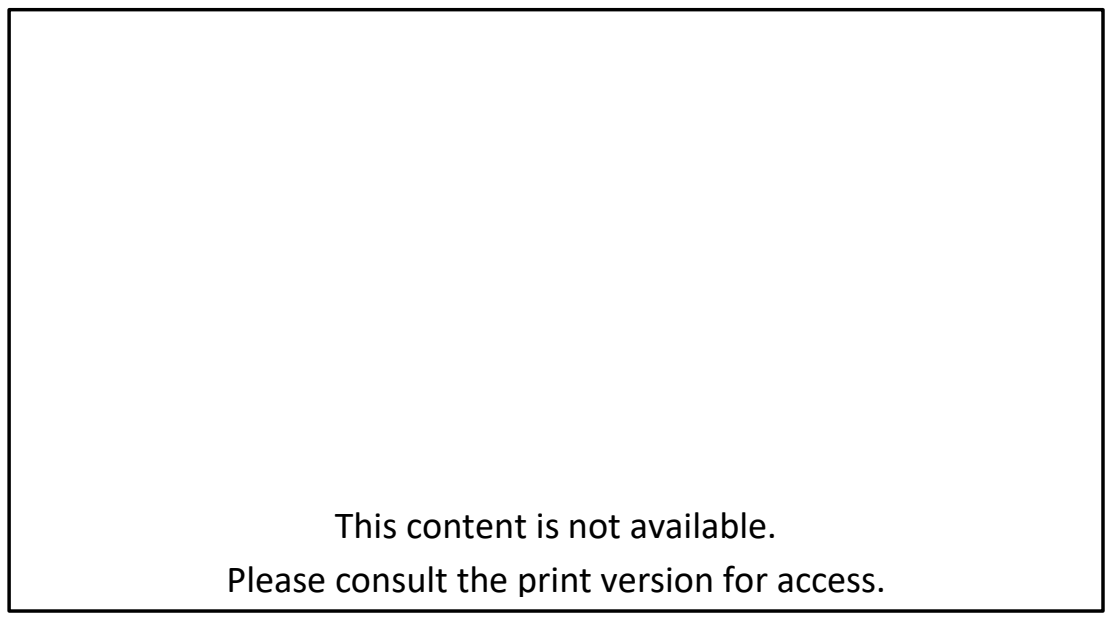

b)

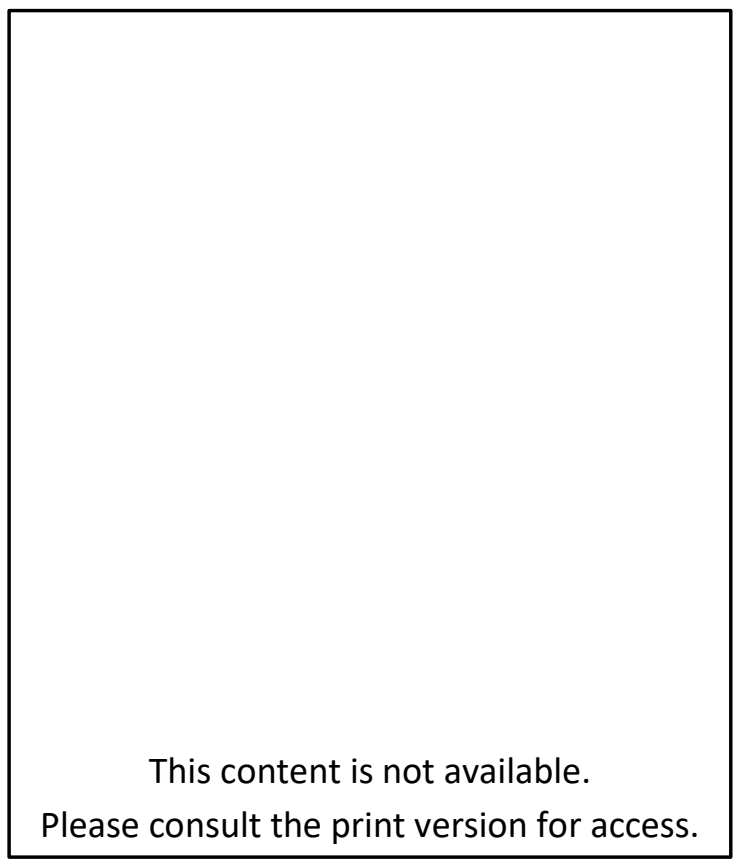

c)

Figure 18: The hearth at Mycenae: a) Remains, b) illustration of construction, c) decoration. (Wace 1949:Plates 96 b, c \& 97a). 
This content is not available. Please consult the print version for access.

Figure 19: Sherd-based hearth from House M, Tiryns (Gercke and Hiesel, 1971:Taf. 20.2). 


\section{Plans}

This content is not available.

Please consult the print version for access.

Plan 1: Akhladia, Building A (Driessen and MacDonald, 1997:Fig. 7.76).

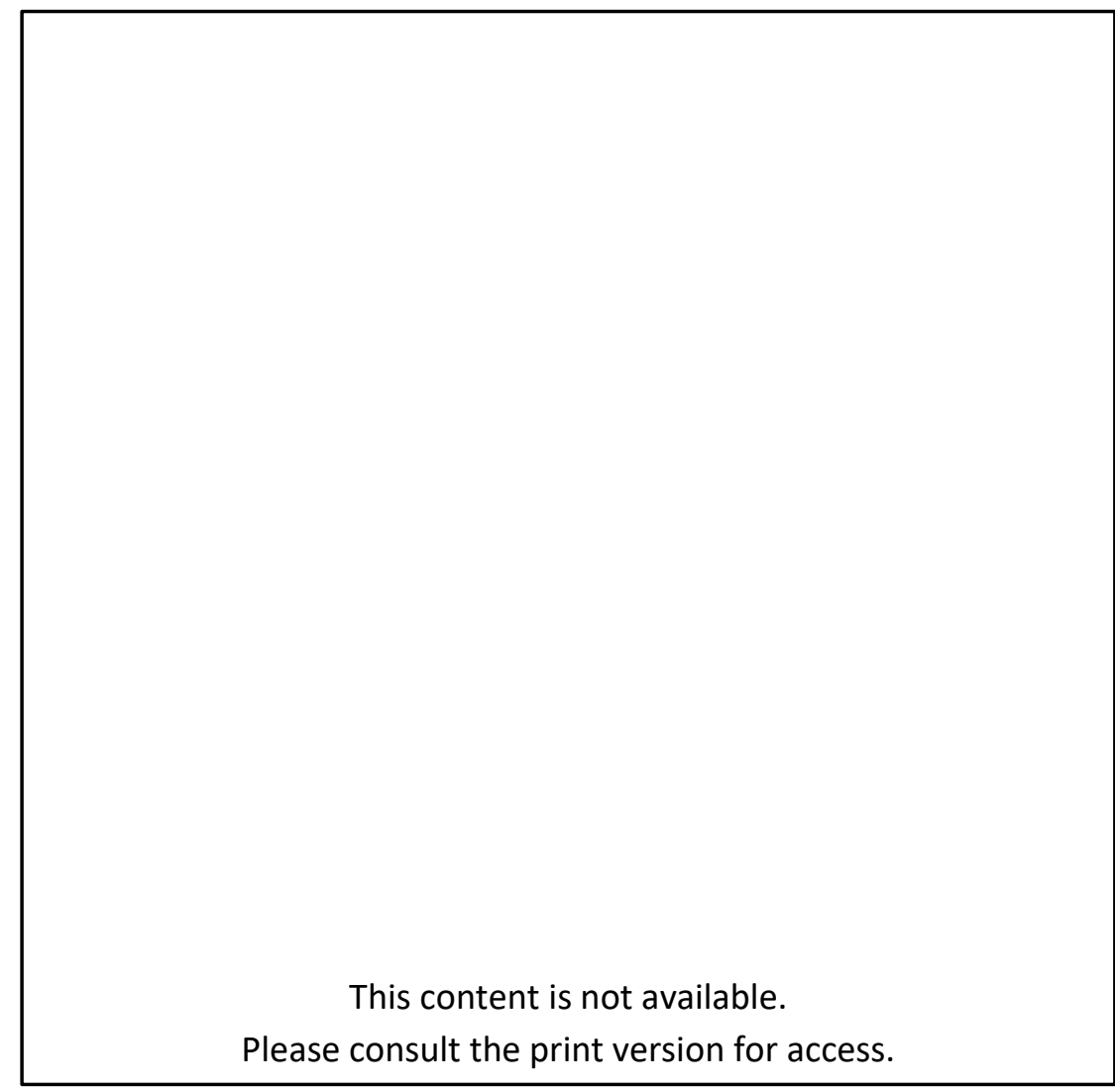

Plan 2: Chania, House 1 (Hallager and Tzedakis, 1985:Fig. 1). 


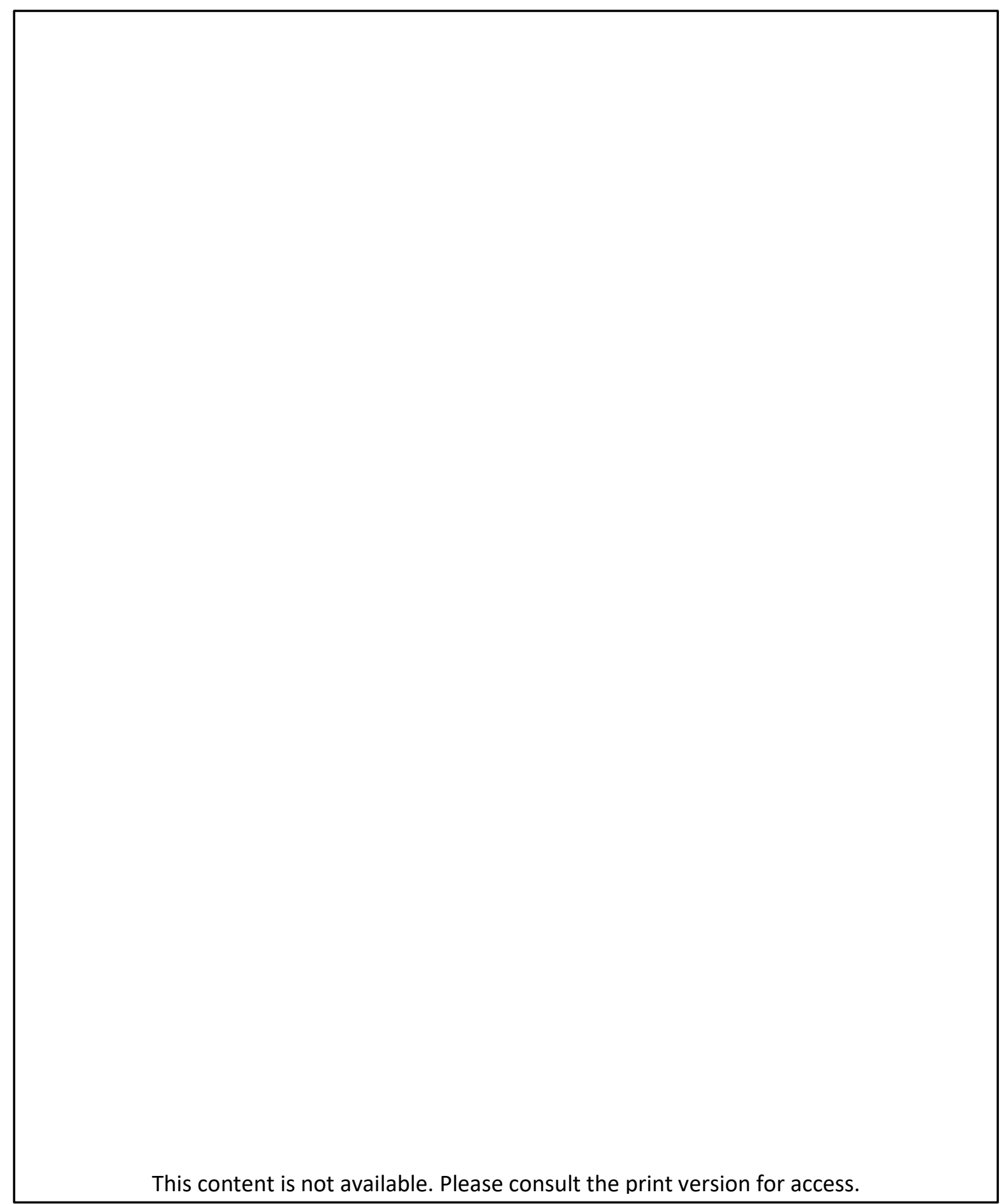

Plan 3: Gournia, Building G/Palace (Soles 1991:Fig. 58). 
This content is not available. Please consult the print version for access.

Plan 4: Knossos, House of the Frescoes (Chapin and Shaw, 2006:Fig. 1). 


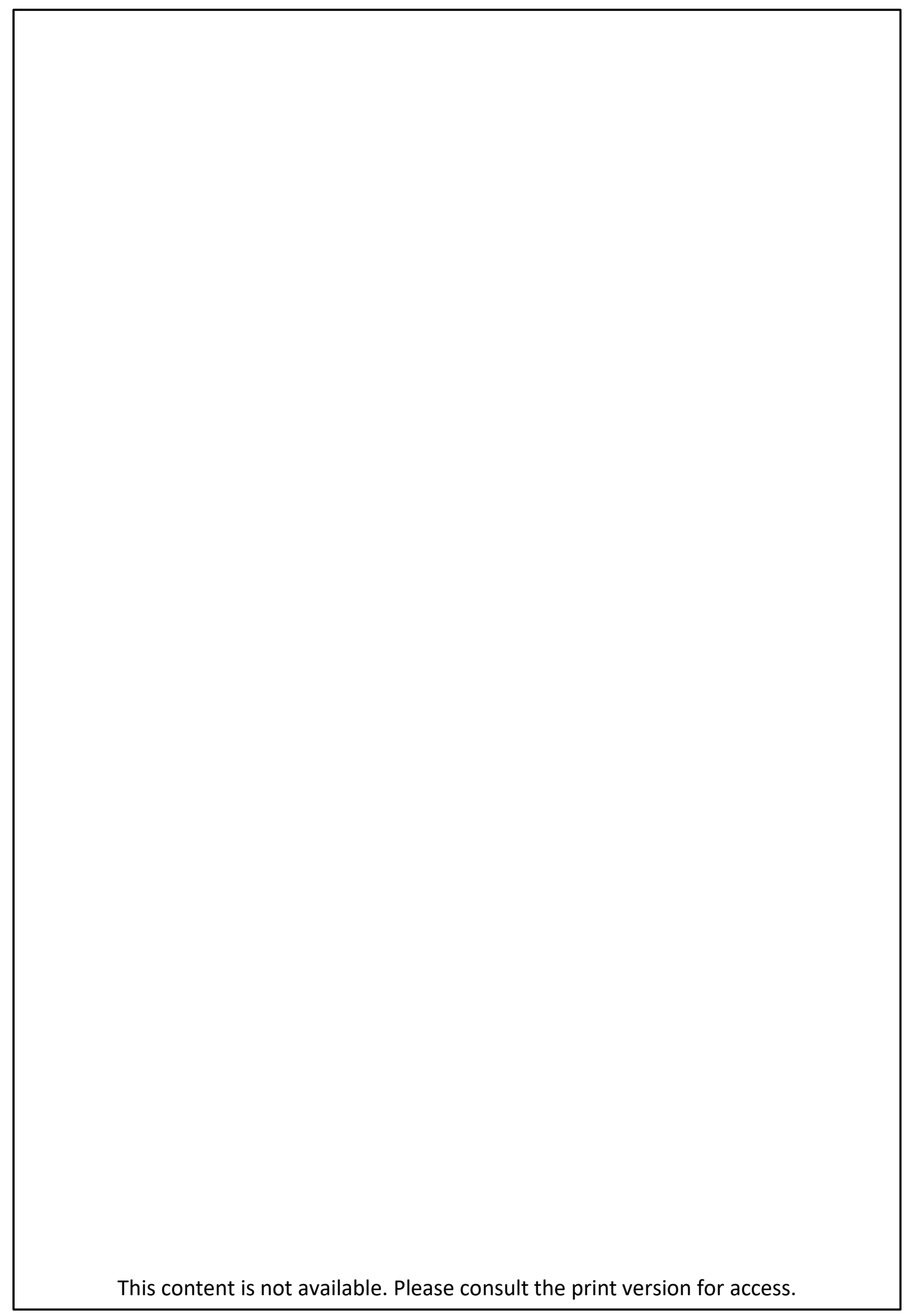

Plan 5: Knossos, Little Palace (Hatzaki 2005:Plan 2). 
This content is not available. Please consult the print version for access.

Plan 6: Knossos, Royal Villa (Fotou 1997:Fig. 1a).

This content is not available. Please consult the print version for access.

Plan 7: Knossos, South House (Evans 1928:Fig. 208). 
This content is not available. Please consult the print version for access.

Plan 8: Malia, Palace Ilôts III and IV (Lloyd 1998:Fig. 11).

This content is not available. Please consult the print version for access.

Plan 9: Malia, Maison $\Delta \alpha$ (Demargne and Gallet de Santerre, 1953:Plate 66). 
This content is not available. Please consult the print version for access.

Plan 10: Malia, Maison Z $\alpha$ (Demargne and Gallet de Santerre, 1953:Plate 66). 


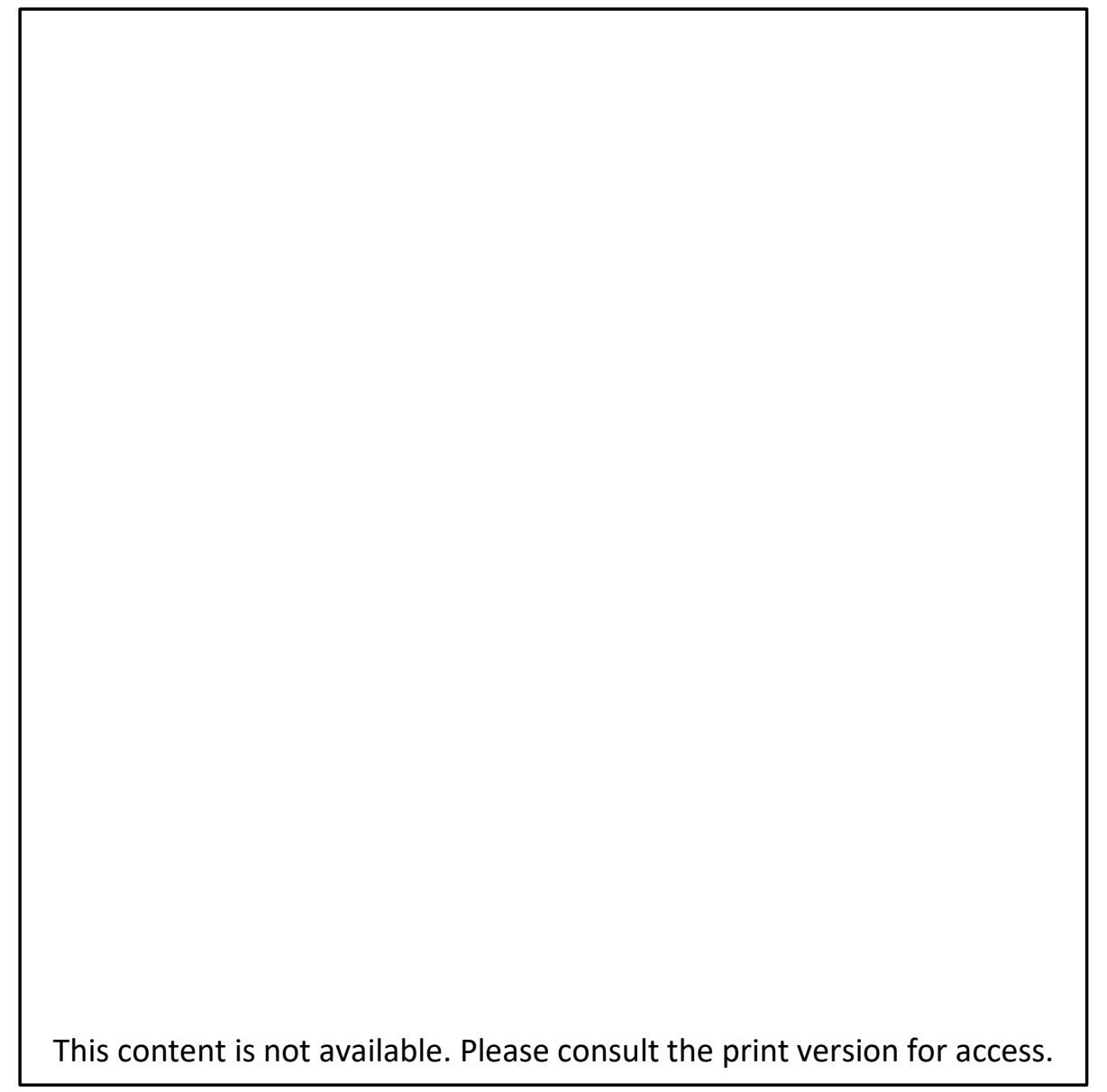

Plan 11: Malia, Maison Z $\beta$ (Deshayes and Dessenne, 1959:Plan 3).

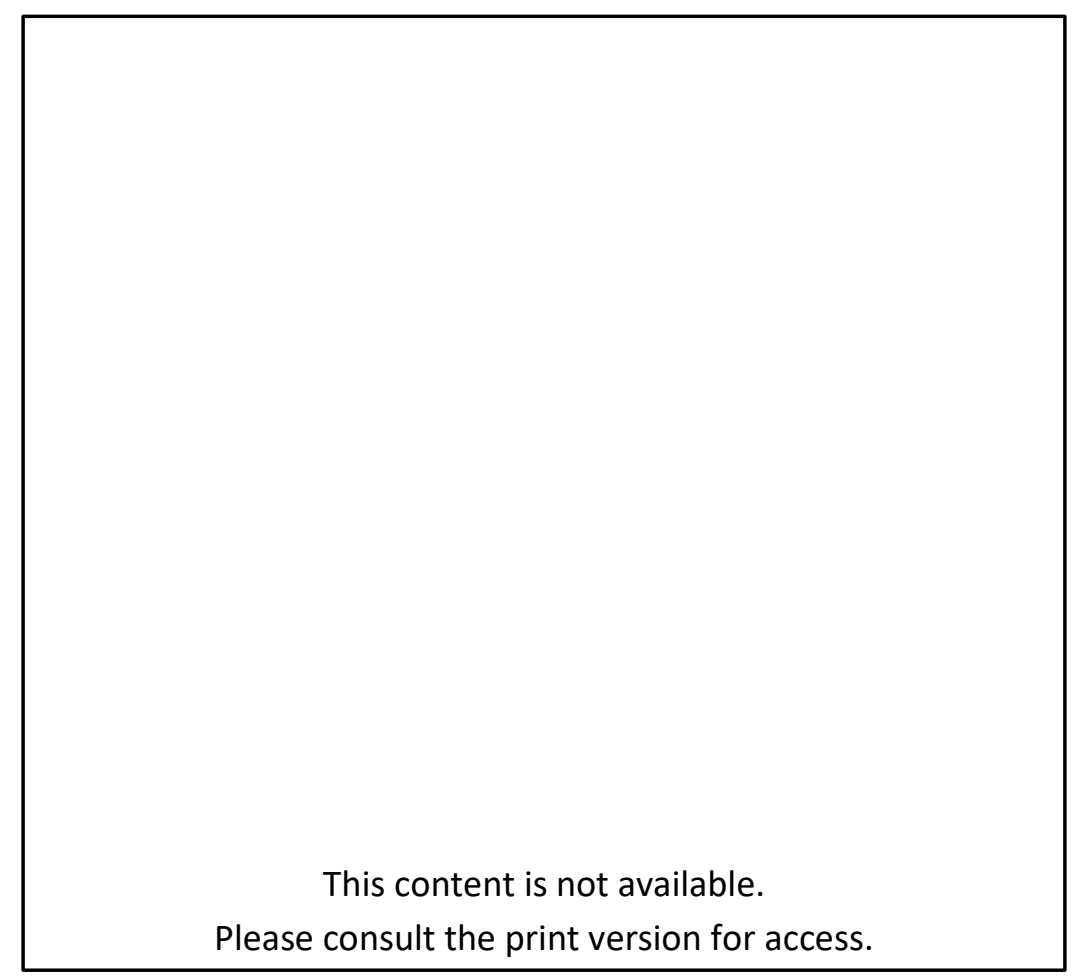

Plan 12: Mochlos, Building B.2, restored plan of second floor, east wing (Soles and Davaras 1996:Fig. 7). 
This content is not available. Please consult the print version for access.

Plan 13: Nirou Hani (Letesson 2013:Fig. 12). 
This content is not available. Please consult the print version for access.

Plan 14: Palaikastro, Building X1-17 (Preziosi 1983:Fig. II.20). 


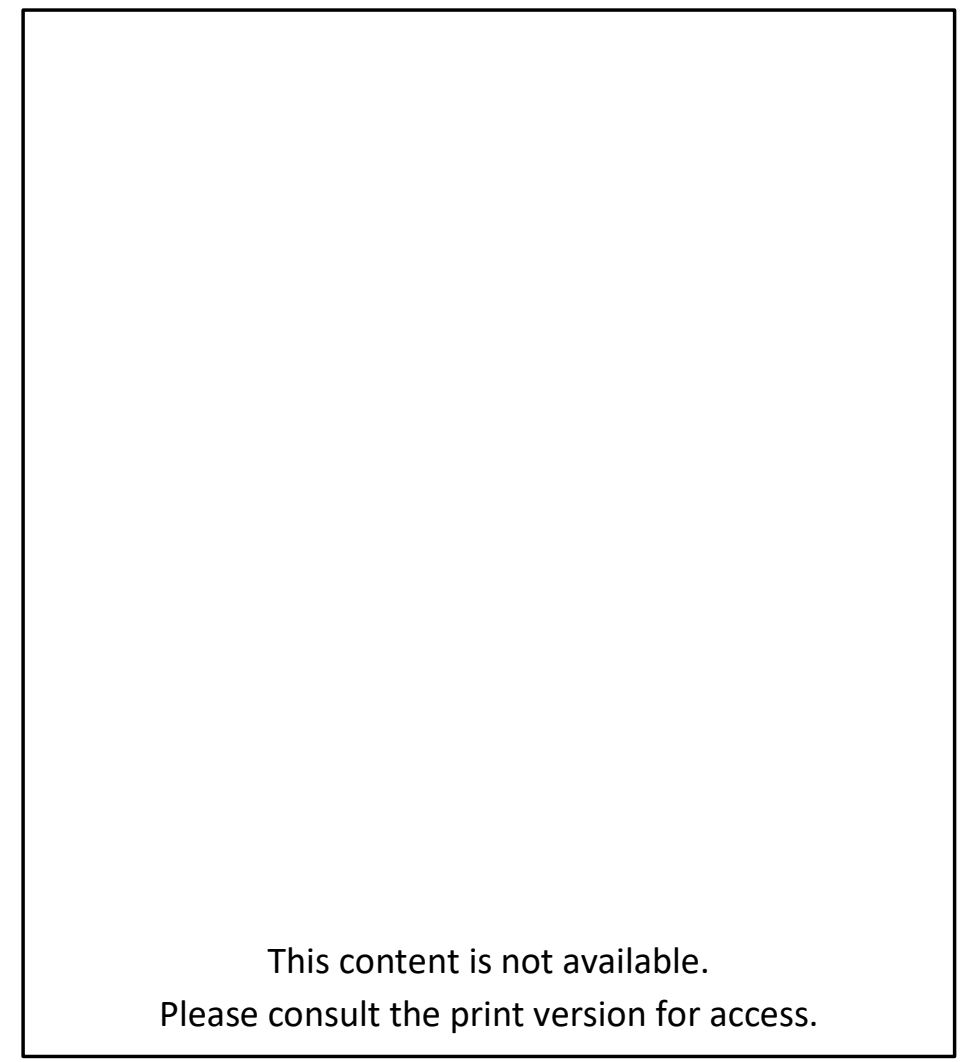

Plan 15: Phaistos, Palace, Secondary Minoan Hall System 63-64 (Hitchcock 2000:Fig. 20, 21).

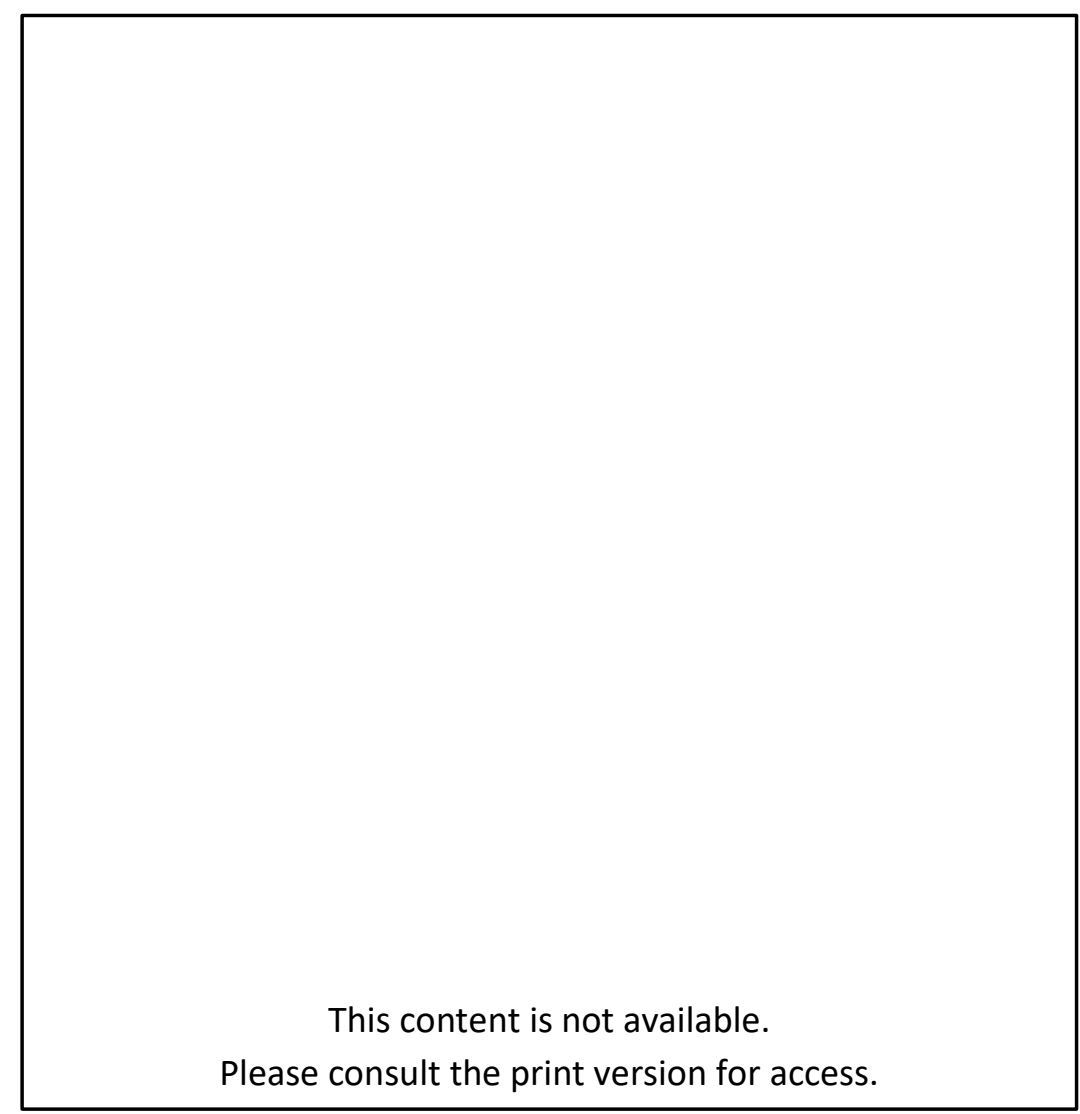

Plan 16: Phaistos, Palace, Residential Quarters, (Hitchcock 2000:Fig. 20, 21). 


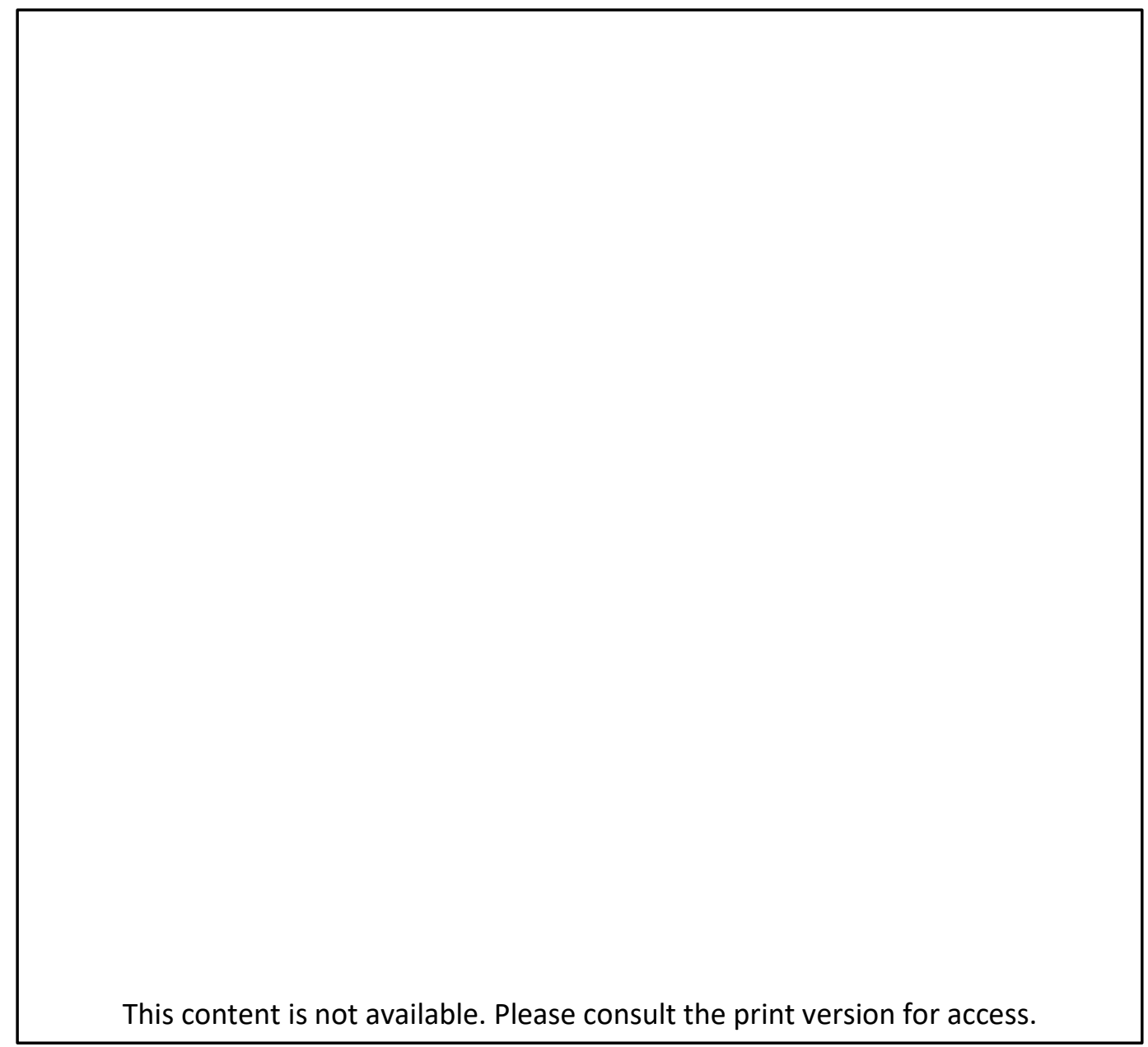

Plan 17: Pseira, Building BC (Letesson 2013:Fig. 11). 


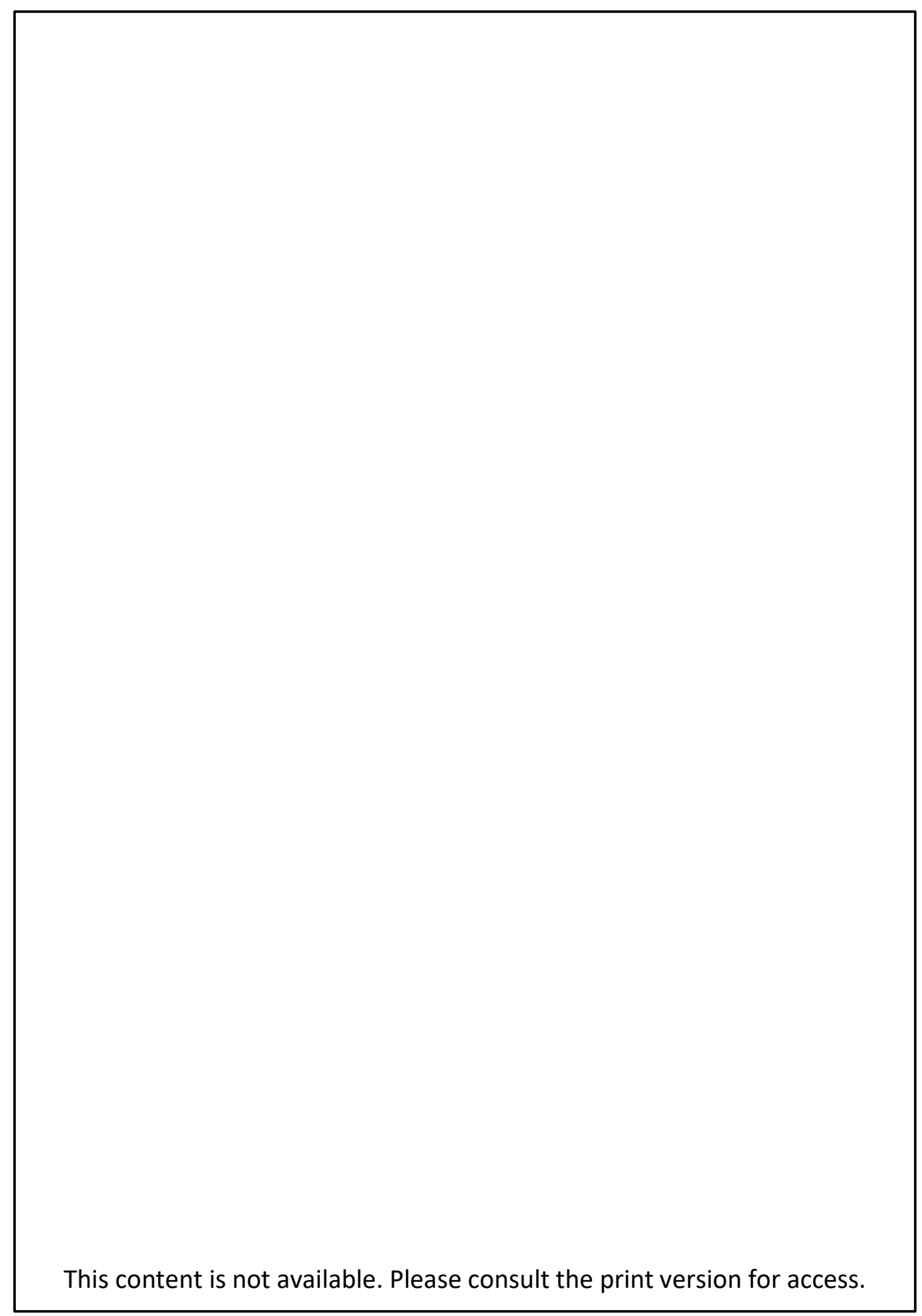

Plan 18: Tylissos, Building A (Hazzidakis 1934:Plate 6). 
This content is not available.

Please consult the print version for access.

Plan 19: Tylissos, Building C (Letesson 2013:Fig. 8)

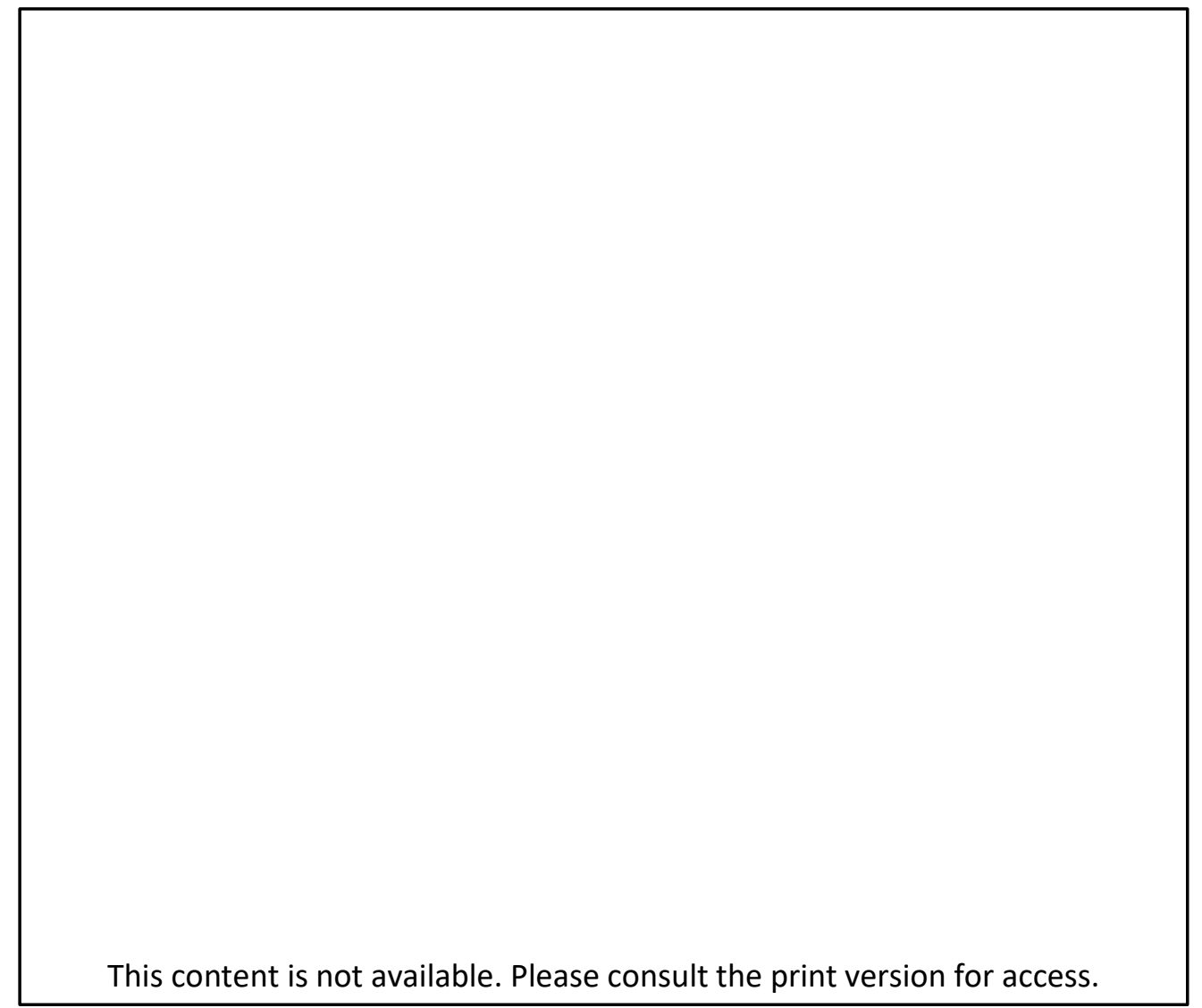

Plan 20: Vathypetro, West Building (Driessen and Sakellarakis, 1997:Fig. 6). 
This content is not available. Please consult the print version for access.

Plan 21: Zakros, Palace, Minoan Hall Systems (Platon 1971:177).

This content is not available. Please consult the print version for access.

Plan 22: Archanes, Villa (Lloyd 1998:Fig. 13). 


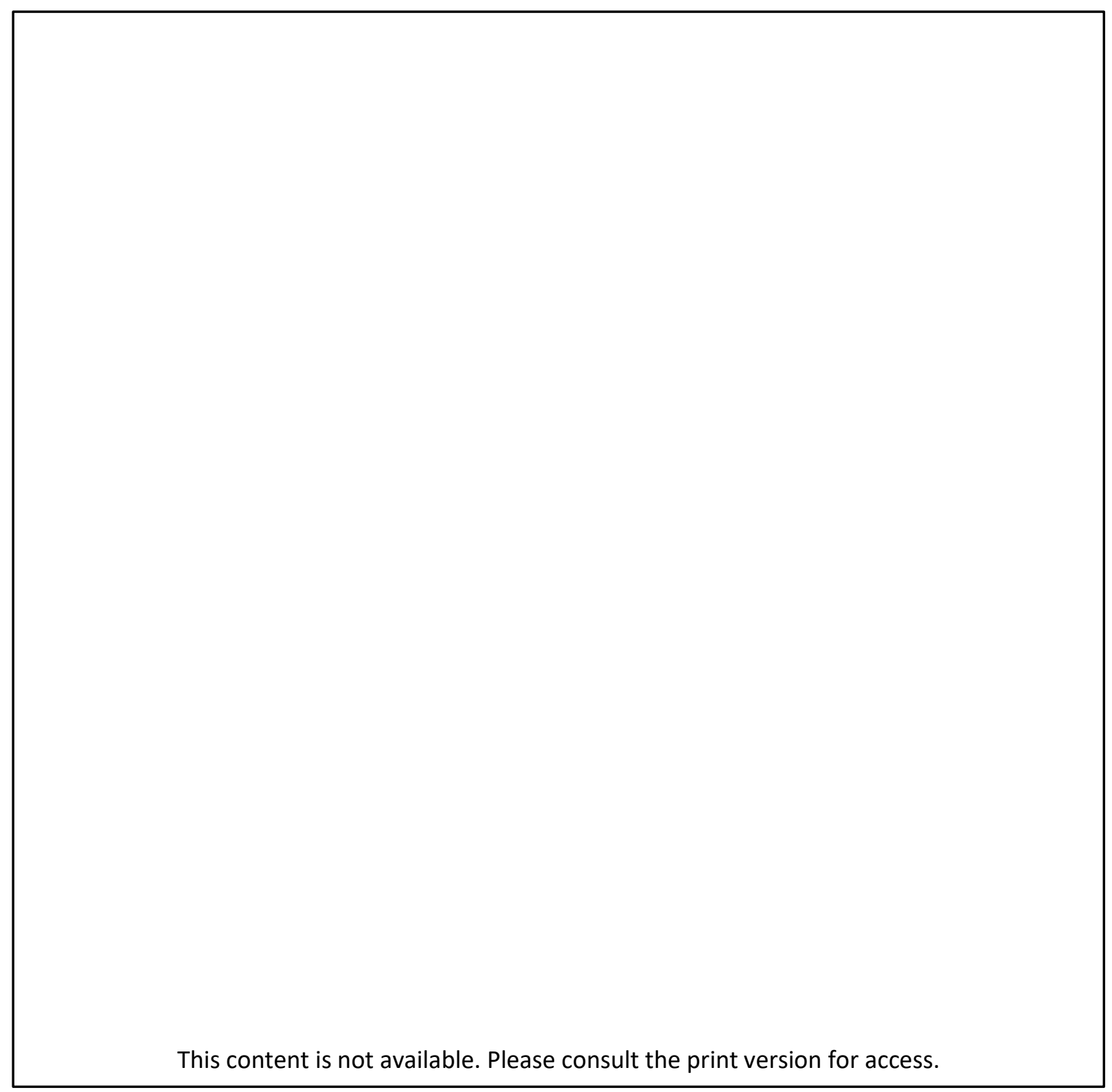

Plan 23: Galatas, Palace. (McEnroe 2010:Fig. 8.5). 


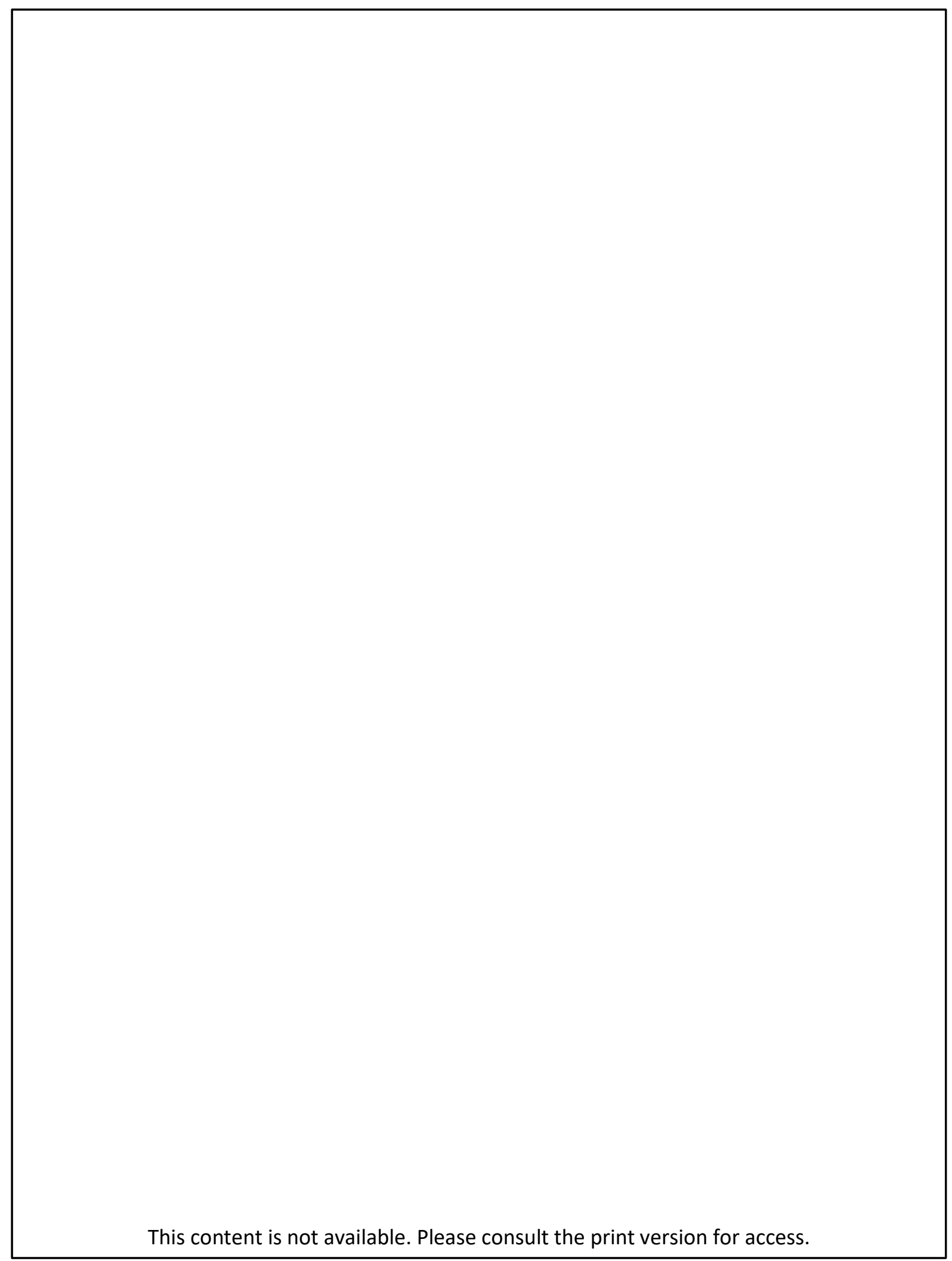

Plan 24: Hagia Triada, Villa Reale (Driessen and MacDonald, 1997:Fig. 7.58). 
This content is not available. Please consult the print version for access.

Plan 25: Knossos, Southeast House (Evans 1921:Fig 306). 


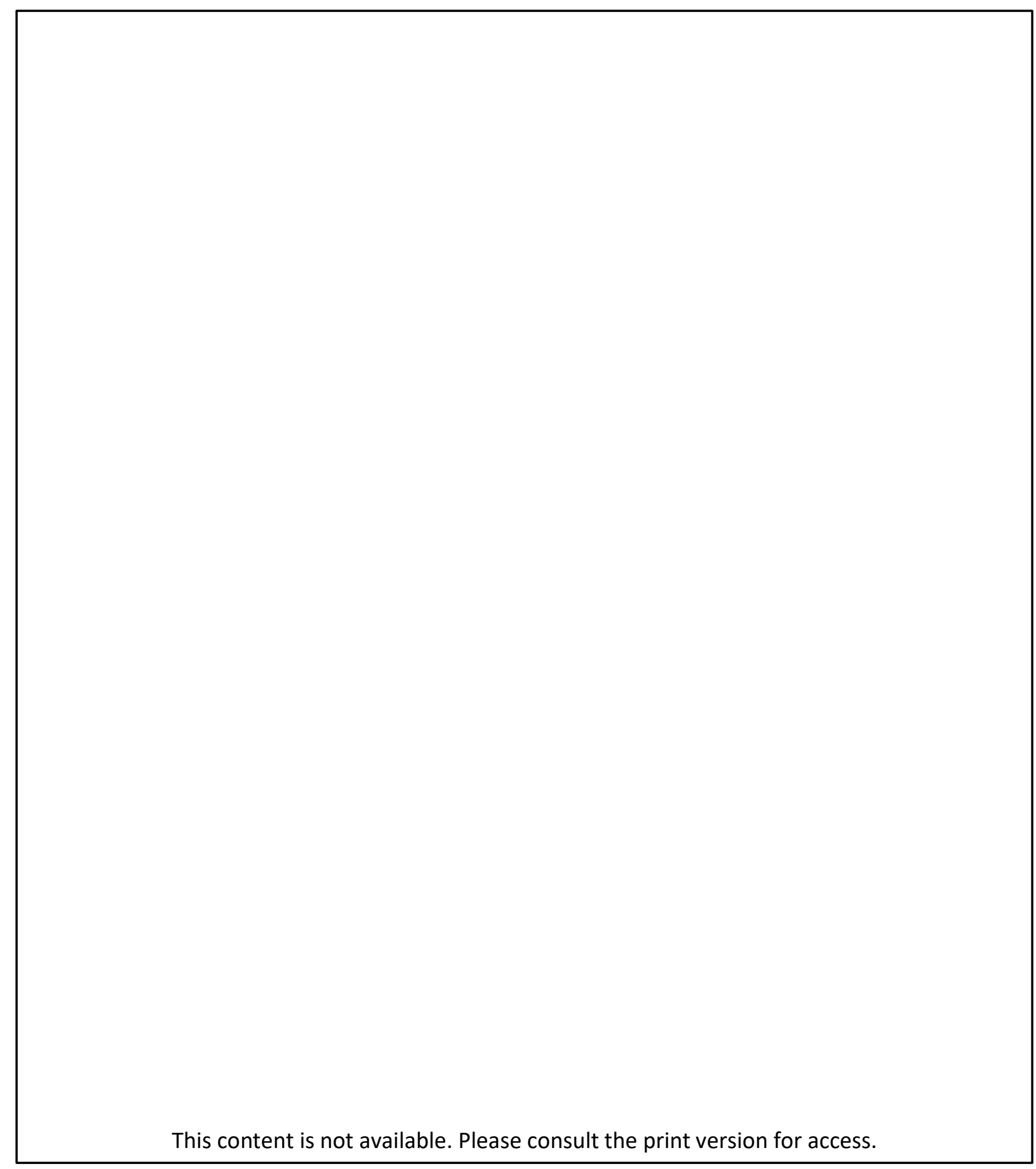

Plan 26: Knossos, Residential Quarter (Letesson 2013:Fig. 2). 
This content is not available. Please consult the print version for access.

Plan 27: Mycenae, Megaron-unit (Darcque 2005:Plan 48). 


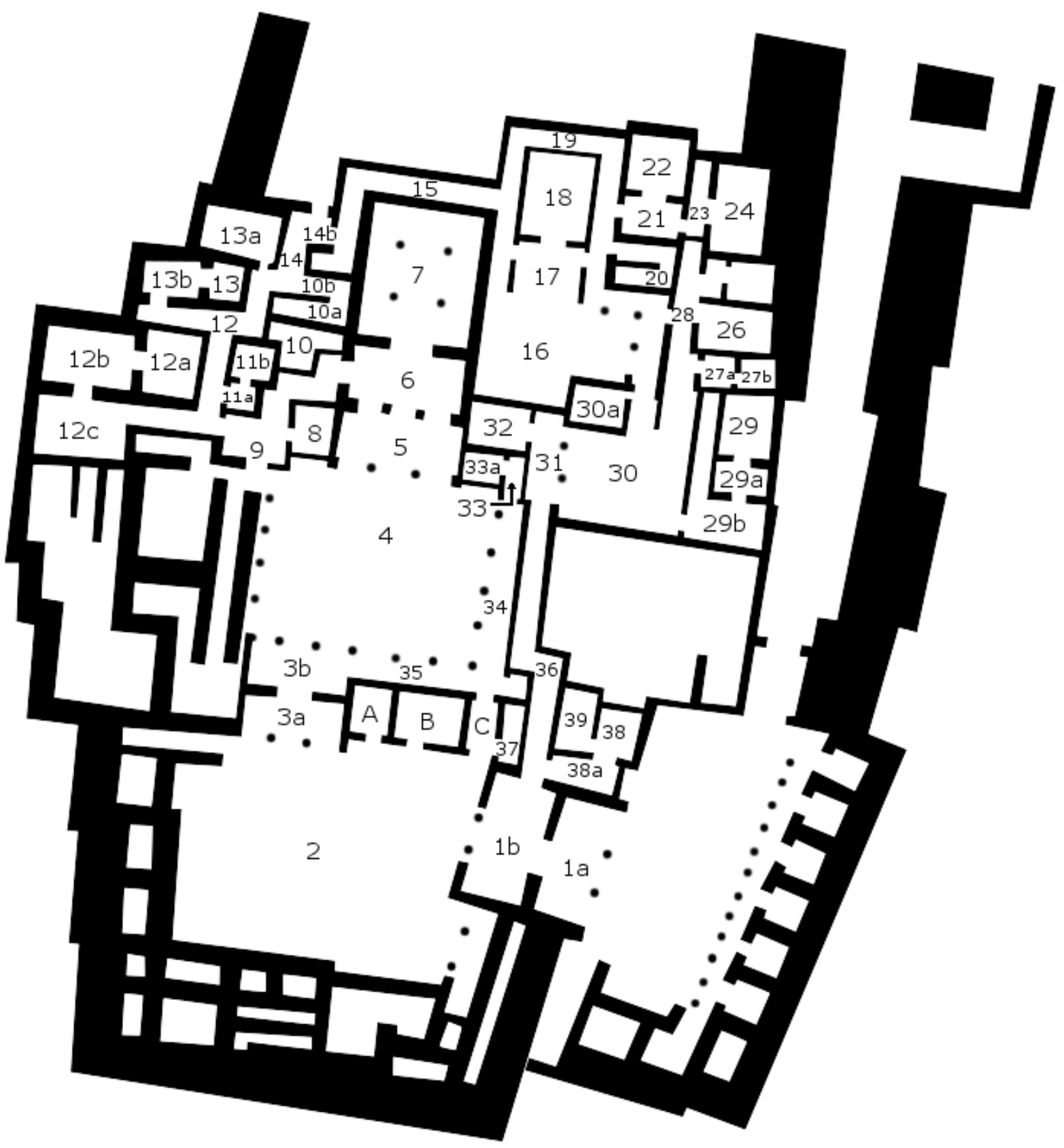

Plan 28: Tiryns, Upper Citadel (Plan by author, after Thaler 2015:Fig. 1). 
This content is not available. Please consult the print version for access.

Plan 29: Pylos, Main Building and South-Western Building (Blegen and Rawson 1966:Key Plan). 


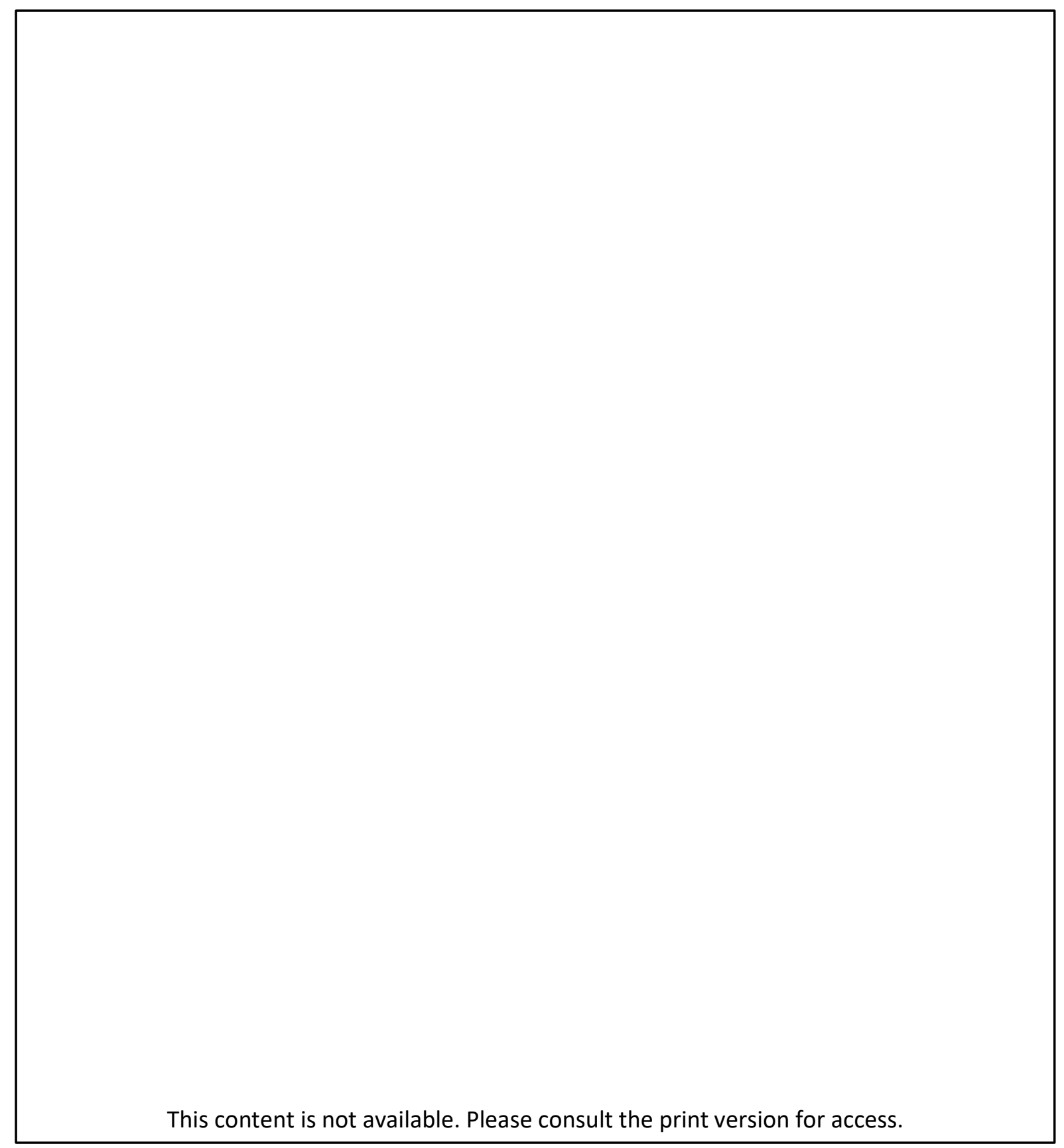

Plan 30: Gla, Residence (lakovidis 2001:Plan 13). 


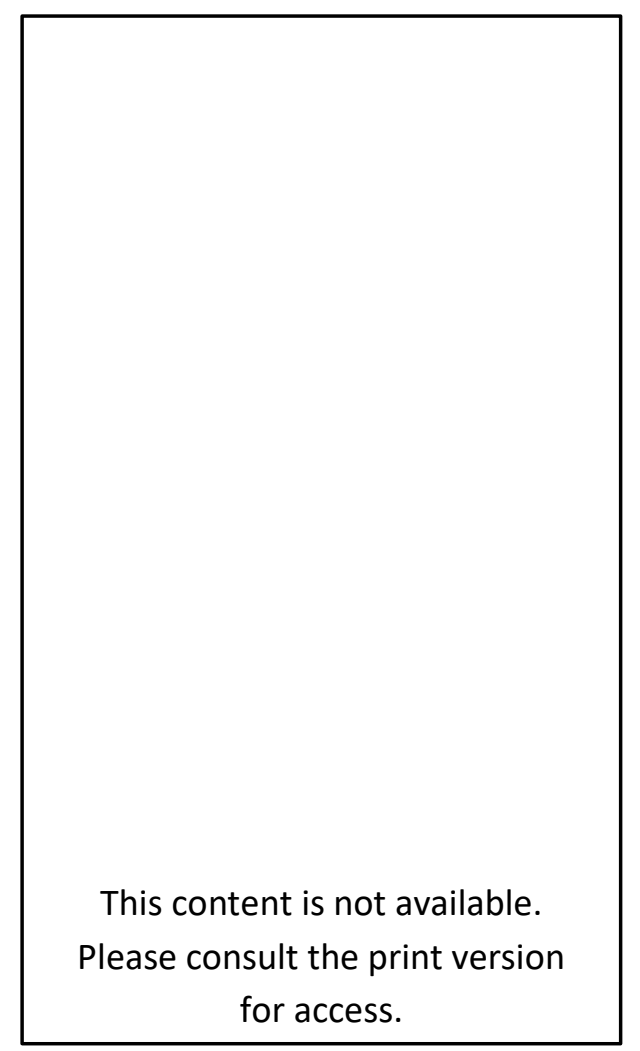

Plan 31: Dimini, Megaron A (Pantou 2010:Fig. 8.4).

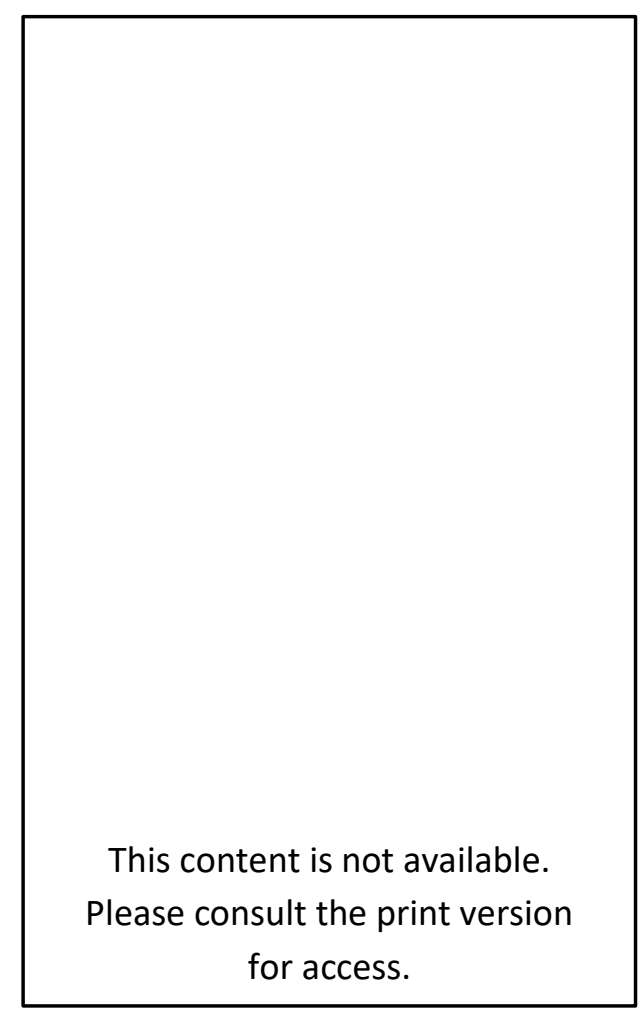

Plan 32: Dimini, Megaron B (Pantou 2010:Fig. 8.7). 
This content is not available.

Please consult the print version for access.

Plan 33: Menelaion, Mansion 1 (Pantou 2010:Fig. 4.12).

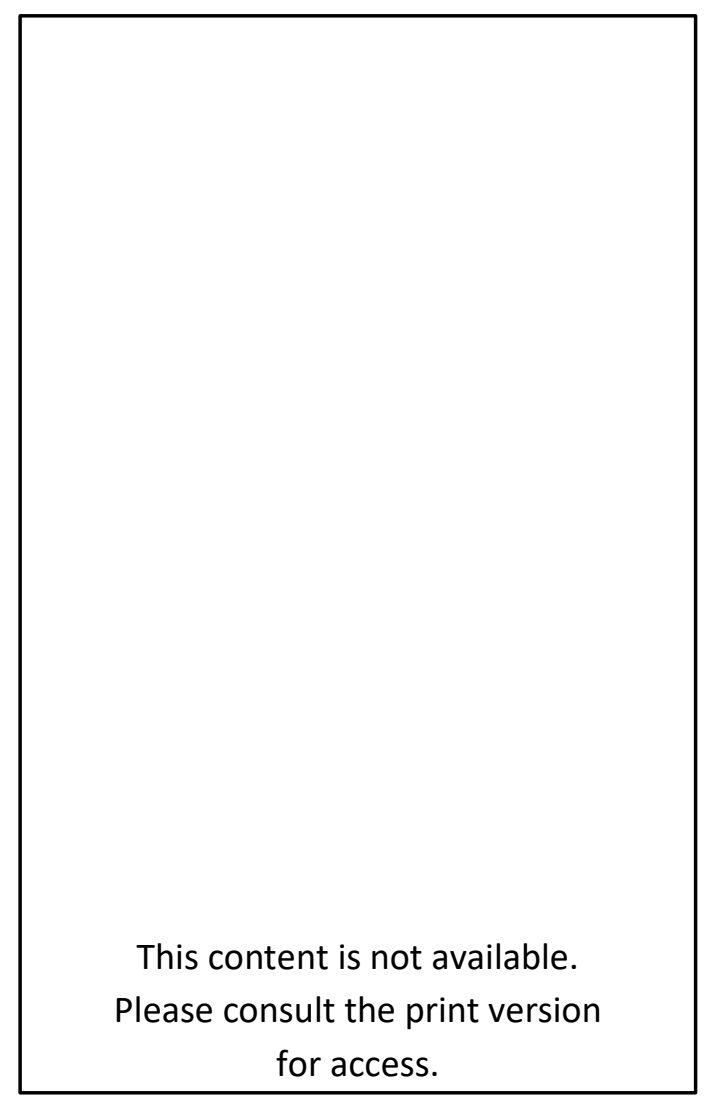

Plan 34: Mycenae, West House (Pantou 2010:Fig. 7.4). 


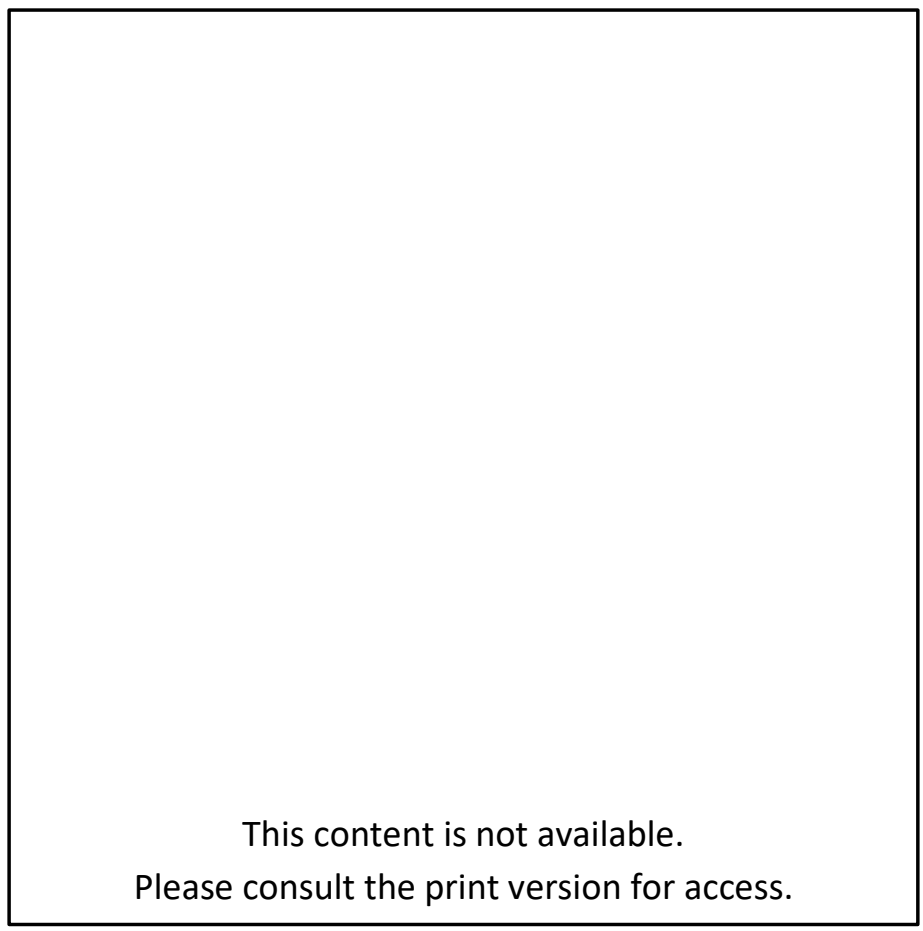

Plan 35: Phylakopi, Megaron (Pantou 2010:Fig. 5.6).

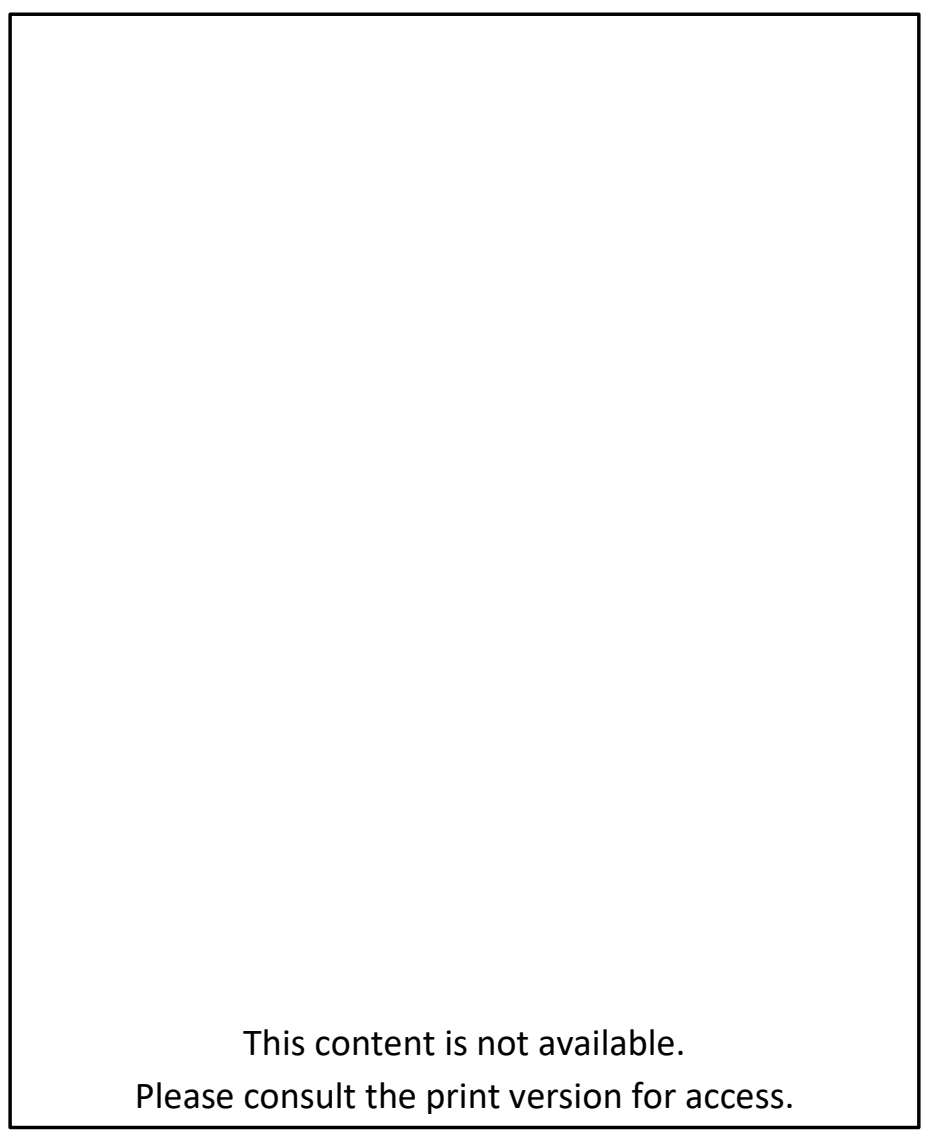

Plan 36: Gournia, House He (Pantou 2010:Fig. 6.2). 
This content is not available.

Please consult the print version for access.

Plan 37: Mycenae, House of the Sphinxes (Pantou 2010:Fig. 7.8).

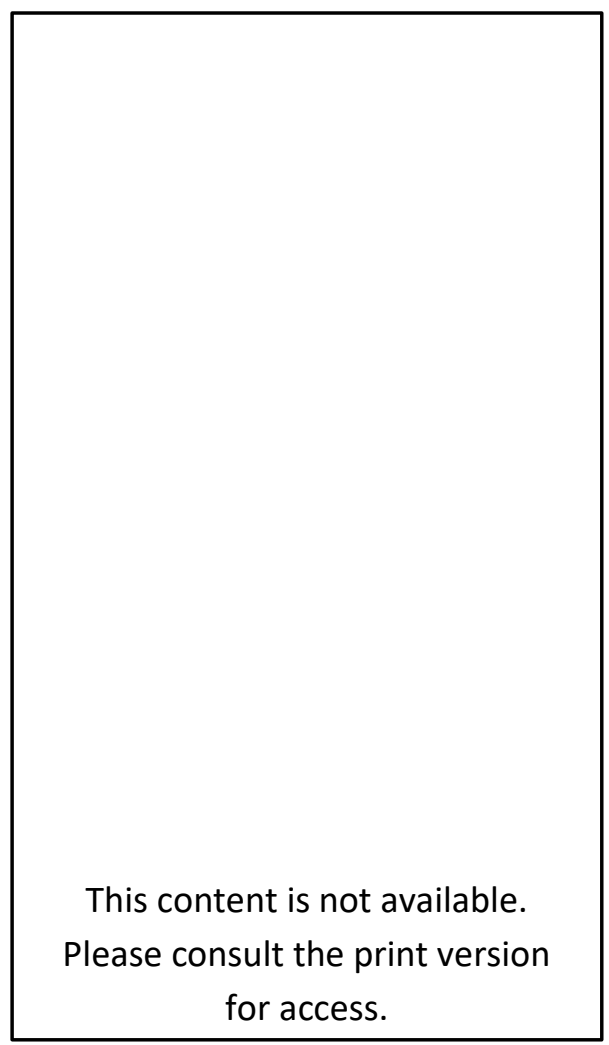

Plan 38: Korakou, House L (Blegen 1921:Fig. 112). 


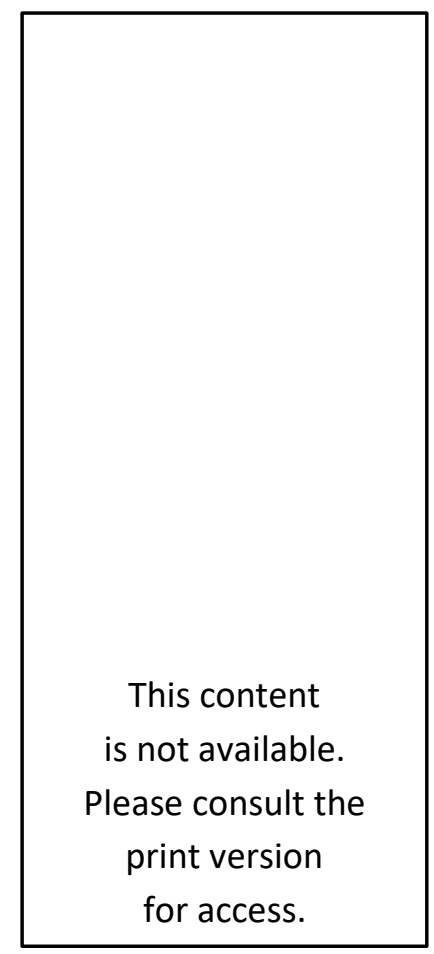

Plan 39: Thermos, Megaron A (Darcque 2005:Plan 120).

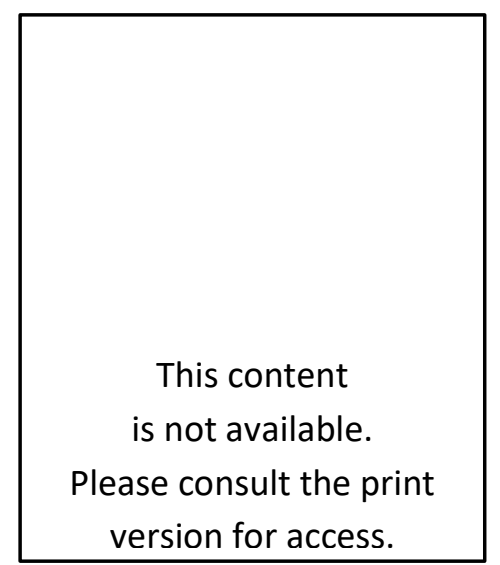

Plan 40: Tiryns, Building 110a (Darcque 2005:Plan 84). 
This content is not available. Please consult the print version for access.

Plan 41: Pyrgos Myrtos (Cadogan 1977-1978:Fig. 21). 